Portland State University

PDXScholar

$12-18-2019$

\title{
Ethnonational Identity and Detached Lives in a Serbian Province: a Study of Parallelism Among Vojvodina's Hungarian Community
}

Uros Prokic

Portland State University

Follow this and additional works at: https://pdxscholar.library.pdx.edu/open_access_etds

Part of the Eastern European Studies Commons, and the Public Policy Commons Let us know how access to this document benefits you.

Recommended Citation

Prokic, Uros, "Ethnonational Identity and Detached Lives in a Serbian Province: a Study of Parallelism Among Vojvodina's Hungarian Community" (2019). Dissertations and Theses. Paper 5413.

https://doi.org/10.15760/etd.7286

This Dissertation is brought to you for free and open access. It has been accepted for inclusion in Dissertations and Theses by an authorized administrator of PDXScholar. Please contact us if we can make this document more accessible: pdxscholar@pdx.edu. 
Ethnonational Identity and Detached Lives in a Serbian Province: A Study of Parallelism Among Vojvodina's Hungarian Community

by

Uros Prokic

A dissertation submitted in partial fulfillment of the requirements for the degree of

\author{
Doctor of Philosophy \\ in \\ Public Affairs and Policy
}
Dissertation Committee:
David Kinsella, Chair
Bruce Gilley
Aleksandar Jokic
Vandy Kanyako

Portland State University

2020 
C 2019 Uros Prokic 


\begin{abstract}
Current theories of interethnic relations generally posit assimilation, integration and marginalization as possible outcomes between minority and dominant groups in Eastern Europe (Berry, 1974; Dimitras \& Papanikolatos, 2002). However, there may be cases that are not adequately described by any of these existing interethnic relations paradigms. This dissertation explores one alternative, dubbed parallelism, which can be described as institutionally-driven self-isolation and detachment leading to communities living side by side on parallel trajectories and not interacting. Using the Hungarian ethnonational minority community in Serbia's autonomous northern province of Vojvodina as a case study, I examine the institutional factors that have led to parallelism. Primary data from 23 interviews and a variety of secondary sources reveal that two institutional factors are responsible for the current dynamic: repeated policy oscillations on the issue of Vojvodina's territorial and cultural autonomy and activism from the minority's kin-state, Hungary. Contentions over Vojvodina's autonomy act as the push factor, leading Hungarians in Vojvodina to self-isolate and cling to ingroup cultural markers, such as language. Hungary's activism towards it's kin-minority across borders, especially the 2001 "Status Law" and the Prosperitati economic assistance program, act as a pull factor, enticing Hungarians in Vojvodina to look to the Republic of Hungary for political, economic, social, and ethnic belonging. These mutually-reinforcing push and pull factors have ultimately resulted in a Vojvodinian Hungarians' disassociation and detachment from the dominant group on a number of levels. In this case, parallelism may just present an optimal solution to maintain the status quo by managing minority nationalism without necessitating border revision and eroding state sovereignty. In this
\end{abstract}


particular case, parallelism has led to largely non-violent relations between Serbs and Hungarians in an otherwise tumultuous region. As there are currently very few in-depth studies of parallelism, elaborating on the factors that lead to such an outcome provides a useful case study that may be referenced when examining whether parallelism may exist in other contexts. 


\section{Acknowledgments}

I am grateful to the members of the Hungarian community in Vojvodina who were so generous to take time out of their schedules to share their stories and perspectives with me for this research. It was an honor being invited into their homes and gaining a glimpse into their lives and experiences. Their hospitality and keenness to partake in this study was uplifting. I only hope that I have done justice to their perspectives and experiences by capturing and retelling them as adequately as possible in this study.

I am indebted to my dissertation committee who have been wonderful mentors throughout this process. I am especially thankful to my dissertation chair, Dr. David Kinsella, for taking me under his stewardship throughout this entire process. His guidance, perseverance, and academic rigor have been invaluable in this experience; he always encouraged me to do better, to ponder the deeper questions and issues, and he inevitably provided me with a roadmap to my work. I am further thankful to Dr. Bruce Gilley for his enthusiasm, astute insight, and alternative approaches to thinking through issues; to Dr. Aleksandar Jokic for always forcing me to consider alternative perspectives and taking care to provide logically-coherent arguments; and to Dr. Vandy Kanyako for impressing on me the need to value the human experience in academic research.

I am further thankful to my wife, Laura, for her loving support and motivation throughout this process. Our continuous discussions about my research, along with countless hours of copy-editing (several times over), have been invaluable in articulating the main ideas in this dissertation. I am blessed to be your husband, Laura Prokic.

I could also not have accomplished this without the support of by fellows in the PAP program, especially Rebecca Jensen Craven who has been a wonderful colleague 
and counselor on this invaluable personal and academic journey. I would also like to thank kuma Mia Grijakovic for her translations, Dan Lyons for his copy-editing, Ethan Snyder for his encouragement, and my dear friend Chris Green for being such a trustworthy confidant throughout this process.

Finally, none of this would have been possible without the immeasurable love and unconditional support of my parents, Miroslav and Gordana. My mother's unwavering belief in me, even when I doubted myself, is humbling. As I wrote this dissertation I found myself reflecting on the intellectually stimulating discussions my mother and I used to have on our regular evening strolls. I am who I am because of my parents' generous sacrifices. I am forever grateful for all that they have done, and continue to do for me. They are both my role models, and my only hope is that I have made them proud with this. My success is their success. 


\section{Table of Contents}

Abstract.......................................................................

Acknowledgments............................................................

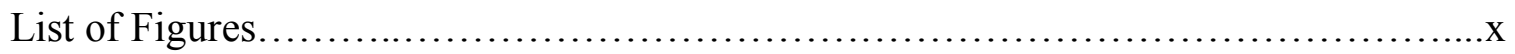

Introduction - Parallel Lives in the Age of Retrenched Ethnonational Identities...........1

Prelude - A Glimpse of Life in the Village.....................................

Vojvodina - A Beacon for Stability Amid Interethnic Separateness..................4

Considering Acculturation Models............................................. 10

The Argument.......................................................... 12

Roadmap to Conclusions................................................ 18

Chapter I - Case Study Approach of Hungarian Community in Vojvodina.............22

Methodology for Examining Hungarian Parallelism...............................25

Chapter II - Issues of Identity in Vojvodina..................................... 30

Hungarian Ethnicity as Collective Identity Basis.................................30

Hungarian Community in Vojvodina as Categorized "Narodnost".....................32

Perspectives on Nationhood............................................... 34

Modernist Perspective on Nations..................................... 34

Ethno-Symbolic Perspective on Nations.................................. 37

Hungarian Community in Vojvodina as an Ethnonationality....................39

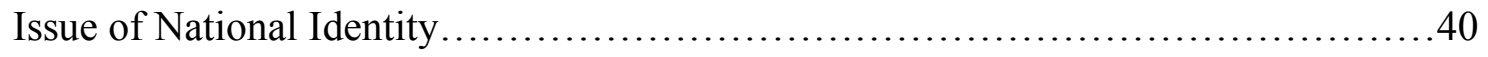

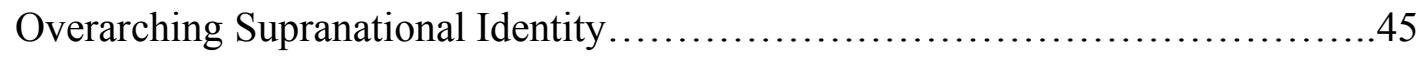

Question of Vojvodinian Identity.......................................46 
Ethnocultural, Multicultural and Liberal Pluralist Interpretation of Vojvodinian

Identity .46

Chapter III - Parallelism................................................. 55

Questions Concerning Multiculturalism and Interculturalism in Vojvodina............57

Interethnic Dynamic of Parallelism.........................................60

Parallelism for the Hungarian Community in Vojvodina............................62

Parallelism Through Language........................................ 75

Parallelism Through Education........................................ 78

Parallelism Through Political Affiliation..................................... 82

Parallelism in Daily Life............................................. 83

Parallelism as a Result of Institutional Realities.................................84

Parallelism as Institutional Outcome Versus Berry's Self-Segregation Outcome...84

Factors Facilitating Hungarian Parallelism in Vojvodina.......................87

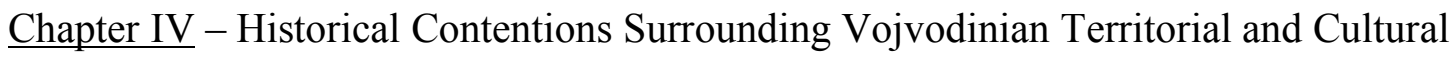

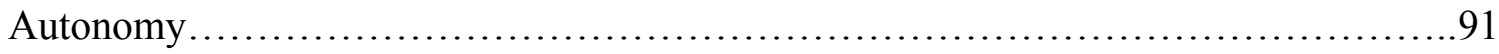

Amplitudes of Autonomy in Vojvodina......................................94

Preluding "Golden Age" of Vojvodinian Autonomy $\ldots \ldots \ldots \ldots \ldots \ldots \ldots \ldots \ldots \ldots \ldots . . . \ldots 7$

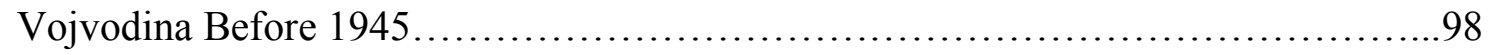

Voivodeship of Serbia and Banat of Temeschwar...........................98

Vojvodina and the First World War......................................99

Vojvodina in the Interwar Kingdom of Yugoslavia.......................... 99

Vojvodina and the Communist Party of Yugoslavia............................ 107

Vojvodina and the Second World War.................................... 108 
Vojvodina During the Communist Era. 109

Vojvodina and the National Question in the FNRJ and Subsequent SFRJ.

Problem of Hungarian National Partiality in the FNRJ and SFRJ

Vojvodina in the FNRJ of the 1950s.

Vojvodina - Administrative Region Versus Political Category.

Debates Concerning Vojvodina's Duties in 1967.

Vojvodina and the 1974 SFRJ Constitution.

1974 Constitution of the Socialist Autonomous Province of Vojvodina

Vojvodina's Status During the Milosevic Era. 128

Vojvodina's Status Suspended Under the 1991 Statue of AP Vojvodina.

Hungarian Ethnonational Mobilization in the 1990s.

Vojvodinian Territorial Autonomy Versus Hungarian Cultural Autonomy

Constraints of the 1991 Statute of AP Vojvodina. 136

Vojvodina in the Present.

Ethnic Territorial Autonomy Versus Cultural Autonomy Amid Democratic

Upheaval............................................................... 138

Victory for Hungarian Cultural Autonomy in Vojvodina. ...

Vojvodina and the 2006 Constitution of the Republic of Serbia - National or

Civic? 141

Law on National Councils of National Minorities.

Establishment of the National Council of the Hungarian National Minority. 143

Vojvodina and the 2009 and 2014 Statute of the AP Vojvodina. 146 
Chapter V - Current Reflections on Vojvodinian Territorial and Cultural Autonomy...150

(Dis)Illusions Concerning Vojvodinian Territorial Autonomy.....................154

Vojvodina's Territorial Autonomy Lacking Economic/Fiscal Autonomy..........155

Yugonostalgia Concerning Vojvodina's Status as per the 1974 SFRJ

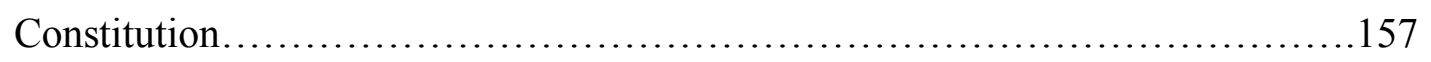

Vojvodinian Hungarian Cultural Autonomy as Community Identity Preservation.....159

Pursuit of Hungarian Territorial Autonomy ......................................161

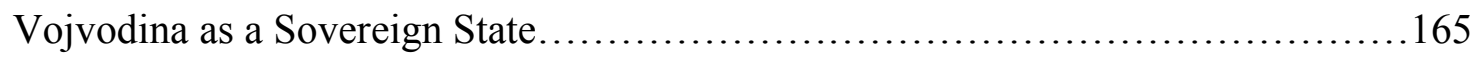

Autonomy as an Institution Fostering Parallelism................................. 169

Chapter VI - Kin-State Phenomenon............................................172

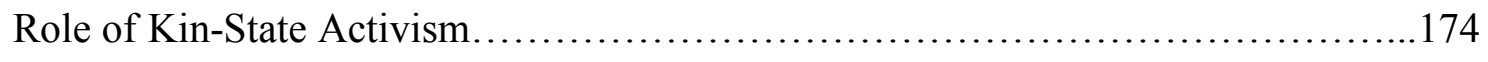

Historical Role of the Hungarian Kin-State......................................181

Evolving Role of the Hungarian Kin-State ....................................183

Legal Basis for Hungarian Kin-State Activism................................187

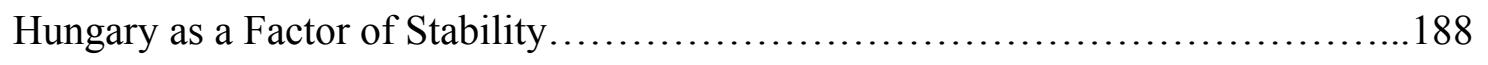

Hungarian Kin-State Legal Activism............................................. 189

Hungary and Citizenship Rights - Proliferation of the Hungarian Status Law.....189

Hungarian Status Law and Reclaiming of Ethnonational Identity and Unity......190

Hungarian Status Law and Economic Self-Interest............................192

Hungarian Status Law and Loyal FIDESZ Diaspora Voters.......................193

Hungarian Status Law and Resettlement Deliberations..........................195

Hungarian Status Law and Hungarian Irredentism.............................197

Ramifications of Status Law on Hungarian Parallelism in Vojvodina..............199 
Hungarian Status Law and Survival of the Hungarian Community in Vojvodina..... 200

Legal Controversies Over Hungarian Status Law...........................201

Hungarian Kin-State Political Activism....................................203

Hungary's Kin-State Economic Activism - Prosperitati........................212

Intertwinement of EU Initiatives and Hungarian Kin-State Activism................225

Reflections on Hungarian Kin-State Activism................................229

$\underline{\text { Conclusions }}$ - Parallelism as Interethnic Relations Optimality..................................233

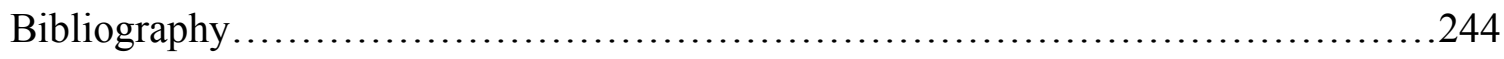

Appendix A - Interview Questions.........................................263 


\section{List of Figures}

Figure 1 - Map of the Socialist Federal Republic of Yugoslavia........................7

Figure 2 - Detachment in Interethnic Relations.................................17

Figure 3 - Parallelism Framework as per Acculturation Models........................18

Figure 4 - 2011 Census Map of Ethnic Hungarians in Vojvodina....................66

Figure 5 - Map of Proposed Hungarian Territorial Autonomy....................... 134 


\section{Introduction - Parallel Lives in the Age of Retrenched Ethnonational Identities}

\section{Prelude - A Glimpse of Life in the Village}

Tibor, a landowner and native of Bacskossuthfalva, wakes up in the morning and puts on a pot of coffee. He turns on his TV, which is already preset to Magyar Televizio 1, and listens intently to Hungarian Prime Minister Viktor Orban's speech on granting dual citizenship to the "external” Hungarians residing outside Hungary's borders. He is pleased with Orban's successes. He switches to TV2 HU and listens to the daily weather forecast for Budapest and close-by Szeged, eager to learn that it will soon rain and rejuvenate his crops. He then quickly changes channels to $T V 2 H U$ to hear the ongoing debate concerning the appropriation of funds to external Hungarians under the Prosperitati program. Tibor is hopeful that this assistance program will continue to be funded and supported by the government in Budapest which has already helped him in renewing his agricultural machinery, and even gifted his recently married daughter and son-in-law 322,0000 Hungarian forint ${ }^{1}$ to buy a home just four houses down in Kosut Lajosa street. As he finishes his coffee and downs a small glass of his Tokai wine, which he proudly makes himself, he jumps into his tractor that was recently bought with funds from that very same Prosperitati program. As he drives towards his fields, he stops by the newspaper stand greeting his fellow Hungarian Attila in proud Hungarian "Jo reggelt! Hogy vagy?" Exchanging the regularities that have marked their previous day, they pick up the same Hungarian provincial newspaper, Magyar Szo, and share musings on Istvan Pastor's latest meeting in Szabadka. They criticize his compromising stance on territorial

\footnotetext{
${ }^{1}$ Approximately equivalent to USD 11,000 or EUR 10,000 by current exchange rates.
} 
autonomy but are hopeful things will turn for the better as soon as Orban comes to straighten things out. Before parting ways, they solemnly reminisce about the golden days for Bacskossuthfalva that saw major economic prosperity. They comment on last Sunday's sermon at their local Calvinist church when their minister expressed his concern for the major outflux of people from the village that has reduced their numbers from just over five thousand to a mere two thousand now. Attila mentions that his younger daughter just moved to Pecs for a job as a medical technician, proud of the fact she is now able to fend for herself and hopefully find a young Hungarian with whom to start a family. Will she ever return back to Bacskossuthfalva is a concern for Attila. They part ways to attend to their daily work.

Slobodan, a long-term resident of Stara Moravica, wakes up the very same morning and makes his Turkish coffee. He turns on the TV which is preset to RTS1 (Radio Television Serbia 1). He cheers his domestic-made apricot rakija as he listens intently to Prime Minister Aleksandar Vucic talk about Serbia's plan to resolve the recent crisis in Kosovo and Metohija created by the tariff war imposed by the self-proclaimed authorities in Pristina. In the background he turns on his radio that plays his favorite Vojvodinian tamburica as he shaves. His cheerfulness is only spoiled when he turns channels to RTV2 (Radio Television Vojvodina 2) and sees the topic of this morning's show - corruption in Novi Sad city bus services. He cannot stand the amount of corruption that is being talked about when compared to his recently reduced salary that is now just under twenty-three thousand Serbian dinars. He is outraged. Turning off the TV he sets off to work at the village chains manufacturing plant - Sila. Sila is undergoing a slow process of liquidating assets after it filed for bankruptcy. The whole privatization 
process that is now taking place is questionable at best. He walks down his Marsala Tita street, but that was just recently renamed Kosut Lajosa, towards the village center. He looks towards the village intersection with the recently demolished petrol station and reminisces about the old days of the former Yugoslavia. He greets the children hurrying to the local village school with the customary Serbian "Dobro jutro." The children do not understand him but respond with the general Hungarian "Jo napot." As he buys his favorite newspaper from Belgrade, Politika, he walks on towards the gates of the factory and reflects on life in Stara Moravica, or as it is now called Bacskossuthfalva. What will he have to talk with his co-worker Attila? Nothing much. This seems all the more shocking given that they both live in the same village; in fact, the very same street. He can only conclude that he lives next to his neighbor, but not with his neighbor. He is disturbed by this remark especially given that Bacskossuthfalva/Stare Moravica is in Serbia.

This short illustration is neither a peculiar nor isolated instance of interactions between Serbs and Hungarians in the Republic of Serbia's northern autonomous province of Vojvodina. Instead, this story is one of many that serves to highlight the general phenomenon of parallel lives that currently defines ethnonational relations Serbs and Hungarians in Vojvodina. These characters represent their respective communities communities that live next to each other but not with one another. It is such a dynamic of 'parallelism' that defines the lives of the Hungarian community in Vojvodina who have diverged and disassociated from the majority. Low levels of interaction, lack of integration, and ultimate separation from the "other" sum up the reality of life for the Hungarian community in Vojvodina. The current life of this community paints a picture 
of a distinct ethnonational minority wholly insulated from its counterpart; living a life that has very little in common despite residing in close proximity and within the same state of the "other." What makes this particular scenario intriguing, however, is the fact that distinct institutions are fostering such an interethnic dynamic in its current form. Therefore, the reality of parallel lives for these characters described here is not the mere product of a seemingly "natural" inevitable collective striving and voluntary communal disposition to be with their "own" at the expense of the "other." Instead, the existence of such a relational outcome of parallel lives among the Hungarians in Vojvodina is institutionally sanctioned. Unearthing the institutional causes for leading such parallel lives, at least for the Hungarian community in Vojvodina, is the central quest of my endeavor and ultimate purpose of this inquiry.

\section{Vojvodina - A Beacon for Stability Amid Interethnic Separateness}

In the present age of reemerging nationalism, issues of national identity and collective consciousness have become all the more salient. The seemingly heightened political polarization and division witnessed on a global scale are often attributed to rising nationalist tendencies. The liberal political order celebrating the rational selfrestrained individual "citizen" has been called into question, replaced by a call to cultural distinction and traditional collective consciousness. Naturally, the liberal state structure founded on universal consent by free citizens has also been severely threatened, replaced by norms that celebrate culture and tradition enveloped in the loaded term - reclamation 
of national identity. ${ }^{2}$ In this turbulent atmosphere, the apparent reversion to nationalism is now considered to be symbolic of a reversal of history in which human progress, venerating democratic rationality, has been replaced by more carnal collectivist instincts that seemingly fuel division on a rudimentary level of identity. Amid this rising trend of nationalism, group relations have become all the more important. No longer is the individual in isolation as important as the individual as part of the collective, as stressed by the most recent publications of political discourse.

The ingroup versus outgroup phenomenon that is currently being emphasized across the globe signals changing times, regardless of the normative judgment that is ascribed to it. In the process, the ideal of transnational and transethnic universal society, previously celebrated, is becoming all the more unachievable. The notion of a global culture and a global society are seemingly unattainable, replaced by a renewed zeal for group differentiation, autonomy, and ultimately separateness. Balkanization, as was vilified and attributed to solely the "barbaric" southeastern Slavs of the early 1990s, has now seemingly spread on a global scale - a global balkanization (Grubacic, 2012). Amid this political balkanization group relations have come to the forefront of political

\footnotetext{
${ }^{2}$ See also The Clash of Civilizations and the Remaking of the World Order by Samuel P. Huntington and the more recent text by Yoram Hazony aptly entitled The Virtue of Nationalism. In his canonic work, The Clash of Civilizations, Huntington proposes future conflict to be precipitated by cultural and religious differences between peoples. Such inter-civilizational conflict is said to be the result of entrenched cultural differences that are becoming exaggerated in this increasingly globalized world. In comparison, Hazony's recently published The Virtue of Nationalism text explores the reclamation of national identity through a novel moralistic argument for nationalism. Hazony asserts the value of the nation-state in protecting the social goods of a particular group thanks to the device of nationalism that fosters social cohesion through bonds of mutual loyalty. Critical of the so-called global progressive order propagating rule-based governance through the model of international empire, Hazony insists that nations are the sole protectors of cultural particularism as well as social and political freedom. To destroy nations and rebuke nationalism is to destroy humanity essentially.
} 
discourse, and are considered as antagonistic and potentially fatalistic to a liberal universalist project if not managed in the right manner.

Referencing "balkanization" often invokes more recent memories of the unfortunate events that unfolded in the 1990s in which a myriad of compounding macro and micro political, economic, and social issues collided and eventually precipitated in outright conflict. The wars in the Socialist Federal Republic of Yugoslavia (SFRJ) of the 1990s, popularly attributed to rising nationalist sentiments, paint a bleak picture for the global future if history is to be repeated but on a grander scale. Namely, if highly contested collective identities have presented an unsurpassable hurdle for interethnic relations in this one part of the world, what does the future hold for apparent growing collective strife on a global stage?

Complex interethnic relations dynamics in the former SFRJ have much to say about current interethnic relations on a global scale. The failure of a constructed allencompassing south Slavic Yugoslav identity may foreshadow the fatality of pursuing "artificially" induced nation-building projects. Furthermore, unsurpassable ethnic division compounded by religious differences, which some scholars have marked as the underlying cause of bloodshed in the SFRJ, give all the more reason to be concerned about the global future that presents even more complex interethnic dynamics, especially those pitting majorities and minorities against each other. 
Figure 1. Map of the Socialist Federal Republic of Yugoslavia

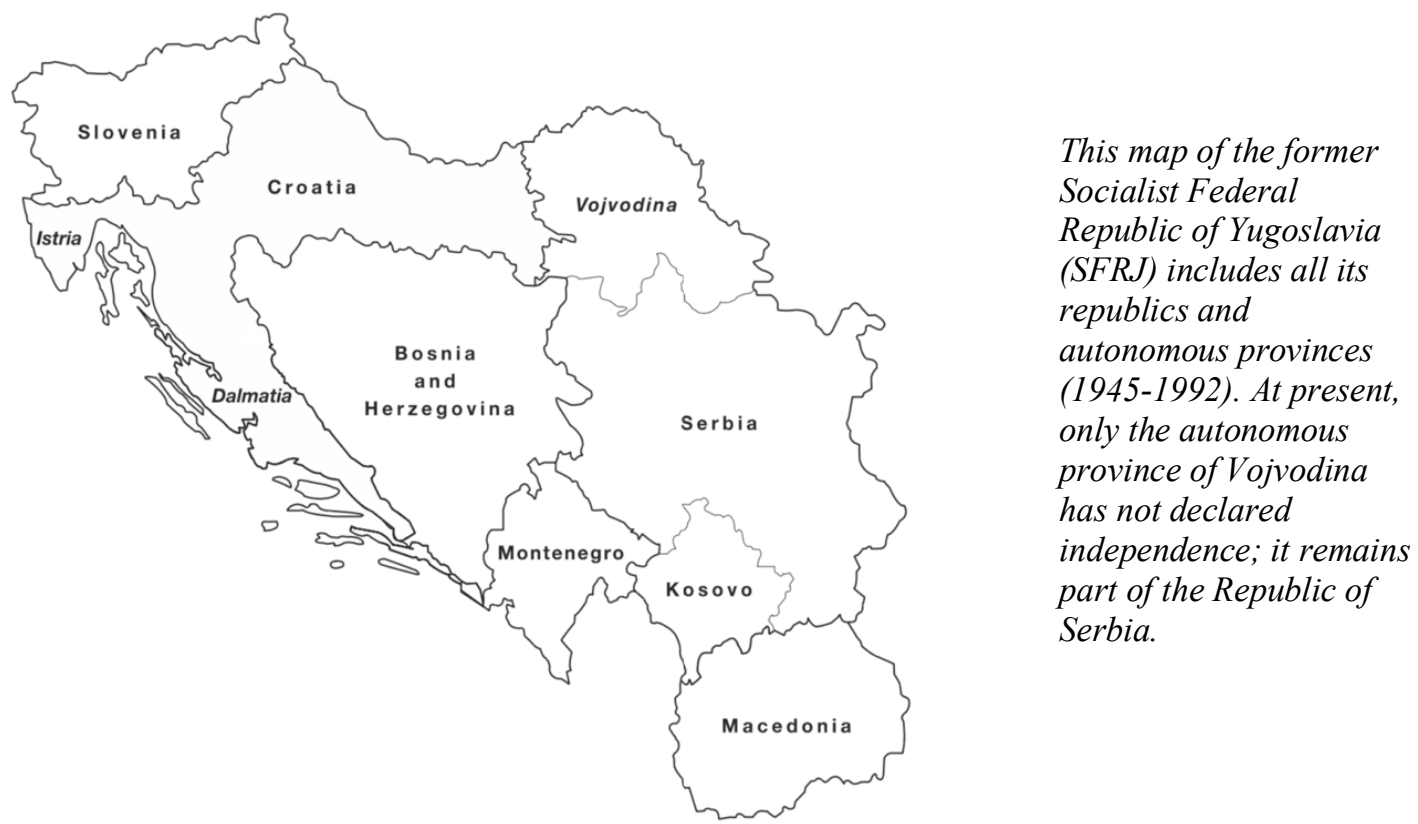

While it is relatively easy to find cause for concern when analyzing Yugoslavia's interethnic conflicts, many times utilized as the textbook example of destructive nationalism and fatalistic interethnic relations, one should not be so blind as to overlook instances in which relations in this part of the world have not precipitated into outright warfare. Arguably, this former federal state and its colorful tapestry of communities provide instances of both conflict and peace. Of course, armed conflict breeding violence is more shocking and therefore usually garners more attention from both journalists and academics. However, this should not lead to underestimating instances of peace and undervaluing the lessons to be learned from these occasions. Therefore, if examples of interethnic relations leading to war in the former Yugoslavia are valuable to study, why should not interethnic dynamics lending to stability be equally research-worthy? I embark on such a quest to investigate one current interethnic relation dynamic that has been 
altogether peaceful in nature, but which provides worthy lessons in the overarching global context that seeks to rekindle ethnic and national passions.

If historical examples of tremulous interethnic relations leading to conflict in the former SFRJ provide valuable insight into the rise of nationalism on a global scale, current examples of interethnic relations in this region that have not erupted into outright conflict should be equally important in unearthing certain trends that forecast stability amid heightened group solidarity and differentiation from the "other." 3 With this as the overarching goal, interethnic relations between Serbs and Hungarians in Serbia's northern province of Vojvodina provides a perfect example of complex relations that have historically diverged, but which have never disintegrated into outright violence as in other neighboring areas. It is my overall aim in this dissertation to shed light on this specific interethnic dynamic between Serbs and Hungarians in Vojvodina so as to provide some explanation for groups facing similar challenges, giving hope for the prospect of stability amid divergence if certain parameters exist.

The research that will be presented here is a case study of the Hungarian community in Vojvodina, emphasizing the importance of collective identity in shaping interethnic relations. The study investigates the perceptions, attitudes, and behaviors of the Hungarian community in Vojvodina, and explores their interactions with the Serb

\footnotetext{
${ }^{3}$ See also Zones of Peace by Christopher Mitchell and London E. Hancock that examines the importance of peace localities within broader areas of conflict. Mitchell considers spatial protection and locational sanctuaries, termed zones of peace (ZOPs), as territorial areas free of violence. Vojvodina and its tapestry of ethnonational communities loosely draws on an unintentional type of peace zone. Within this framework, Vojvodina and its 'peace community' may be deemed an example of a "successful sanctuary offering lessons...that help to analyze the factors that help to maintain inviolability in volatile circumstances" (Mitchell, 2007, p. 23). However, this analysis differs as it focuses on parallelism as the possible contributing reason for "quiescence of those within the sanctuary" rather than protection of violence (Mitchell, 2007, p. 15).
} 
majority. The case study reveals the separateness and detachment of the Hungarian community in Vojvodina, pinpointing two important institutional factors, Vojvodina's volatile autonomous status and the ever-increasing presence and activity of its kin-state, Hungary, as shaping interethnic relations.

This study will also serve to highlight the power of institutional mechanisms in enabling a novel interethnic relations outcome. In the process, the notion of selfdetermination which is generally synonymous with national identity and national “choices" will be challenged. More specifically, the nation as a political unit with a distinct collective consciousness is subtly established on the notion of "consent." The supposition is that collective consent is fundamental to creating bonds and obligations towards national members apart from the "other." Such a view places the individual as primary in this ontological debate, with relationships between in the ingroup and outgroup predicted on choice. My research, however, challenges this conventional conception by instead emphasizing the manner in which choice becomes very much peripheral to compounding institutional mechanisms. In uncovering the interethnic outcome that most adequately describes the Hungarian community in Vojvodina, I demonstrate the manner in which institutions direct group behavior and intergroup dynamics by first limiting, and then rendering meaning to the choices left. Quite simply, what my research will show is the power of institutions in steering collective choices; in the process, questioning the very premise of "natural" national solidarity. Better understood, self-determination is replaced with institutionally-sanctioned national determination that has powerful ramification for intergroup dynamics. 
In times of rising minority nationalism, precipitated by heightened conflicts of interests and identities between various majorities and minorities, issues of assimilation, integration, and even segregation have come to the forefront. Conventional wisdom would have us believe that assimilation and integration are to be favored as more stable outcomes. My research, however, supports a different, unorthodox conclusion: an alternative pattern of interethnic relations, one approaching a type of segregation, can lead to equally optimal stable outcomes if certain institutional conditions are present. To comprehend this, one must first recognize that dynamics of interethnic relations are very different in Western and Eastern Europe.

\section{Considering Acculturation Models}

What are the options offered minorities in Eastern European states, specifically the former Yugoslav states, in terms of interethnic relations? What is certain is that interethnic relations are quite different in Eastern Europe than in Western Europe. The notion of the 'nation-state' reigns supreme in Eastern Europe where the idea of one nation per state is still an aspiration, compared to Western Europe where this ideal has been realized. Moreover, the democratic tradition that has been nurtured in Western Europe for far longer than in Eastern Europe has allowed for minority interests and rights to be more or less realized within the parameters of the social contract defining the political community, considering it purely in terms of equality of each individual citizen (Safran, 1999). This is far different in Eastern Europe where minority relations are considered in terms of groupness and therefore realized through specific institutions (i.e. cultural autonomy) which caters to this perspective. For this reason, ethno-cultural 
diversity has always presented a problem for these states since it threatens the very notion of solidarity which national identity first and foremost nurtures (Zigmanov, 2006, p. 74). In fact, minorities have been regarded as a danger by dominant groupings, fearing their presence an omnipresent threat to the survival of the fragile nation-state. In this regard, granting political and legal recognition and rights to minorities has been associated with opening Pandora's box, potentially leading to balkanization.

Panayote Dimitras and Nafsika Papanikolatos (2002) discern four options for ethnic minorities in relation to the dominant groups in Eastern Europe. The first option is permanent marginalization in which the minority is destined to live on the fringes of life, regardless of what they try. The second option, which is favored for mainly security reasons in Eastern Europe, is assimilation by which the minority group adopts virtually all the cultural characteristics of the majority and thereby ceases to be culturally distinctive. The third option is integration "where minorities acquire some characteristics of the majority's societal culture but also keep many of their own distinct cultural characteristics" (Dimitras \& Papanikolatos, 2002, p. 189). However, within integration, two types of integration outcomes are identified. The first is the establishment of de facto autonomy for the minority group that has a territorial basis. Such integration, which includes territorial autonomy, allows for the establishment of separate economic, political, and educational institutions in the minority's language with the purpose of increasing their political/civic participation. The other form of integration refers to personal cultural autonomy and removes the territorial element altogether. Instead, the dominant culture allows the minority to nurture their own cultural characteristics on a 
personal level without resorting to creating separate institutions in territories they inhabit (Dimitras \& Papanikolatos, 2002, p. 190).

These four outcomes are evident when surveying a variety of cases in the region. This typology presupposes a clear-cut separation between outcomes that suggests a sort of rational policy planning on the part of the majority imposed on the minority. But what if these outcomes are the result of a confluence of factors that is not necessarily purposefully imposed and, in fact, are the choice of the minority rather than the majority? In analyzing the case of the Hungarian community in Vojvodina, it becomes apparent that the assimilation typology commonly applied to cases of ethnic cleavages in Eastern Europe does not fully hold. Interethnic relations in Vojvodina are characterized by low levels of interaction between minority and majority groups; the Hungarian minority is clearly not assimilated. But neither are they marginalized. Furthermore, although the third and fourth patterns -- de facto autonomy and personal cultural autonomy -- are present, they do not really amount to integration. ${ }^{4}$ Rather, these patterns of interethnic relations are manifestations of an institutionally sanctioned "self-induced isolation" (Zigmanov, 2006, p. 70). This outcome is best understood using the concept of parallelism, to which I return below.

\section{The Argument}

Far too often institutional factors influencing nations are neglected. This research seeks to highlight the manner in which state institutions affect national choices - thereby

\footnotetext{
${ }^{4}$ See also Dosije Autonomna Pokrajina Vojvodina, in which Milos Dinic provides an alternative argument for majority-minority relations in Vojvodina. Dincic claims that "high levels of integration into Serbia's state system" are evidenced among national minorities, especially Hungarians (Dinic, 2014, p. 22).
} 
emphasizing the manner in which institutions have an ingroup homogenizing effect on national solidarity and ultimately steer national choices. Commonly, discourse on nations and nationalism focuses on communal self-determined will fueling a sense of collective solidarity. Such an approach neglects the various institutional push and pull factors that influence why nations behave a certain way. I argue that national resilience is the result of two specific institutions that have had an ingroup homogenizing effect, thereby rendering Vojvodinian Hungarian ethnonational solidarity an outcome rather than a cause of the current dynamic. The two institutions under scrutiny in this inquiry are (i) Vojvodinian territorial and non-territorial autonomy and (ii) Hungarian kin-state activism. These institutional factors mutually reinforce each other and serve to build ingroup homogeneity among Vojvodina's Hungarian majority and encourage separation from the Serb majority.

This dissertation begins by conceiving of the Hungarian community in Vojvodina as an ethnonational minority group in Vojvodina, and as part of the greater Hungarian nation. Both modernist and ethno-symbolic perspectives on nations serve as theoretical foundations for this research. Both perspectives are crucial in comprehending the myriad of elements that are salient to the collective national identity of the Hungarian community in Vojvodina, especially those pertaining to collective homogenization for the purposes of building communal resilience for the sake of self-preservation from the "other." I then juxtapose the concept of parallelism with a descriptive account of Hungarian community life in Vojvodina from the perspective of several individuals interviewed for this study. Secondary data analysis adds context to this discussion, lending weight to the argument 
that parallelism is indeed the dynamic currently defining Hungarian ethnic life in Vojvodina.

To answer the question of whether a distinct Vojvodinian identity - encompassing Hungarians, Serbs, and other groups -- exists, I examine three conceptualizations of interethnic relations in Vojvodina: multiculturalism, ethnonationalism, and liberal pluralism. On the whole, this inquiry refutes the notion that a distinct Vojvodinian identity exists. A supranational narrative, a prerequisite for multiculturalism in Vojvodina, is largely absent. National fractures have not been overcome, everyone's voice is not equally heard, and ethnonational communities are not engaging in meaningful interactions, at least from the perspective of the Hungarian community. Moreover, a narrative celebrating a Vojvodinian identity, one encouraging all ethnonational groups to partake in a shared identity, is also absent - or indeed rejected by Hungarians when interpreted as an assimilationist narrative of Serbianization. Lastly, liberal pluralism, which posits distinct ethnonational communities coexisting and thriving under the umbrella of a national and regional identity, eventually neutralizing ethnocultural markers, is also a poor fit. The parallelism we observe in Vojvodina is actually an expression of the Hungarian community's lack of confidence in ethnocultural neutrality. Ethnonational distinction persists and Hungarian cultural isolation remains a central feature of social relations in Vojvodina.

Having rejected the notion of a single or integrated Vojvodinian identity and having made a case that parallelism is the most appropriate lens for viewing complex interethnic relations between Serbs and Hungarians in Vojvodina, I turn to an analysis of two distinct, yet mutually reinforcing, institutional factors that have facilitated the 
development of parallelism: Vojvodina's territorial and non-territorial autonomy and Hungarian kin-state activism.

Issues related to both territorial and non-territorial autonomy in Vojvodina have enabled Hungarians to pursue a parallel community life. Contention over Vojvodina's territorial autonomy has been ever present, creating a legacy of one step forward one step back; any progress that has been made in terms of guaranteeing and protecting Vojvodina's territorial autonomy has been swiftly followed by state re-centralization. This cyclical political instability, exacerbated by persistent inconsistencies in policy implementation, has contributed to the alienation of the Hungarian community and its detachment from Vojvodinian provincial affairs. The state's granting of Hungarian cultural autonomy in Vojvodina, as is the case today, is but an acknowledgement of de facto parallelism in interethnic relations. While maximizing their autonomy in most facets of daily life, the Hungarian community has become further disassociated from provincial matters and separated from the dominant group.

However, as my inquiry will show, this might not be the final stage of the evolution of parallelism by the Hungarian community in Vojvodina. Achieving ethnic territorial autonomy for the Hungarian community in Vojvodina is highly salient to many of the individuals I interviewed for this study, and suggests the possibility of further institutionalization of a community life separate from the majority. Such a compounding of territorial and cultural autonomy for the Hungarian community in Vojvodina would symbolize the completion of a project aimed at community self-preservation. What started out as a faltering push for Vojvodinian territorial autonomy evolved into a practice of cultural autonomy and the enabling of parallelism. If ethnic territorial 
autonomy is realized and institutionalized by the Hungarian community in Vojvodina, it could lead to complete ethnic homogenization and detachment.

The second institutional factor that has facilitated the development of parallelism among the Hungarian community in Vojvodina is kin-state activism. Hungarian kin-state activism has filled the void left by contentions over territorial and cultural autonomy in Vojvodina, furthering the process of parallelism. The cultural autonomy currently afforded the Hungarian community in Vojvodina has opened opportunities for the Republic of Hungary to become a powerful factor in the lives of its kin-minority across the border. The Republic of Hungary is an important stakeholder in the lives of the Hungarian community in Vojvodina, influencing this community's choices and behaviors, and is perceived as a provider of security and sustenance by the Hungarian community in Vojvodina. Thus, one focus of my research is on discerning the political, economic, and logistical support Hungary has provided its kin-minority in Vojvodina. I examine Hungary's clientelist nemzetpolitika and the repercussions of the Hungarian "Status Law," the economic stimulus package Prosperitati, and its strategic partnering role in EU development initiatives. It is this sort of kin-state activism that has fostered greater ethnonational homogeneity among Vojvodina's Hungarians. I contend that a rational transactionalism forms the basis for relations between the Hungarian kin-state and its kin-minority in Vojvodina, giving rise to the crucial institutional role that kin-state activism plays in the lives of this ethnonational community. Hungary's active involvement in Vojvodina has had the effect of diminishing the Hungarian community's reliance on the Serb majority by reducing the costs of opting out. The level of ethnonational homogenization enabled by Hungarian kin-state activism ensures a degree 
of national solidarity among this community that finds its expression in separateness from the dominant Serb group with whom it shares a living space, as well as a detachment from Vojvodinian provincial affairs.

The following diagrams illustrate the manner in which the two mutually reinforcing factors, autonomy and kin-state activism, enable parallelism for the Hungarian community in Vojvodina. In the first diagram, parallelism is placed within the aforementioned acculturation model on a continuum of detachment. The second diagram shows how self-segregation, usually a sub-category of marginalization can produce a new level of detachment, parallelism, when fueled by two institutional factors: autonomy and kin-state activism.

Figure 2. Detachment in interethnic relations 
Figure 3. Parallelism framework as per acculturation models ${ }^{5}$

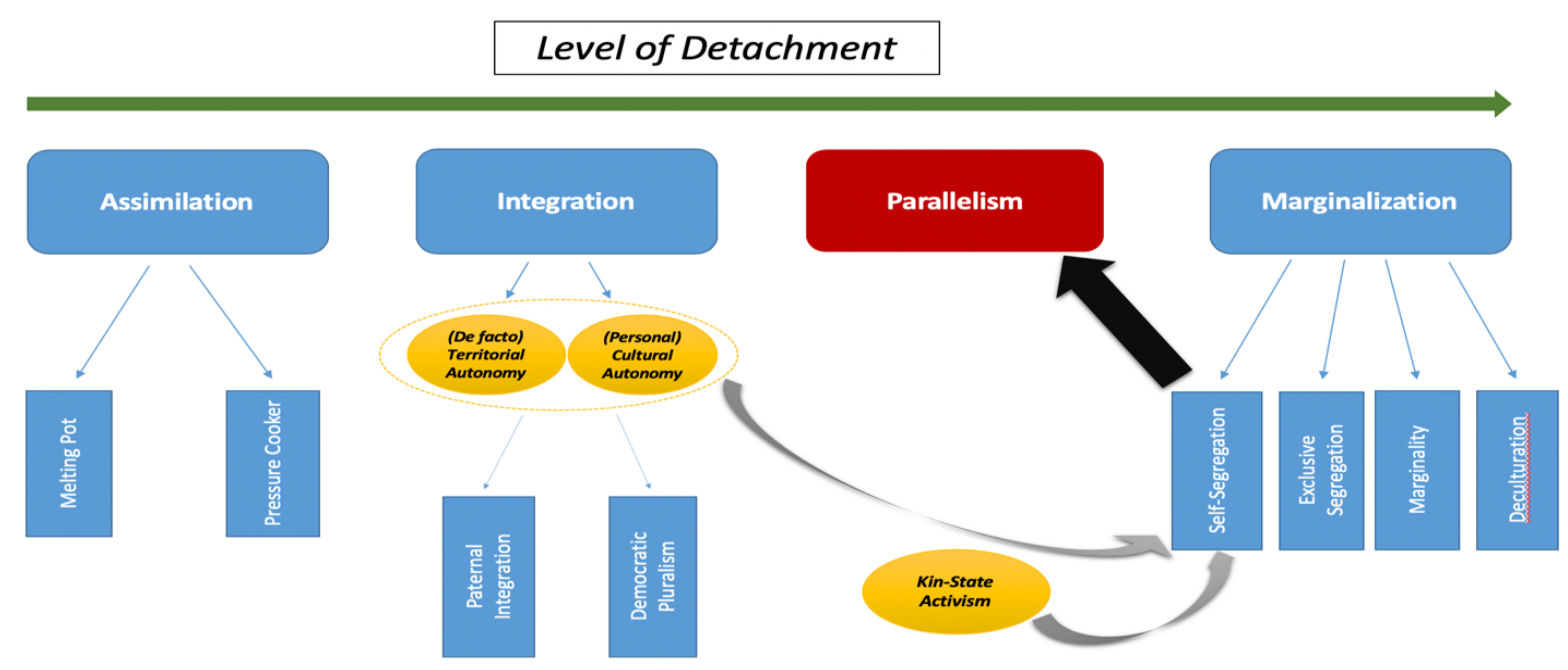

\section{Roadmap to Conclusions}

In an age of rising minority nationalism and kin-state cross-border nationalist reunification projects, alternative models of interethnic relations are becoming increasingly pertinent to understanding the political landscape. Conventional political wisdom would have us believe that community detachment and indifference, reinvigorated by ethnonational homogenization and community-building for the sake of self-preservation, is a recipe for instability and possibly overt conflict. However, this dissertation will show that this may not be the case when certain circumstances exist. I will argue that, in the case of Vojvodina's Hungarians, a certain type of institutionally-

\footnotetext{
${ }^{5}$ This Parallelism Framework Diagram places the phenomenon of parallelism within the context of a combination of two dominant acculturation models: Panayote Dimitras/Nafsika Papanikolatos' Eastern European majority-minority typology and John W. Berry's modes of group relations typology. Please also see 'Parallelism as Institutional Outcome Versus Berry's Self-Segregation Outcome' section on pg. 80 for further discussion of Berry's typology.
} 
induced segregation, termed parallelism, has actually led to stable interethnic relations in the province.

Interethnic friction is persistent in an imperfect nation-state system where state borders rarely correspond with national borders. However, there may not be cause for concern if certain institutions exist that lend stability - specifically autonomy and the presence of the kin-state. As my dissertation will attempt to show, parallelism may be just that optimal solution for distinct peoples to live side by side without having to live with one another. In such a model of interethnic relations, parallelism does not require messy border revisions, but does provide ethnonationalities a way to preserve their distinctiveness and separateness apart from the "other."

Parallelism may not be unique to the Hungarian community in Vojvodina, but neither is it very common. Other instances of parallelism may exist, but we should look for the presence of the favorable institutional conditions like those I explore in this study. Consider the cases of the Basques in Spain, the French-speaking Quebecois in Canada, the Yazidis in Armenia, and even the Kurds in Iraq. For the French-speaking Quebecois and the Basques in Spain, a process of integration seems to be taking place based on de facto territorial autonomy lines, while for the Yazidis in Armenia and Kurds in Iraq, a process of marginalization may be the best way to describe their interethnic dynamics. But in all four cases, further investigation is warranted and special care must be taken to discern between typologies, especially those that seem to exhibit self-segregation versus separateness encouraged and sustained by the institutional developments I will more fully examine in the chapters ahead. For the Hungarian community in Vojvodina, parallelism is the result of two distinct yet mutually reinforcing institutional factors: contentions over 
Vojvodinian territorial and cultural autonomy as well as kin-state activism. For other groups, the exact form of these institutional factors may differ but certain structural dimensions will be present if the phenomenon of parallelism is at play. For this reason, there are likely to be a rather limited number of examples. The most similar instances of parallelism may be found in the Jewish community of the Jewish Autonomous Oblast of the Russian Federation, the Serbian community in Bosnia and Herzegovina, the Russian community in Kazakhstan, and possibly even the Swedish community inhabiting the autonomous Aland Island off the coast of Finland. All of these cases refer to distinct minority populations whose interethnic relations with the majority are defined by discrete institutional factors.

Mutually reinforcing institutions act as complementary push and pull factors that "steer" people; parallelism is an outcome of institutions. The institutions of autonomy and kin-state activism foster a level of ethnonational homogenization and solidarity that are ultimately expressed in distinct patterns of separateness from the "other." Absent these institutions, parallelism would have never been realized for the Hungarian community in Vojvodina. Parallelism is, for better or worse, institutionally-induced segregation.

In times of rising nationalist sentiment, in a region ripe with ethnic nationalism where multiculturalism is but a mere figment of imagination and integration of minorities is proving to bear near impossible, parallelism may just be the most stable outcome for majority-minority dynamics. Given that nation-states rarely incapsulate the entirety of nations, parallelism provides a peaceful alternative for communities to live side by side without having to neither integrate, assimilate, or be marginalized. Although seemingly 
unorthodox, this study will show that parallelism as an interethnic dynamic predicated on communal detachment and indifference provides the optimal peaceful status quo solution for national reunification without border revision. In fact, parallelism is the equilibrium outcome for virtual nation-building that institutionally sanctions self-determination of national communities but also preserves state sovereignty intact. If these institutions persist, parallelism is a very real, stable, and plausible interethnic outcome that fosters national solidarity, nurtures cross-border national unity, without undermining state stability. 


\section{Chapter I - Case Study Approach to Hungarian Community in Vojvodina}

This research is a case study of the Hungarian community in Vojvodina, specifically examining the importance of collective identity and institutions in shaping interethnic relations. The study focuses on the perceptions, attitudes, and behaviors of the Hungarian minority in Vojvodina, Serbia's autonomous northern province, and explores their interaction with the Serbian majority. I posit that separateness and detachment characterize the relationship between Hungarians and Serbs in Vojvodina. This case study specifically investigates the influence of two important institutional factors which have contributed to the development of this dynamic: Vojvodina's volatile autonomous status and the ever-increasing presence and activity of its kin-state.

This dissertation explores Hungarian identity in Vojvodina through the framework of the theory of parallelism, which is defined as institutionally-sanctioned communal detachment/self-separation. This research specifically examines the role of institutions in fostering this distinct interethnic relations outcome. This study seeks to determine factors that have enabled such an outcome and ultimately argues that two institutional factors, autonomy and kin-state activism, have supported the development of parallelism. More specifically, I find that contentions over territorial and cultural autonomy in Vojvodina as well as Hungarian kin-state activism have led to the current outcome of parallel lives for the Hungarian community in Vojvodina.

The proposed explanation for parallelism evidenced among the Hungarian community in Vojvodina hinges on two, mutually interconnected, hypotheses: a "push" factor and a "pull" factor. The first hypothesis is that the contentions over territorial and cultural autonomy in Vojvodina acts as the "push" factor, causing the Hungarian 
community disassociate politically-and territorially with the province and socio-cultural alienation from the Serb majority. The second hypothesis is that the Republic of Hungary's diffusion of trans-border nationalism through kin-state activism acts as the complimentary "pull" factor, repositioning Hungarian community relations towards the homeland, providing a way to "opt-out" from interacting with the Serbian majority. With Hungary acting as the dominant element of stability and sustenance for this minority, kinstate activism redirects reliance on the state and decreases the cost of not interacting with the "other." Together, these two mutually reinforcing factors have fostered parallelism for the Hungarian community in Vojvodina.

With regards to the notion that autonomy has encouraged parallelism, I do not break away from conventional theories which consider autonomy as an institutional mechanism for managing ethnonational conflict (Stjepanovic, 2018). However, I do attempt to question the influence of autonomy in producing interethnic relations outcome. Furthermore, I will challenge traditional arguments that consider kin-state activism to be a securitization issue, pitting host-state nationalism against kin-state, trans-border homeland nationalism. Instead, I examine the role of kin-state activism in reordering minority relations (Brubaker, 1996; Liebich, 2017).

I explore the above factors with a single-case study designed to illuminate their role in fostering parallelism. The Hungarian community in Vojvodina is the central unit of analysis of this research. One critique of the single-case study methodology is that it offers weak analytic leverage and provides limited generalizable conclusions by rendering "exceptionalistic explanations" (Stjepanovic, 2018, p. 9). However, the case study approach is most appropriate for this research since it explores a new theory and 
contemporary phenomenon - parallelism - within its real-life context, offering the most accurate especially when "boundaries between phenomenon and context are not clearly evident" (Yin, 2003, p. 13). Divorcing the phenomenon of parallelism from its context in Vojvodina and the subjective perceptions of its Hungarian population is nearly impossible. Any other research design that would wholly rely on structural analysis of variables using solely objective data to explain the theory of parallelism in this particular case would be insufficient, since it would fail to consider the institutional context of this area. The results generated from this study are applicable to the Hungarian community in Vojvodina at this current time and hold as long as these two institutional factors persist and remain salient for the population.

The research design employed is a single-case study that identifies two factors enabling parallelism. This case study research relies on "process tracing to deduce theories from observations" within this single case (Van Evera, 2007, p. 68). The research is heuristic and explanatory in scope, and it does not aspire to produce widely generalizable conclusions. The results of this study may be generalizable to other communities experiencing detachment but only if the factors responsible for this outcome are similarly institutionally sanctioned. Causal analogies are only partial and cannot be universally applied. Further research is certainly necessary to determine to what extent similar institutional factors may lead to parallelism elsewhere. My aim at this point is twofold: (a) contribute to interethnic relations discourse by adding a new middle-range theory of parallelism which also presents itself as a new category within well-established acculturation models; and (b) examine two institutional factors that have caused this phenomenon of parallel lives at least as far as the Hungarian community is concerned. 
The value of this study still lies in providing a new perspective on interethnic relations in Vojvodina, particularly as far as the Hungarian community in concerned, and adding a new category to typical acculturation models. Academic investigation that focuses on "social history and the interactions between various groups in the province," are sorely lacking; this inquiry can be considered part of the long overdue remedy (Stjepanovic, 2018, p. 145).

\section{Methodology for Examining Parallelism}

This study uses primary data collected from interviews to obtain thick analysis describing the behaviors and attitudes related to the phenomenon of parallelism among Hungarians in Vojvodina. Given the self-isolating tendencies of this community, one of the initial challenges for this research was to devise a strategy to accurately capture the attitudes and sentiments of this community. The stereotypical Hungarian in Vojvodina is quiet and secluded, and politically correct and socially restrained. According to several interviewees, members of the Hungarian community in Vojvodina are usually guarded when it comes to discussing ethnic matters, and generally refuse to participate in any type of survey and/or are skeptical that so-called "researchers" are actually political party recruiters. Previous survey studies conducted in this area and targeting this community seem to have been unsuccessful, specifically because they had a difficult time recruiting members to participate. Therefore, the task was to find an appropriate method that would be most effective in recruiting interviewees to speak candidly on politically-charged issues, specifically tapping into their honest feelings and attitudes. Both subject 
participation and subject honestly were two important factors that weighed heavily on the choice of effective method to employ for the purposes of this inquiry.

Given this rather private nature of the Hungarian community in Vojvodina, and their general suspicion of all things political, one-on-one interviews were considered the most effective and arguably the only means to study parallelism in this context. Participants were recruited from the two districts of Vojvodina where ethnic Hungarians constitute a majority: North Backa and North Banat. More specifically, the majority of participants originated from the villages of Stara Moravica, Pacir, Backa Topola, Mali Idjos, Senta, and Novi Sad. All of these places have an ethnic Hungarian majority, except Novi Sad. The rationale for introducing subjects from Novi Sad into this study was to control for the discrepancy between the rural and urban centers (Novi Sad being a larger, urban area).

A total of 23 subjects were interviewed by the author. All interviewees were recruited through snowball sampling, in which one participant referred another. The sample constitutes just under $0.01 \%$ of the total Hungarian minority population in Vojvodina. Although effort was taken to balance demographic characteristics, the sample contains a far greater proportion of male participants. Thus, this sample is not representative of the entire Hungarian community in Vojvodina, which is important to consider when drawing general conclusions about this community as a whole. The sample does, however, manage to loosely reflect the normal distribution of age (the sample includes more middle-aged and senior males than younger adults), occupation (the majority of the sample includes agricultural workers and artisans), and socioeconomic status (majority of sample are low- to medium-income households). 
I, the sole researcher of this study, conducted interviews in two discrete times: throughout November, 2018 and in the second part of March, 2019. All interviews were conducted in Serbian. When necessary, family members were called to act as informal interpreters for specific words or phrases. The majority of interviews were conducted in subjects' homes for privacy purposes. Only four interviews took place at the subjects' workplace. Participants' ages range approximately 20 to 85 years old. Subjects' socioeconomic backgrounds and professions were equally diverse, and included private construction entrepreneurs, priests, municipality officials, industrial metallurgy workers, homemakers, public mental institution caretakers, and agricultural farmers. The sample comprised six adult female and seventeen adult male interviewees. As shown in the fieldwork, women were extremely difficult to recruit for the purposes of this inquiry. Despite being referred by fellow members of their community, many women declined to be part of this research, usually stating that they either feel uncomfortable talking about anything political or had no views or knowledge of ethnic matters. Many referred to their husbands or partners for further comment.

One notable factor influencing this data connection (and one possible reason for the difficulty in recruiting participants) is that the research investigator is male and of Serbian origin. The issue of my Serbian identity was frequently highlighted by both male and female interviewees; many subjects expressed that they were skeptical that the research was actually of a political nature, rather than purely academic. Some subjects were surprised that a "clean" Serbian (not of mixed ethnic background) without political affiliations was interested in their community. As a result, many participants were somewhat reserved in their responses in the early stages of their interviews. Often, they 
asked me how honest and frank can they be in their responses, and asked if I would be offended if they say something critical about their experiences with Serbs and the Serbian state apparatus in general. Several participants, especially female, inquired whether they could trust that their responses would remain anonymous and wanted assurances that I would not share any information with the Serbian government and/or any political party. However, as the interviews progressed subjects evidently became more comfortable, and began to express their views and opinions more freely. On the whole, participants were extremely hospitable and receptive to me as an interviewer, despite my ethnic "otherness."

Furthermore, the required IRB consent form that accompanied the primary research collection proved to be a major obstacle for many potential research participants. Women, especially, were reluctant to sign the form, instead, referring their husbands to sign the form. This could possibly further highlight their reluctance to formally express political opinion. Similarly, male participants, especially older subjects, were very skeptical when they were informed that the researcher was associated with an American research institution. Either in good humor or in open conversation, the link between my research, the CIA, and George Soros was brought into question.

Participants were asked to respond to a series of semi-structured interview questions (Please refer to Appendix A for a list of standard interview questions). Questions focused on participants' primary collective identity, their political and religious affiliation, their views on interethnic relations between Hungarians and Serbs in Vojvodina, the role the Republic of Hungary in their lives, and their perceptions of Vojvodina's territorial and cultural autonomous status. I used field notes to transcribe 
direct quotes and main ideas, making every effort to adhere to the original statements and sentiments. All transcriptions were first written in Serbian and later translated into English. Upon completing the primary data collection, all data underwent qualitative thematic coding analysis. The main themes included primary identity markers (Hungarian, Yugoslav Hungarian, Vojvodinian Hungarian), feelings of tolerance, notions of discrimination, perceptions of self-isolation, behaviors of loyalty and adoration for the kin-state, and views concerning provincial regional autonomy compared to minority cultural and territorial autonomy.

Alongside this primary data collection and analysis, secondary data served to add context to this inquiry. Official statistics, election data, opinion polls, and attitudes surveys lend context to the interethnic dynamic discussed here. Historical analysis and legal qualitative analysis of Vojvodina's autonomy were imperative to understanding the evolution of policy and how this has influenced its current status, and Hungarians perceptions of the same. Publicly available data on types and amount of support offered by the Republic of Hungary proved vital in understanding Hungarian perceptions and behaviors of reliance on the kin-state. Together, the synergy of primary and secondary data collection and analysis provides a comprehensive approach to this inquiry, the conclusions of which will be expanded on in the following chapters. 


\section{Chapter II - Issues of Identity in Vojvodina}

This dissertation focuses on the factors that have facilitated the current, observable dynamic of two ethnic communities living parallel lives: living side by side, yet stopping short of integrating or, even less, assimilating. Before delving into a complete exploration of these two institutional factors facilitating the development of parallelism on the part of the Hungarian community in Vojvodina, however, a discussion of national identity is of paramount importance in order to frame the acculturation strategy that defines this type of interethnic relation. To this effect, understanding the meaning of ethnonational identity in relation to Vojvodina is of crucial significance.

\section{Hungarian Ethnicity as Collective Identity Basis}

In order to grasp the complexity of interethnic relations in Vojvodina, one must first comprehend the inner workings of collective identity. The focus here is on ethnic identity, specifically in its more political form - ethnonationality. The proposition is that the Hungarian community in Vojvodina is a distinct ethnonationality whose cultural distinction, group solidarity, and boundaries for group inclusion are reinforced by a political agenda and group mobilization to realize the same. The apparent self-separation of the Hungarian community in Vojvodina, which has been termed parallelism, is the exhibited collective group behavior that also has a very political connotation in Vojvodina. More specifically, it is the foundation upon which the collective resilience of this community should be understood.

Taking ethnonational identity as the starting point for this discussion, the premise is that ethnic belonging affects everyone in Vojvodina, including the Hungarian 
community. As a common marker of collective identity, ethnicity influences how this group conceives of itself as distinct, how it views others, its belief system, the thinking and reasoning patterns it adopts, and the attitudes and behaviors it diffuses. As an ethnic group, the Hungarians are a distinct community with a common ancestral background, shared cultural background, attached to a specific territory, with a shared outlook on the past and future, and marked by common myths and symbols (Smith, 1991). For the Hungarians in Vojvodina, their collective ethnic identity ultimately limits the choices and behaviors of its individuals' members. In this way, ethnicity can be conceived of as a plausibility structure in that it creates a set of specific beliefs that the community embraces for the sake of self-preservation (Berger, 1967).

Considering the Hungarians in Vojvodina first and foremost in terms of ethnicity illuminates the essentialist element associated with this community, and supposes that identifying with their ethnic group is a natural fact of human nature that it is organically passed down from generation to generation. Such a primordial conceptualization of Hungarian ethnicity understands communal attachments to be inevitably formed on the basis of "cultural givens" of social existence (Smith, p. 56). In this view, communal attachments organically predispose cooperation with the Hungarian ingroup to the detriment of relations with the outgroup, since members of the collective inherently feel and believe in the natural exclusionary bonds that tie their ethnic group together (Horowitz, 1985; Smith, 2010).

A primordial approach to Hungarian ethnicity, however, is surely not entirely sufficient to understand this group's behaviors. The instrumentalist critique to the primordial approach to ethnicity asserts that ethnic identity only becomes salient in times 
of mass mobilization for the sake of collective competition. In other words, ethnicity becomes a powerful instrument for elite-driven mass mobilization that agitates the "us" versus "them." This instrumental lens can be useful to understanding how Hungarian ethnicity in Vojvodina is manipulated by political elites, and may even serve to compliment the primordial approach in stressing the natural inclination towards cooperation between individuals of the "same blood." However, for this inquiry, the value of the instrumental approach is as the platform for assessing the nationhood of the Hungarian community in Vojvodina. Such an instrumentalist approach to Hungarian ethnic identity, stressing the primary role of politicization in steering ethnic behaviors, introduces the concept of nation and nationalism as its primary instrument for achieving cohesive political goals (Breuilly, 1994). Therefore, comprehending the Hungarians in Vojvodina in terms of typologies of nationhood rather than purely ethnicity provides a more holistic approach to this community by including a myriad of elements previously addressed.

\section{Hungarian Community in Vojvodina as Categorized "Narodnost"}

If ethnicity is the starting point for understanding the Hungarian community in Vojvodina, the question then becomes whether this community can be considered a nation. A solid case can be made for considering the ethnic Hungarian community in Vojvodina as part of the greater Hungarian nation, at least in terms of sharing a political consciousness. This view is further reinforced when assessing the unique manner in which the former Socialist Federal Republic of Yugoslavia (SFRJ) defined, categorized, and regulated national status. Yugoslav policy was guided by the overarching distinction 
between narod and narodnosti. More specifically, "narod means Slav nations having only Yugoslavia as their mother state: Slovenes, Croats, Muslims ${ }^{6}$, Serbs, Macedonians, and Montenegrins were such nations. Narodnost means national minority: Albanians, Hungarians, Turks, Italians, and others living in Yugoslavia but having some other mother state" (Hodson, Sekulic \& Massey, 1994, p. 1543). Critics contend that such a distinction between nations and nationalities set the tone for the unequal relationship between communities, limiting the rights of nationalities compared to that of the nations, specifically in terms of their right to self-determination (Stojanovic, 1997, p. 135). Regardless of this debate, however, even former Yugoslav policy did acknowledge narodnost as nations to some extent, recognizing their separate political consciousness and need for political self-government, even if stopping short in accepting their political self-determination. Given this legacy, comprehending the Hungarian community in terms of nationhood is imperative. Even more recent research findings affirm this position, indicating that Hungarians in Vojvodina consider themselves above all else a "national community" and favor to be regarded and officially labeled as such by the external world (Lazar, 2010, p. 33).

\footnotetext{
${ }^{6}$ Muslims with an administratively capitalized "M" only became a recognized distinct ethnic group, and eventually a constitutive nation, under the amendments to the 1971 Constitution of the Socialist Federal Republic of Yugoslavia. They should not be confused with the administratively termed "muslims" as a generally designated religious grouping. Muslims in Bosnia only gained the status of an ethnic group with the ascent of the Socialist Federal Republic of Yugoslavia (SFRJ). Up until then, even in the Kingdom of Yugoslavia, Muslims either had to declare as Serbs, Croats, Yugoslavs, or "Other." It was not until the communists came to power in Federal People's Republic of Yugoslavia (FNRJ), that the subsequent leadership in the later renamed SFRJ finally recognized Muslims in the national sense, in conjunction with their religious persuasion.
} 


\section{Perspectives on Nationhood}

\section{Modernist Perspective on Nations}

The two dominant and, arguably, most applicable paradigms through which to understanding nations and nationalism in this context are modernism and ethnosymbolism. The modernist perspective presupposes that nations are a modern phenomenon and nationalism is a product of modernity (Smith, 2010, p. 50). The socioeconomic modernist perspective asserts that nations are derived from the unique social and economic structures of modernity (Smith, 2010, p. 51). Tom Nairn (1977), a prominent socioeconomic modernist, claims that nationalism is caused by the combination of the uneven development of capitalism and the class consequences of the uneven diffusion of capital. Differentiating between the core and the periphery, Nairn understands nationalism as a cross-class movement that feeds on already defined ethnic sentiment/differentiation. He claims that the outcast periphery is mobilized into a "militant inter-class community rendered strongly (if mythically) aware of its own separate identity vis-à-vis the outside forces of domination" (Nairn, 1977, p. 340). Such a perspective is loosely applicable to the Hungarian community in Vojvodina, which in this case should be considered Nairn's disenfranchised periphery, politically exploited and oppressed by the Serb core, and extremely self-aware of their identity. Over time, this ethnic group can be said to have gained a political consciousness that sets it apart from the majority, developing a very specific pattern of behaviors and mobilizing as a community around nationalist sentiment. However, the Hungarian parallelism that is apparent in Vojvodina does not express itself in militant terms, nor does it seek political 
self-determination presently, and as such this case study does not conform exactly to Nairn's typology.

Another prominent socioeconomic modernist approach that could be utilized in understanding the Hungarian community in Vojvodina is presented by Michael Hechter (2000). This modernist scholar postulates that direct centralized rule, as a definitive feature of modern state governance, creates conflict in culturally heterogeneous states (Hechter, 2000). Hechter contends that direct rule characterized by governing centralization agitates competing national identities, making cultural distinctions more salient. Direct rule comes at the detriment of local (minority) elites, causing them to lose power and thus rationally calculate and mobilize nationalist opposition for selfdetermination in order to reacquire political strength (Hechter \& Levi, 1994, p. 188-189; Smith, 2010, p. 73). Such a perspective linking direct rule with the development of national sentiment is highly applicable to understanding how contestations over Vojvodina's autonomy has influenced the development of parallelism. The manner in which Hungarian political elites in Vojvodina have been able to mobilize their followers around animosity towards Belgrade's direct rule is the subject of a later chapter.

A more holistic sociocultural approach to nationalism is espoused by Ernest Gellner (2006) who contends that nations are a product of the age of nationalism. Claiming that nationalism's function is to "strive to make culture and policy congruent, to endow a culture with its own political roof, and not more than one roof at all," Gellner seeks to fuse the notions of will and culture under the umbrella of the polity when conceiving of the nation (Gellner, 2006, p. 42). By equating the nation with the imposition of "standardized, homogenous centrally sustained high cultures," Gellner 
emphasizes the importance of reinventing pre-existing folk cultures into high-culture nations, internalized through the education system and protected by the state (Gellner, 2006, p. 54). Overall, Gellner's expansive theory of nationalism, encompassing both the voluntary and cultural determinant elements of nationhood, is applicable to this particular study in its focus on the element of high culture institutionalized through the education system. Gellner's theory is particularly pertinent in that it focuses on language use as the primary cultural identifier. This is especially true of the Hungarian community in Vojvodina, and has ultimately resulted in the development of a separate political conscious.

Although rather abstract, constructivist modernist approaches to nations can also be of some use to understanding the Hungarian community in Vojvodina. Benedict Anderson's conception of the nation as an "imagined political community - and imagined as both inherently limited and sovereign" casts light on the power of ideas that define nations and how they behave (Anderson, 1991, p. 6). For Anderson, nations are a social construction; "nations are imagined because the members of even the smallest nation will never know most of their fellow-members, meet them, or even hear of them, yet in the minds of each lives the image of their communion" (Anderson, 2001, p. 6). In this manner, parallelism too can be understood as a social construction on the part of the Hungarian community in Vojvodina that may not be the result of tangible factors but rather the simple power of belief/imagination in their distinctiveness and separateness from the dominant Serb community. How this community conceives of themselves and their relation with the "other" is what matters in creating the outcome of parallelism. 


\section{Ethno-Symbolic Perspective on Nations}

Altogether, the modernist perspective on nations is rather limited in its explanatory power in regards to the Hungarian community in Vojvodina. The modernist understanding of nationalism as necessarily a condition of modern man fails to fully consider the possible historical origins of nations in terms of inner ethnies - something that is deeply tied to the Hungarians in Vojvodina. Moreover, the limited modernist comprehension of nations in terms of the evolution of values, culture, myths, and symbols only further constrains its applicability to the analysis of this specific community. In contrast, therefore, the paradigm of ethno-symbolism propagated by John A. Armstrong, John Hutchinson, and Anthony D. Smith (1982/1991) is more pertinent to this case study of the Hungarian community in Vojvodina. Essentially, ethno-symbolism studies nations through the evolution of ethnic groups, as the Hungarians in Vojvodina would surely be defined. Rather than relegating nationhood to modernity, therefore, this critical approach highlights the subjective elements in the creation of nations, focusing on long-term analysis of social and cultural patterns that define ethnies. Rather than focus on perennial material factors, ethno-symbolism emphasizes the cluster of symbolic boundary mechanisms that come to define ethnic groups. In the process, the ethno-symbolic paradigm highlights the long-term reciprocal relationship between "elites" and the "people," something that the modernist perspective fails to do by solely considering elite-

orientated national power structures through the lens of modernity (Smith, 2010, p. 61).

Anthony D. Smith argues that nations are reinterpretations of pre-existing cultural motifs and reconstructions of historical ethnic ties, claiming that "we need to understand nationalism as a type of collective conduct, based on the collective will of a moral 
community; and this means that we need to grasp the nation as a political form of the sacred community of citizens" (Smith, 2010, p. 89). John A. Armstrong further asserts that ethnic identification persists not as an historical genesis of material factors, but rather as a recurrent attitude that at a group displays (Armstrong, 1994, p. 145). Is parallelism one such recurrent attitude displayed by the Hungarians in Vojvodina? Quite possibly. Focusing on the importance of symbols as a means to preserve ethnic continuity, specifically, Armstrong stresses the maintenance of social boundaries of "us" versus "them" as the prerequisite for the creation of nations. For Armstrong, the "boundary approach clearly implies that ethnicity is a bundle of shifting interactions rather than a nuclear component of social organization" (Armstrong, 1994, p. 142). One such type of interaction, or in this case lack thereof, is also parallelism.

Possibly the most applicable (ethno-symbolic) approach to conceiving of the Hungarian community in Vojvodina is espoused by John Hutchinson. Differentiating between cultural versus political nationalism, Hutchinson equates cultural nationalism with a "moral regeneration" undertaken by many communities whose sense of self is being lost (Hutchinson, 1994, p. 123). "Typically, cultural nationalists establish informal and decentralized clusters of cultural societies and journals, designed to inspire a spontaneous love of community in its different members by educating them to their common heritage of splendor and suffering" (Hutchinson, 1994, p. 124). Such a moral rejuvenation can be evidenced by Vojvodina's Hungarian elite through the increased cultural mobilization of the community in the province. In this sense, the parallelism that is expressed on the part of the Hungarian community can be considered as one element of cultural nationalism. 


\section{Hungarian Community in Vojvodina as an Ethnonationality}

Adopting Smith's definition of the nation as "a named human community residing in a perceived homeland, and having common myths and a shared history, a distinct public culture, and common laws and customs for all members" is arguably the most accurate way to consider the Hungarian community in Vojvodina (Smith, 2010, p. 13). Most importantly, such a definition allows for conceiving of the Hungarian community in Vojvodina as an ethnonationality: one of several subsets of the greater Hungarian nation that is presently outside of Hungary's borders. This conceptualization is also in line with the common understanding of eastern nationalism. According to Hans Kohn (1994), a distinction is made between the western versus eastern understanding of a nation and, ultimately, western versus eastern nationalisms. The western perspective stresses the civic aspect, conceiving of the nation as a liberal, rational association of citizens that are bound by law on a specific territory. In contrast, the eastern conception of the nation emphasizes the natural and indivisible collective whole composed of individual members who identify with one another based on shared cultural and ethnic background (Kohn, 1994, p. 164). In regards to the Hungarian community in Vojvodina, this eastern perspective of ethnic nationalism becomes extremely important. At its core, Vojvodinian Hungarian nationalism is based on shared cultural heritage as the simultaneous impetus for ethnic Hungarian solidarity as well as distinction and differentiation from the dominant Serb community. This becomes all the more salient in the context that Serbia is conceived of as a national state and not a civic state, thus holding very much true to Kohn's version of eastern nationalism (Komsic, 2015, p. 118). 
There seems to be a loose general association between Kohn's western versus eastern conceptualization of nations and the distinction between the modernist and ethnosymbolic paradigm. Kohn's eastern conception of the nation holds much in common with the ethno-symbolic perspective. Its focus on the inner working of ethnies, the evolution of symbols and their values among the collective, and the meaning that is derived from a common cultural background surely draw on Kohn's eastern nationalism. On the other hand, the western conception of the nation only holds some common ground with the modernist perspective. Certainly, Kohn's western perspective, stressing the more rational side of the citizen association, draws on the modernist perspective. In fact, the emphasis on the advent of a distinctive public culture, which binds people to the law, is something that both share in common. On the other hand, however, Kohn's western conception of the nation is not confined to modernity as the modernist paradigm would have us believe, and as such is more fluid in its understanding of the nation in terms of historical origin.

\section{Issue of National Identity}

Until this point, much has been said about the Hungarian community in Vojvodina as an ethnic group and as an ethnonationality. If ethnonationality is arguably the most accurate manner in which to define the Hungarian community in Vojvodina, we must explore the role of ethnonational identity in bringing about this phenomenon of parallelism.

National identity constitutes an integral part of the modern human condition. Modernists contend that the issue of national identity is a modern phenomenon that is socially constructed and pertains to the manner in which a given group of people 
"conceive of themselves" and embrace a collective identification (Miller, 1997, p. 17).

Smith further contends that national identity should be considered in terms of the "continuous reproduction and reinterpretation by the members of a national community of the pattern of symbols, values, myths, memories and traditions that compose the distinctive heritage of nations, and the variable identification of individual members of that community with that heritage and its cultural elements" (Smith, 2009, p. 109). In this case, an interpretation and articulation of what the ethnic Hungarians in Vojvodina believe of themselves and the factors that influence their specific behavior is the basis for their divergence with the Serb community, leading to the outcome of parallel lives. This research will focus specifically on two of the main functions of national identity: building resilience, and creating and hindering relationships with others (Guibernau, 1996, p. 73).

Sinisa Malesevic argues that national identity cannot be taken at face value, but should only be explored through complex historical social processes, specifically the "ideologisation of solidarity," that is best conceptualized through nationalism (Malesevic, 2011, p. 287). By this reasoning, it is solidarity with the ingroup that leads each member of the Hungarian community to live next to, but not with, members of the other ethnonational communities in Vojvodina. Others are, however, more skeptical of the term "national identity," arguing that it presupposes a type of societal homogenization that causes Hungarians in Vojvodina lead parallel lives in relation to the dominant group (Miscevic, 2000). For example, Nenad Miscevic is skeptical of using the term national identity, claiming that such a new term presumes that "the national identity of the group is essential for the personal identity of each of its members" (Miscevic, 2000, p. 239). This issue of false collective homogenization (group sameness) imbedded in the concept 
of national identity gradually replaces more adequate terms such as "national character" and "national consciousness" in scholarship on nationalism-- terms which are far less multi-dimensional and that do not presuppose necessary "groupism" or identitarianism (Brubaker, 2004, p. 8). By groupism Brubaker understands the "tendency to take discrete, bounded groups as basic constituents of social life, chief protagonists of social conflicts, and fundamental units of social analysis" (Brubaker, 2004, p. 8).

According to Smith, however, to think of communities as having a collective national identity is valuable since it recognizes the reconstructed layering of identity that the product of both the individual and the collective, and is historically continuous yet susceptible to change (Smith, 2010, pp. 18-23). In this way, Smith understands national identity as both synergistic and evolutionary malleable. National identity is far more than a collection of individual national identities; it is a synergic collective cultural identity. However, this collective cultural identity has inputs from the spectrum of individual identities that are in solidarity but do not presuppose homogeneity. Hence, Smith understands national identity to encompass both the individual and collective sense of self. It is this sense of self that is of paramount importance in understanding attitudes towards certain factors that have facilitated the development of parallelism on the part of the Hungarian community in Vojvodina.

In On Nationality, Miller outlines five important features of national identity.

First, national identity is said to be connected to a specific conception of modern communities (nations) that are constituted by beliefs. Second, national identity is connected to the notion of historical continuity that introduces specific community obligations and mutual commitments through time (Miller, 1997, p. 27). Along with this, 
the third element is active identity. Active identity is the process of consciously interconnecting the past, present, and future of the given community that actively and collectively participates in sharing the rights and obligations associated with its existence and function. The fourth element associated with national identity is geography. National identity is tied to a particular geographical territory; a "homeland" in this sense. This idea of homeland becomes extremely important when discussing the relationship between nation and state and determining territorial control and integrity. Finally, the fifth element of national identity is the notion of "national character" (Miller, 1997, p. 25). Miller argues that people who share a common national identity share a common set of features that can include anything from ideologies to collective myths, values, and traditions, and ultimately behaviors displayed towards others outside their community. This "distinct public culture" distinguishes one national community from other such groups (Miller, 1997, p. 25).

Smith recognizes that national identity has "become the main legitimation for social order and solidarity today" (Smith, 1991, p. 16). Smith builds on this presupposition by asserting that national identity has become the mechanism for the creation of a homogenous culture in which the discovery of the so-called "authentic self" can only be discovered in comparison to another separate community with wholly different historical symbolic-cultural attributes (Smith, 1991, p. 20). Such an approach to national identity as espoused by Smith lends perspective to the exaggerated need for differentiation and separateness between groups that live in the vicinity of each other, yet do not intermix. 
The core ideas of solidarity and belonging associated with national identity gain a certain political legitimacy through the principle of self-determination. Of course, nations have different degrees of political and social salience in different times and contexts. Some scholars argue that cultural conflicts between different communities increase the salience for political and social self-determination (Hutchinson, 2010). The underlying premise of this study is that cultural conflicts in developing countries are especially heightened due to exaggerated processes of collective identification assisted by "centrifugal ideologization of solidarity" for the sake of "maintenance and heritage of nations," leading to a heightened focus on self-determination that create clear demarcations between competing national identities (Malesevic, 2011, p. 17; Malesevic, 2006, p. 28). After all, in volatile conditions, the threat of the "other" emphasizes the sense of "us," leading to heightened sentiments for homogenized national communal identification (Hobsbawn, 1990, p. 170)

The idea that national identity is the most powerful form of collective cultural identity forms the theoretical foundation of this research. Nationalism in the political sense -- the idea that the cultural boundaries of an ethnic community should be congruent with the political boundaries of that community -- is of little importance here. However, nationalism in the cultural sense - that is, a worldview that offers individual and collective identity distinction based on common historical-cultural background, ethnosymbolism, sense of communal homeland, and shared historic destiny--is of central significance. Most importantly, in this case national identity has developed as a means of "lending strength and resilience" to the ethnic Hungarian community in order to differentiate themselves from the "threatening other" with whom they cohabitate but do 
not interact (Guibernau, 1996). It is on this basis that we will explore the parallelism within this specific ethno-national community. Parallelism is one more institutionallysanctioned avenue through which to understand the resilience of national identity as an alternative to interaction and integration. The ability of the national Hungarian community to maintain a separated and indifferent relationship with the Serb "other" in Vojvodina provides a unique approach to nurturing national resilience.

\section{Overarching Supranational Identity}

There seems to be a gap in the current literature as to whether the existence of parallelism, as the defining feature of interethnic relations for the Hungarian community in Vojvodina, possibly exists in the wider context of pluralism, or even liberal pluralism. Such pluralism could even possibly suggest that a type of interculturalism is taking place. After all, "pluralism allows for many different groupings but, unlike multiculturalism, does not try to impose one uniform status on all of them. It allows a thousand flowers to bloom, with minorities forming communities of faith, ethnicity or culture within a society - but under the overarching umbrella of a national identity to whose core values everyone signs up" (Phillips, 2007, para. 23). Such an understanding of pluralism still requires an overarching identity so that all other ethnonational identities can partake in its shared common values and thrive under its banner. Arguably, a so-called Vojvodinian identity fits this pluralist conception and could possibly be acceptable for all-- an overarching identity that transcends national fervor, as opposed to a necessarily Serbian or Hungarian identity. A Vojvodinian identity, in pluralist terms, would ultimately be supranational in character, allowing a plurality of distinct ethnonational communities to ascribe to 
common "Vojvodinian values." This has never been a reality, however. Enter a necessary analysis of the failings of establishing such an integrative regional Vojvodinian identity as a possible highest value nurtured in the province.

\section{Question of Vojvodinian Identity}

Does a Vojvodinian identity exist? The answer to this question is complex, yet arguably at present answered in the negative. Data collected by the Center for Political Research and Public Opinion in 2003 show that the population of Vojvodina, regardless of ethnic distinction, are least likely to associate with Vojvodina as a region. This study also found that the Hungarian population associates the least with Vojvodina and most with their own place of residence (village and town), compared to other ethnic groups. (CPIJM, 2003). The study concludes that that members of the ethnic Hungarian community identify inordinately with ethnonational markers. Thus, the authors argue that Hungarians are the most unsatisfied with the political status of Vojvodina, which leads them to overwhelmingly favor increased ethnic territorial autonomy for their community on the basis of cultural distinction (CESID, 2006; Lazar \& Marinkovic, 2003). My own findings concur with the general findings of past research, but present a more nuanced picture, as will be shown in what follows.

Ethnocultural, Multicultural and Liberal Pluralist Interpretations of Vojvodinian Identity

Vojvodinian identity can be understood in terms of three conceptualizations: ethnonational, multicultural, and liberal pluralism. The multicultural perspective will be 
discussed in more briefly generally here for sake of comparison. The ethnonational perspective requires further elaboration. Finally, the liberal pluralist approach, possibly the most controversial, will be assessed in full and in relation to the failed creation of an "intercultural" Vojvodinian identity.

An overwhelming majority of interview participants (21 out of 23 ) reported that they consider their Hungarian ethnicity to be their primary collective identity marker. The two remaining participants claim that although they are fully ethnically Hungarian, their primary collective identity is Yugoslav "because that is the identity of all good people in the best country that ever existed" (anonymous source, in discussion with author, November 7, 2018). One participant who proclaimed his primary identity as Yugoslav is the former diocesan bishop of the Roman Catholic Church for the North Backa jurisdiction. He elaborates that "only such a Yugoslav Hungarian identity is a truly European identity that we should all aspire to because it consciously transcends nationalist tendencies under the banner of a secular understanding of interfaith brotherhood and unity" (anonymous source, in discussion with author, November 10, 2018).

Of the 21 subjects who proclaimed that their Hungarian ethnicity is their primary identity, virtually all supplemented this with the label "Vojvodinian" - Vojvodinian Hungarian. This response seems to indicate a high salience for the provincial identity marker among the Hungarian community in Vojvodina. However, much of the data indicate that this may not be the case. In fact, when pressed, only a few participants could even explain what they meant by the term Vojvodinian without referring to what it is not. As a dog obedience trainer from Vojvodina solemnly professes, "by me telling you that I 
am Vojvodinian Hungarian I am not telling you anything other than that I am carrying the political and economic burdens of Serbia even though I am Hungarian” (anonymous source, in discussion with author, November 24, 2018). Others are even less connected to the term "Vojovodinian," relating it merely to the "territorial demarcation where I was born as a member of the Hungarian nation" (anonymous source, in discussion with author, November 12, 2018). Some are more skeptical of this, however, such as the construction entrepreneur from Stara Moravica who claims that the "Vojvodinian" prefix to his Hungarian identity does not speak so much to a regional identity per se, but rather to his distinction from the "wider Hungarian nation" (anonymous source, in discussion with author, November 12, 2018). One goldsmith from Backa Topola agrees, arguing that "Hungarians in Vojvodina think a bit differently than Hungarians in Hungary even though we are the same" (anonymous source, in discussion with author, November 14, 2018). A mental health caregiver takes it even further, claiming that there are "subtle cultural differences that only us Hungarians would know" (anonymous source, in discussion with author, November 14, 2018). The Calvinist priest refutes this by explaining that there is no distinction between "the Hungarian nation as a whole. Vojvodinian Hungarians are merely Hungarians born on this territory that is now called Vojvodina" (anonymous source, in discussion with author, November 14, 2018). The local municipality official takes a similar approach:

“Claiming you are 'Vojvodinian' Hungarian does not mean you have some niche Hungarian identity...You are not 'owning the fact' that you are Vojvodinian but claiming you are geographically from this territory like a Transylvania Hungarian would claim he is Hungarian from Romania. But we all are 
Hungarians...Europeans if you will.” (anonymous source, in discussion with author, November 12, 2018)

How little this prefix "Vojvodinian" matters to the community in Vojvodina is probably best illustrated by the wealthy landowner from Stara Moravica who clearly states in as little words as possible: "Vojvodina means nothing. It means something to you Serbs. As a Vojvodinian Hungarian I am merely telling my Hungarian brothers I am a Hungarian outside Hungary's borders" (anonymous source, in discussion with author, November 19, 2018). Such a view is reaffirmed by the public relations official of the National Council of the Hungarian National Minority, who concludes that the term "Vojvodinian Hungarian" is a "Yugoslav communist fabrication. It does not exist and has never existed in reality. Today we do not talk of this term since it has been proven irrelevant" (anonymous source, in discussion with author, March 23, 2019).

Essentially, the Republic of Serbia, of which Vojvodina is a constitutive element, is considered a national state and not a civic state (Komsic, 2015, p. 118). This fact alone makes ethnonational identity more salient. On the other hand, much has been spoken of an ethnoregional Vojvodinian identity that seeks to condense ethnic solidarities on the basis of geography (Schopflin, 2002, p. 114). Historically, the existence of a Vojvodinian nation is vehemently refuted, and all attempts to create the same have been rejected. The possibility of a distinct Vojvodinian identity has been the subject of debate on several occasions, especially in more recent history. Yet, the inability to clearly define Vojvodinian identity, let alone describe it, makes it seem as though it is more aspirational than realistic. 
There is a sense that Vojvodinian identity, if it at all exists, is rather abstract. For example, some claim that a "Vojvodinian is a state of spirit, a Vojvodinian is a person who inhabits this area, a person who accepts differences, who lives in differences and who considers such differences of the upmost value...A Vojvodinian is a person of any faith or nation, regardless of origin, or time of settlement, who upholds these values" (Kostres, 2006, p. 9). Though progressive, such a definition of Vojvodinian identity is rather normative if not aspirational in the context of the region of the world and history in which it operates. Such a definition is civic in nature, invoking a type of civic nationalism based on shared values and norms. This idea directly clashes with the ethnic nationalism that is nurtured by the Serbian state. ${ }^{7}$ The value placed on tolerance, in particular, becomes synonymous with Vojvodinian identity, turning Vojvodina and the Vojvodinian from a geographical/regional demarcation into a political concept (Budakov, 2006, p. 94). The majority of interviewees did use the term tolerance to describe interethnic relations in Vojvodina. However, as we will see later, for the Hungarian community in Vojvodina tolerance seems to refer to respectful self-isolation, rather than to any kind of interethnic, civic nationalism.

The fact that Vojvodina is a heterogeneous community, defined by its multiethnic character, has been problematic to reconcile with a Serbian state that has historically been built in very (ethno)national terms. The cultural, regional, and national have always been in conflict; a struggle that defined the debate concerning Vojvodina's autonomous status. On the one hand, the ethnonational elements attempt to understand Vojvodina in very

\footnotetext{
${ }^{7}$ See also Dosije Autonomna Pokrajina Vojvodina in which Slobodan Antonic defends a more radical perspective, arguing that "Vojvodinian identity" is necessarily founded on anti-Serbian sentiments, rhetoric, and escalating secessionist pretensions (Antonic, 2014, pp. 173-237).
} 
simple nationalistic terms: Vojvodina was and is Serbian and all others have to assimilate (Domonji, 2006, p. 88). The other multicultural conception of Vojvodina stresses a supranational narrative, claiming that cultural diversity is the result of a historic dynamic that makes the province a unique entity (Losonc, 2006, p. 38). It supposes that Vojvodina will eventually overcome national fractures and that everyone's voice is equally heard. However, the problem with this picture of Vojvodina is that it requires an implied consensus among all of the ethnonational communities in the province, which has never occurred. Such a multicultural character requires an "genuinely regional understanding of history" among different ethnic groups, which is simply lacking in the case of Vojvodina. Even Serbian histographies between so-called autonomists and centrists collide-Hungarian histographies of Vojvodina which are even more drastically different (Stjepanovic, 2018, pp.193- 201).

For many, especially the Hungarian community, the only "consensus" that happens is Serb-dominated and Serb-led and is perceived as simply another form of assimilation. This assimilation in the supranational conception is also an imposed Serbian version of Vojvodinian identity that the Hungarian community interprets as Serbianization (Ludanyi, 1979). Even in a supranational conception of Vojvodina that allows for a type of interculturalism and celebrates Vojvodinian identity, there are a number of obstacles to Hungarians' participation. In the words of the agricultural worker from Stara Moravica:

"Vojvodina does not mean anything to me...Vojvodina is the southern occupied territory of Hungary. Only Serbs call this territory Vojvodina because they have occupied it and colonized us Hungarians as the indigenous people of this fertile 
land. Serbs should understand that they are guests here. Vojvodina is multiethnic and not multicultural. A Vojvodinian identity is specifically devised by the Serbs to undermine Hungarians living here." (anonymous source, in discussion with author, November 19, 2018)

The fact that Vojvodina is established as a territorially autonomous, civic, nonethnic province serves to complicate matters further since it clashes with the national character of the state (Komsic, 2006, p. 47). As will be explored in chapters four and five that follow, many consider this territorial autonomy granted to Vojvodina as paradoxical given that Serbia is conceived of in national terms. At the same time, however, the nonethnic nature of Vojvodinian autonomy does play into the possibility of establishing a regional Vojvodinian identity that is civic in nature. Simultaneously, however, the territorial character of Vojvodinian autonomy has been a stumbling block for many in Vojvodina that has only served to incite nationalist sentiment. As in similar postcommunist societies, many regard "territorial autonomy as a stepping stone to secession" (Kolsto, 2002, p. 202). As such, it comes as no surprise that the question of autonomy, territorial and non-territorial, in Vojvodina has been the subject of much contention and has spurred ethnocentric tendencies to the detriment of creating and embracing an integrative Vojvodinian identity.

Vojvodinian identity has been considered in terms of the ethnonational conception, which heralds Vojvodina a Serbian province and Vojvodinians as Serbs. Vojvodina's identity can also be evaluated from the multicultural perspective. However, as will become abundantly clear in the following chapter, this multicultural perspective does not adequately describe Vojvodinian identity due to the observable lack of 
interaction between ethnic groups. Put briefly, the presupposed levels of active public interaction and engagement of different cultures required to warrant multiculturalism are insufficiently met according to members of the Hungarian community.

Finally, the plural conception remains debatable for a variety of reasons. What is certain is that a pluralism that fosters an intercultural Vojvodinian identity does not exist at the present time. Interculturalism, for the Hungarian community, has always been interpreted as Serbianization. Given that a distinct Vojvodinian identity does not exist, what becomes all the more apparent is that a plural intercultural Vojvodinian community cannot be the topic of discussion here. Put simply, if we are to suppose that in a plural society in which all these distinct communities are thriving under the umbrella of a national or even regional identity to whose core values everyone accepts, such a scenario is not what is being currently evidenced here. Instead, what is at play here is merely a plurality of distinct ethnonational communities that do not interact and do not partake from one source of what is potentially Vojvodinian identity and community.

In the same vein, it is also important to consider whether a liberal pluralism is at play in Vojvodina. Liberal pluralism begins with the premise the "membership in cultural communities is essential to our personal identity and provides individuals with the necessary framework to exercise true liberty" (Deets \& Stroschein, 2005, p. 286). Walzer claims that any discussion of liberalism must involve a "sharp divorce of state and ethnicity" (Walzer, 1992). In the case of Vojvodina this is surely not the case; as interview responses indicate, Hungarians overwhelmingly hold as high salience for ethnic identity markers. Therefore, it can be concluded that the "principle of ethnocultural neutrality" that defines liberal pluralism is not a defining feature of life in Vojvodina 
(Kymlicka \& Opalski, 2002, p. 16). Indeed, the parallelism of the Hungarian community that is under scrutiny here is possibly a reaction to the lack of ethnocultural neutrality.

Cultural distinction between communities remains the central feature of interethnic relations in Vojvodina. Culture dictates relations, since culture creates identity intrinsic to collective resilience and individual existence. However, in Vojvodina, cultures are not interacting and no Vojvodinian identity has been established or embraced in a way that transcends ethnonational differences. Thus, national-cultural isolation characterizes relations in Vojvodina (Komsic, 2006, p. 46). In fact, ethnonational distinction remains an omnipresent feature of life in Vojvodina. Relations between the two largest groups, Serbs and Hungarians, sets the tone for all other communities in Vojvodina (Komsic, 2006, p. 47). The institutional factors that have facilitated the entrenchment of this separate ethnonational Hungarian identity in Vojvodina is the subject of the chapters that follow. However, before an analysis of its institutional causes, a careful discussion of parallelism is warranted. 


\section{Chapter III - Parallelism}

In the revealing words of one Hungarian private entrepreneur residing in Novi

Sad:

"Minorities are always in a precarious position, whether in Serbia, Hungary, or even the United States. The majority always denies the problems the minority faces. This is a battle of strengths; those in power set the dynamic which always denies the minority's problems as fictive. They say that a dog is man's best friend. Now, that is what man says. No one asks the dog what it thinks. In this way you can also understand how Serbia understands and treats the Hungarian minority." (anonymous source, in discussion with author, November 24, 2018)

The motivation for this research is hearing the other side - that of the Hungarian community in Vojvodina.

Interethnic relations in the province which is now called Vojvodina have always been complex, if not tremulous. From the time of its inception in the Kingdom of Serbs, Croats and Slovenes in 1918, and up until its present status in the Republic of Serbia, the province of Vojvodina, has had its fair share of unique interethnic issues. Many political, economic, and cultural factors, as well as policies related to its autonomy, have had a varied impact on the interethnic relations in the province. However, tensions and conflict have never precipitated into outright violence in Vojvodina post-1945, despite the development of major ethnonational sentiments and tendencies throughout the years. This province, with its complex ethnic composition, presents an intriguing case of peaceful interethnic relations in the midst of a region that has been embroiled in bitter ethnonational conflict and secession for prolonged periods of time. 
Vojvodina is an autonomous province within the Republic of Serbia and is known for its multiethnicity. The province comprises the three geographical subdivisions of Backa, Banat, and Srem. Serbs form a continuous overall numerical majority in the Republic of Serbia, as well as a growing numerical majority in its constitutive province of Vojvodina. However, the province also hosts twenty-six other national groups. The most numerous of these groups are the ethnic Hungarians, who have historically occupied the northern part of Vojvodina since the ninth century (Goncz \& Voros, 2005, p.188). Colonization by Hungarians in Vojvodina reached its zenith during the 1700s and early 1800s, culminating during the time of Maria Theresa and her successor Joseph II (Cerovic, 2014, p. 126). Hungarian colonists first came to Backa in vast numbers, later to Banat, and only in the early 1800 s to some areas of Srem. Hungarian elements in the Habsburg monarchy considered the mass colonization of Vojvodina by Hungarians an effective manner to assimilate non-Hungarians already living in the region (Cerovic, 2014, p. 126).

By the most recent statistics, Serbs account for $67 \%$ (just under 1.5 million) of the province, while the ethnic Hungarians number around 240,000 (13\%). The Hungarian population has been in constant decline since 1945 when they numbered just under 500,000 after the population exchanges that followed the Second World War, and the more recent voluntary exodus during the Yugoslav wars of secession in the 1990s.

Currently, Vojvodina is divided into seven administrative districts, and further subdivided into forty-five municipalities. Forty-one of these municipalities are considered multiethnic, meaning that more than $5 \%$ of the local population belongs to a minority group. Ethnic Hungarians in the province as a whole constitute a majority in the districts 
of North Backa and North Banat, and an absolute majority in five municipalities inclusive of Kanjiza, Senta, Backa Topola, Ada, and Mali Idjos.

\section{Questions Concerning Multiculturalism and Interculturalism in Vojvodina}

Vojvodina, as an ethnically diverse province, is often praised as a functioning example and success story of multiculturalism in southeastern Europe (Petsinis, 2004). Earlier prominent research on interethnic relations in the province considers Vojvodina a multiethnic region and a "melting pot of cultures." Petsinis (2004) unequivocally accepts multiculturalism for the minorities as implied in Vojvodina and argues that it even functions side by side with a supposed interculturalism that constitutes a definitive regional "Vojvodinian" identity, at least as far as the dominant Serb group in the province is concerned (Petsinis, 2004). Such a position assumes that there is some sort of multicultural interaction and exchange between ethnic groups in Vojvodina and that these same ethnic groups partake in the deeply shred ideas and cultural norms of an intercultural "Vojvodinian" identity. As articulated in the previous chapter, this research rejects the notion of an overarching "Vojvodinian" identity for the Hungarian community for a variety of reasons.

The "privately nurtured tradition of high-levels of mixed-marriages between Serbs and Hungarians," is also often cited as proof of this supposed celebration of multiculturalism in Vojvodina (Ladancsik, 2016). But even this metric is extremely complex, if not problematic, since newer data show that the rate of ethnically heterogeneous marriages is lower than expected, and has been in constant decline since 1956. In fact, ethnically heterogeneous marriages were at an all-time low in 2008, 
especially among Hungarians and Serbs in Vojvodina (Sokolovska, 2008). Such a position is reaffirmed by one farmer from Stara Moravica who concludes that "marriages between Serbs and Hungarians are becoming all the rarer, especially after the turmoil in the early 1990s. The feeling of public collective fear has affected people on an intimate level also" (anonymous source, in discussion with author, November 19, 2018). A Protestant priest from the same area even takes this one step further, arguing that a "family tradition of not supporting marriages between couples of different faiths has always existed among Hungarians, specifically those that involve Orthodox Serbs. This, however, does not mean that they do not exist at all but that they are rather uncommon among the Calvinists at least" (anonymous source, in discussion with author, November 14, 2018). Given this attitude, it comes as no surprise that Vojvodina's multicultural character is becoming increasingly contested and highly controversial (Ilic, 2009).

While multiethnicity simply supposes the presence of a multitude of ethnicities inhabiting a territory, it is, by definition, rather passive. On the other hand, multiculturalism presupposes a level of active public interaction and engagement of different cultures, regardless if this interaction is constructive or destructive for the different groups involved (Ilic, 2009). Therefore, intermarriage alone, relegated to the private realm and becoming all the rarer, is weak proof of Vojvodina's multiculturalism. Deriving conclusions regarding Vojvodina's multicultural character from studying dominant Serb attitudes, while completely neglecting to address the minorities' perspectives, is even more problematic for deducing the existence of multiculturalism. Making reliable claims regarding Vojvodina's multiculturality requires consideration of the perspectives of both the ethnic majority and minorities, with all communities 
generally agreeing that an adequate level of active public interaction occurs between them.

That Vojvodina is multiethnic does not necessarily mean that it is multicultural. If culture is very broadly understood in terms of the intangible subjective confluence of ethnicity, religion, and language, then multiculturalism presupposes a level of active interaction of these diverse elements on a given territory (Ilic, 2009). In the case of Vojvodina, a multitude of ethnicities inhabit the province, a diversity of languages is spoken, and a number of religions are practiced, but the interaction between these groups is surprisingly low if not wholly lacking. For this reason, some have defined Vojvodina as multiethnic but not necessarily multicultural. As Snezana Ilic clearly states, Vojvodina, as an integral part of Serbia, "remains multiethnic but increasingly less multicultural" (Ilic, 2009, p. 365).

Several studies support this argument, finding low salience of attitudes towards learning the language of neighboring ethnic communities for the purposes of interacting with the Vojvodinian "other" (Pusic, 2008). There is an increased sense that ethnic groups in Vojvodina simply neither feel the need to nor do they want to learn the language of another ethnic minority (Pavlovic, 2004). Instead, each ethnic community simply relies upon their own mother tongue to function in the province. In this way, language functions as a persistent symbol of community preservation, even though this choice may restrict an individual's future prospects in such a multiethnic province. This leads to the conclusion that there is an "unstable social basis for sustainable multiculturalism," attributed to a generally low perceived need for integration coupled 
with an extenuated striving for ingroup affirmation for the sake of survival among nearly all the ethnic communities in Vojvodina (Pusic, 2008, pp.175-179).

\section{Interethnic Dynamic of Parallelism}

Having established that integration on the premise of multiculturalism in Vojvodina seems to be nonexistent, the question remains: what type of interethnic dynamic defines current relations between communities in the province, specifically as it relates to the Hungarians? Analyzing the Hungarians in neighboring Romania's region of Transylvania, George Schopflin argues that what is occurring across Eastern and Central Europe is that "members of different ethnic groups meet at the surface level, go through ritual courtesies and leave it that. There is no deeper communication or understanding, let alone 'sharing' so beloved of multiculturalists. Contact between Hungarians and Romanians is minimal, polite, and superficial" (Schopflin, 2002, p. 122). Arguably, this is much like the current dynamic in Vojvodina between the ethnic Hungarians and the dominant Serbs. More specifically, what we see is that:

dealing with ethnic others is burdened by infinitely greater problems of lack of trust, of solidarity and absence of shared codes of informal communication. They [ethnic groups] make the world differently and believe that theirs is the best and only morally legitimate way of doing so...The outcome is perfectly logical and sticks in the craw of Western multiculturalists - and their local allies - the existence of parallel societies, which have a minimum of overlap and are engaged primarily in producing and reproducing their own thought-worlds and thoughtstyles without paying much attention to other groups. (Schopflin, 2002, p. 121) 
Prior field research in multiethnic communities in Vojvodina, conducted in 2005, seems to concur that a phenomenon of "parallel lives" characterizes relations between different ethnonationalities (Ilic, 2009, p. 365; Bieber \& Winterhagen, 2006, p. 41). The underlying premise of this so-called phenomenon of parallelism emphasizes the presence of "parallel societies, co-existing alongside the dominant society, without necessarily much interaction between them" (Kymlicka, 2002, p. 12). Simply stated, parallelism connotes the lack of interaction and integration between two communities, which is amplified through institutionally-induced detachment. Having been "overshadowed in every sphere of social life," ethnic Hungarians in Vojvodina have disassociated with the Serbs in the province, leading separate lives (Goncz \& Voros, 2005, p. 195). Hence, in the case of the Hungarian community in Vojvodina, the current state of interethnic relations is a general attitude of apathy, indifference, and detachment, and very little interest in learning about and interacting with the dominant Serb group. In other words, what is being currently witnessed in terms of interethnic relations in Vojvodina is "parallel lives of different ethnic communities living side by side but not interacting; establishing a connection between the climate of fear and ignorance between communities" (Garabaye, 2010, p. 168). These communities live side by side but their paths rarely willingly cross; rather, they live on distinct paths indifferent towards the "other."

It must be stressed that parallelism differs from mere ingroup homogenization and voluntary self-separation precisely because it is institutionally induced. These institutions provide sustained ordering structures for collective Hungarian relations in Vojvodina. Certainly, institutions have served to boost Hungarian ethnonational homogenization, but 
in this process, they have ultimately defined and sustained a specific "thought world" outcome regarding how to interact with the Serb majority. I argue that ethnonational homogenization alone can lead to a variety of interethnic relations outcomes with the "other." However, what is currently evident among the Hungarian community in Vojvodina is a consistent pattern of attitudes and behaviors, fostered by institutions, which result in a distinct interethnic relations outcome. Homogenization alone fails to describe this ordered lack of interactions; therefore, I argue that institutions serve as a casual mechanism in supporting this distinct and sustained dynamic of detachment leading to the outcome of parallel lives. In this manner, parallelism can be understood a second-tier interethnic relations dynamic that builds on Hungarian ethnonational homogenization by producing a specific outcome for Vojvodinian Hungarian interactions with the "other."

\section{Parallelism for the Hungarian Community in Vojvodina}

In describing relations between Serbs and Hungarians in Vojvodina, one wealthy landowner from Stara Moravica describes parallelism perfectly when he says: "we live next to one another but not with one another" (anonymous source, in discussion with author, November 19, 2018). Essentially, what this respondent is referring to is the notion of self-isolation of the Hungarian community from the Serbian group. Pressed on the reason for this, he responded that he believes Vojvodina to be a Hungarian territory which was "colonized" Serbs as far as 1918. With their entrance into the region, Hungarians were collectively deemed as either a distraction or a problem, and, consequently, have since been marginalized, he claims. "Serbs do not care about us and 
do not regard us as equal. Why would we want to interact and be good partners and neighbors with someone who has shown, countless times, that they do not want us?" (anonymous source, in discussion with author, November 19, 2018). A recently retired metallurgy worker originally from Pacir more subtly expressed the community's desire to use self-isolation as a means of protecting against perceived harsh external realities. She feels that "the Hungarian community is not wanted here. Serbs and Hungarians are very different...We have somehow always been considered a burden, or maybe we see it that way. Isolation is probably our only option to keep what little we have left...We must rely on our own skills to sustain individually and collectively as a community here" (anonymous source, in discussion with author, November 14, 2018). Fundamentally, both subjects refer to a perceived differentiation and, hence, lack of overarching trust in the "other" which ultimately warrants a need for self-isolation.

This same notion of the Hungarian community's self-isolation is further reiterated by a local municipality official who describes a resounding level of "self-segregation of our community in smaller localities that are predominantly if not completely Hungarian" (anonymous source, in discussion with author, November 12, 2018). The Protestant priest agrees with this picture of reality, claiming that the "percentage of Hungarians residing in a locality directly correlates to the level of self-isolation. The more rural, the more isolated and hence self-sustaining they are" (anonymous source, in discussion with author, November 14, 2018). But even an urbanite representative of the Hungarian community implicitly contends that although he perceives some instances of integration, he still seeks to lead a life separate from the Serbs for the sake of preserving his distinct 
Hungarian identity and to prevent himself from being assimilated into the Serbian majority (anonymous source, in discussion with author, November 24, 2018).

In the case of the Hungarian community in Vojvodina, therefore, parallelism refers to the demonstrated pattern of low levels of social, cultural, political, and even economic interaction, and ultimately integration, between Hungarians and the dominant ethnic Serbs that is altogether peaceful in nature. In other words, this parallelism presents itself as a peaceful but objectively real cultural, social, political, and economic detachment between the Hungarians and Serbs, but also a subjective perception which is equally important as it forms the foundation of interethnic interaction. With minimal willingness to partake and engage in each other's worlds, peaceful parallel lives exist side-by-side. Indifference and ignorance of each other's cultures seems to be the currency in Vojvodina, with communities nurturing their identity in isolation from one another.

If this parallelism is to be accepted as the dominant conceptualization through which to understand interethnic relations in Vojvodina, the next question becomes: what does it look like for the Hungarian community in question? Probably the best way to describe parallelism is "two solitudes," one Serbian and other Hungarian, that do not interact but rather display an attitude of indifference towards one another (Kymlicka, 2002, p. 12). First, it must be noted that the separateness highlighted by a lack of interaction between Hungarians and Serbs does not always have to involve physical boundaries. The parallelism described by respondents here is characterized by a certain peaceful indifference, dissonance, and separateness, but does not necessarily always involve physical separation. It is this indifference, witnessed through lack of interaction, which this group exhibits towards the "other" that is important here. This parallelism 
manifests itself in a variety of ways, whether through language, religion, tradition and cultural identity, political outlook, and even daily economic choices.

Certainly, there is a physical separation of the two communities, to some extent. Parallelism for the Hungarian community is best illustrated by the ethnic map below that shows the share of Hungarians in the total population of municipalities and cities in the Republic of Serbia. Visually, this census map shows a clear clustering of the Hungarian community in several municipalities, symbolizing the overall (geographical) separation of this community from the predominant "other." The Minorities at Risk Dataset affirms this observation, rendering the group spatial distribution for the Hungarian community in Vojvodina extremely limited and "concentrated in one region" (Minorities at Risk Project, 2009). As previously noted, Hungarians in the province as a whole constitute a majority in the districts of North Backa and North Banat, and an absolute majority in only five municipalities (Kanjiza, Senta, Backa Topola, Ada, and Mali Idjos) - municipalities that are all huddled together as opposed to dispersed across the entire Serbian state. This is quite unique since other ethnic groups in Serbia, especially the Romani but also the Slovaks and Montenegrins, form majorities in municipalities that are rather geographically dispersed across Serbia (Statistical Office of the Republic of Serbia, 2012). 
Figure 4. 2011 Census map of ethnic Hungarians in Vojvodina

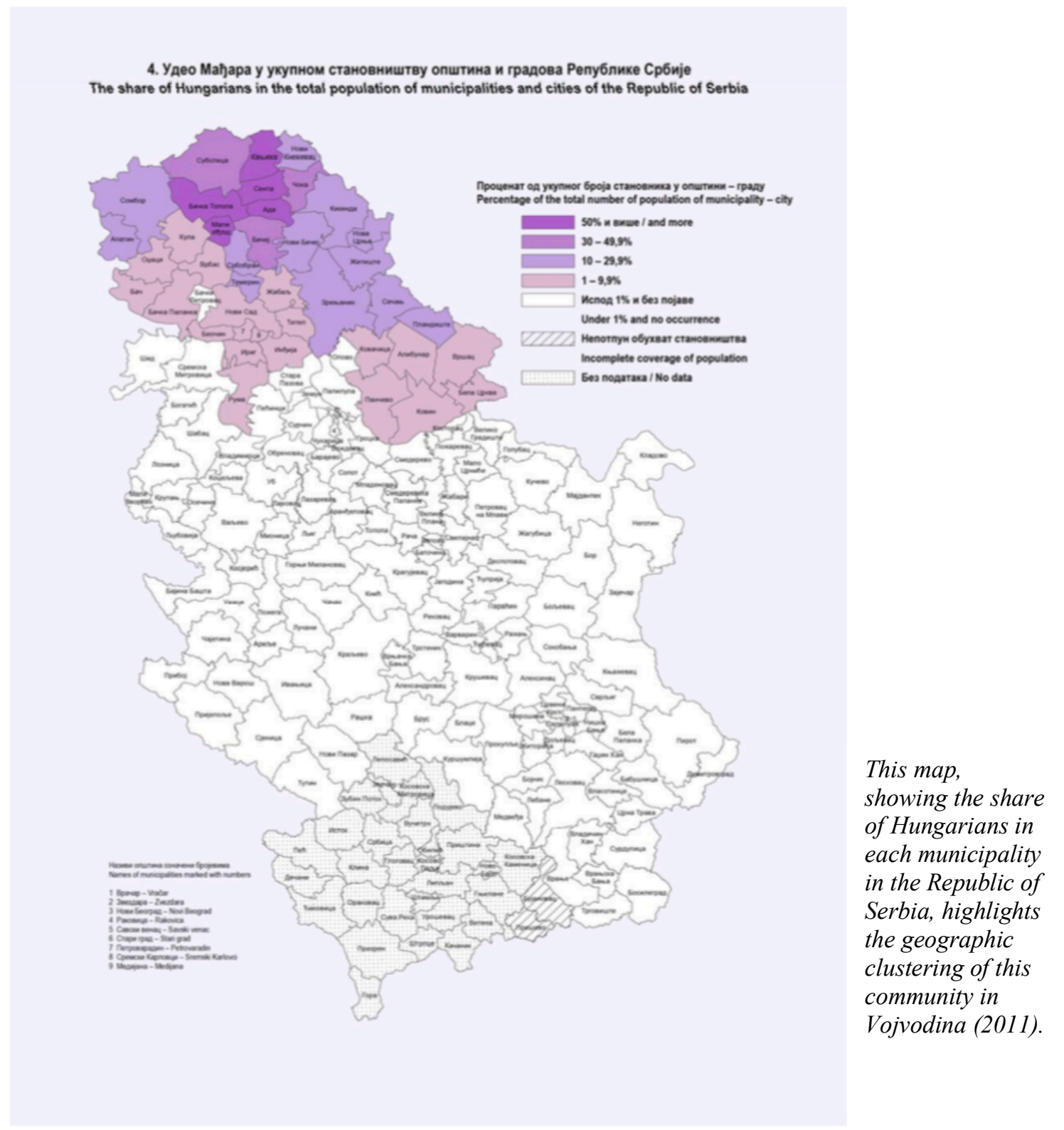

Apart from this geographic separation, the Hungarian community in Vojvodina is separate in its language and education. Secondary data from the Minorities at Risk Project indicate that the Hungarian community in Vojvodina "speaks primarily one language which is different from the plurality group" (Minorities at Risk Project, 2009). 
Furthermore, drawing on this language distinction, secondary data also indicate that public schools in the two districts in which Hungarians constitute a majority offer a Hungarian language curriculum. In these schools, Hungarian pupils choose to attend classes separate from students of other ethnicities - usually Serbs. Currently, there are 28 municipalities (all in Vojvodina) in which there is at least one public elementary school that offers a Hungarian language curriculum catering to its Hungarian students. Overall, there are 69 public elementary schools that include at least one separate grade class in which Hungarian is exclusively the language of instruction. There are only 4 public elementary schools in Vojvodina that are composed entirely of Hungarian classes. The allocated number of secondary school class groups in which Hungarian is the language of instruction is smaller in proportion to the calculated attrition rate for Hungarian students in Vojvodina. Including both universal high schools (gimnazija) and technical schools there are 88 Hungarian class groups total. Cumulatively, therefore, there are exactly 833 elementary and secondary Hungarian grade classes currently operating in Vojvodina (National Council of the Hungarian National Minority Statistics, 2019). Ultimately, such a separateness in language and education fosters a distinct and separate national consciousness which finds its expression in self-induced isolation as will be further explored later on in this research. This reinforces the claim that education defines identity, as Gellner's argues when he says that

"the employability, dignity, security and self-respect of individuals, typically, and for the majority of men hinges on their education; and the limits of the culture within which they were educated are also the limits of the world within which they can, morally and professionally, breathe" (Gellner, 2006, p. 35). 
Hungarians in Vojvodina also overwhelmingly support their own Hungarian public media outlets that are seemingly detached from current affairs in Serbia or even Vojvodina. Given the media privatization law (Zakon o javnom informisanju i medijama) that was enacted in Serbia in 2015, local public media services catering to Hungarian language audiences have been in steep decline due to scarce funding. Nevertheless, the National Council of the Hungarian National Minority has stepped in and played a vital role in preserving and ensuring a separate Hungarian language frequency be emitted on Szabadkai Radio that specifically caters to its Hungarian community in Vojvodina. The only other, and even more influential, Hungarian media outlet in Vojvodina is Pannon $R T V$ which consists of both a radio and television station. Pannon $R T V$ was established in 2006 as a regional Vojvodinian media outlet. However, Pannon RTV experienced a drastic restructuring in 2012 when the Hungarian National Council took over management as part of its "cultural strategy" (Pannon RTV, 2017). It is at this time that Pannon RTV gradually became the de facto media outlet of the Hungarian community in Vojvodina, managed by its very own National Council and funded entirely through a combination of donations from private Hungarian community sponsors and grants from the Republic of Hungary (anonymous source, in discussion with author, March 23, 2019). Controversies, however, abound as to whether both Szabadkai Radio and Pannon RTV promote a distinct Hungarian culture and propagate Hungarian national politics at the expense of undermining local news and topics relevant to the Hungarian community in Vojvodina specifically. The fact that Pannon RTV works in close relation with the Hungarian public media service, $M T V A$, only further complicates matters. While both Szabadkai Radio and Pannon RTV emit shows exclusively in Hungarian and claims to 
focus on topics relevant to their community in Vojvodina, "many shows actually dedicate more attention to current events happening across the border in Hungary than in our localities here," says one source. "There is an overwhelming bias towards propagating current Hungarian national interests and emphasizing political events and economic activities taking place across the border in Hungary" (anonymous source, in discussion with author, November 12, 2018). In addition, one of the main cable television providers in the Hungarian-majority municipalities in Vojvodina, SAT-Trakt, offers a wide variety of state and private channels emitting directly from Hungary due to increasing customer demand in their serviced municipalities. Together, these media outlets paint a picture of Hungarian disengagement from Vojvodina, and, ultimately, Serbian affairs.

The Hungarian community in Vojvodina also nurtures its own separate print publications. The Hungarian community in Vojvodina controls two publication houses: the Vojvodinian Hungarian daily newspaper, Magyar Szo, and weekly magazine Het Nap. Opinion data shows that Magyar Szo is especially popular among the Hungarian ethnonational community in the province (National Council of the Hungarian National Minority Statistics). Apart from a growing internet readership, 2.4 million newspapers are printed annually and circulated solely in municipalities where Hungarians reside. One public relations official of the National Council of the Hungarian National Minority is adamant that "Magyar Szo retains the strongest readership and remains the most popular, if not only, daily newspaper read by the Hungarian community in Vojvodina" (anonymous source, in discussion with author, in correspondence with author, March 23, 2019). 
Most importantly, the Hungarian community in Vojvodina declares a distinct and separate identity which they perceive sets them apart from Serbia and its northern province in which they historically reside. Survey data gathered by the National Council of the Hungarian National Minority indicates that the Hungarian community in Vojvodina primarily identifies as "Hungarian" currently. Provided with a multitude of options ranging from "citizen of the Republic of Serbia," "Vojvodinian," "Vojvodinian Hungarian," or simply "Hungarian" the vast majority of respondents claimed that they were "Hungarian" (anonymous source, in discussion with author, March 23, 2019). ${ }^{8}$ This issue of primary identification warrants further exploration of interview data gathered in this study and will be the topic of the following chapter. However, what is important to highlight here is the overall disassociation that the Hungarian ethnonational community perceives in relation to the state and province in which it resides. For certain, the current cultural autonomy granted to the Hungarian community in Vojvodina is not only one institutional incubator of parallelism but is also the ultimate expression and reflection of primary identity: the triumph of the distinctly Hungarian ethnonational individual over a potential Serbian/Vojvodinian supranational citizen. Taken even further, it is the dominance of this ethnonational identity that allows Hungarians in Vojvodina to associate even more with the greater Hungarian nation across the border instead. Both primary and secondary data analysis attests to the identity detachment that is apparent

\footnotetext{
${ }^{8}$ Respondent is full-time staff member of the National Council of the Hungarian National Minority fulfilling the responsibilities of both foreign relations liaison and statistical data management/archives. He is an expert on this data as attested by his official title as Nacelnik strucne sluzbe (Head of Expert Services) for this organization.
} 
among members of the Hungarian community in Vojvodina and will be further elaborated in what follows.

When it comes to occupation, Hungarians in Vojvodina are least likely to be employed in the public sector - a mere $11.8 \%$ of the Hungarian community in Vojvodina is employed in either public education, communal services, and/or public health services. Contrast this statistic with an astounding $33.2 \%$ of Hungarians who are self-employed in the agricultural industry and we see the prospects of interacting and socially integrating with the majority on the job are relatively low (Ministarstvo za Ljudska i Manjinska Prava Srbije i Crne Gore, 2004). Even in economic choices, therefore, the Hungarian community in Vojvodina engage in professions that allows them to be economically independent and socially detached from the majority in the province.

It comes as no surprise that the Hungarian community in Vojvodina also leads a political life in parallel to the Serb majority. Secondary data analysis indicates that while the Hungarian community in Vojvodina is represented in the legislative branch of Serbia's government, it fails to be represented in its executive branch (Minorities at Risk Project, 2019). Moreover, data derived from this study shows that political affairs in the Republic of Hungary are more salient for the Hungarian community in Vojvodina compared to politics in the Republic of Serbia (or even Vojvodina). As discussion of data on kin-state activism will later show, this is a logical outcome given the level of interaction and solidarity between the kin-minority and Hungary. Secondary data analysis corroborates the findings of this study also, with coding for qualitative variables indicating a heightened kindred bond between this Hungarian community and its adjoining country (Hungary) (Minorities at Risk Project, 2019). Apart from expressing 
support for their own ethnic Hungarian minority parties in Serbia, especially the dominant Alliance of Vojvodina Hungarians (VMSZ), what is most intriguing is that Hungarians in Vojvodina are actually more likely to vote in Hungarian elections than in Serbian elections. In fact, as will be discussed later, voter turnout for two recent local elections indicates that Hungarians in Vojvodina are nearly twice as likely to participate in elections in Hungary. This shows the overall level of political detachment, and ultimately parallelism, demonstrated by the Hungarian community in Vojvodina.

It is this manner that the Hungarian community has been able to form a life next to but also so far removed psychologically and socially from the Serbian majority. The two communities live side by side, yet do not interact, do not integrate, and do not assimilate with one another. This segmentation manifests itself in a delineation between interethnic communities that goes much further than less clear physical separation. Ultimately, it comes down to differences in identity that lead to cohabitation between ethnic communities without active engagement and integration; not mixing yet cohabiting is key here.

When asked to define interethnic relations in Vojvodina in one word, 19 out of 23 participants used the word "tolerance." When asked to expand on this, one respondent who used to work as the chief ambulance driver in Backa Topola presented a genealogy of relations between Serbs and Hungarians in Vojvodina. Nostalgic about the former Socialist Federal Republic of Yugoslavia (SFRJ), this individual recalls the:

"golden age when Hungarians like me felt increasingly at home and seemingly part of the Yugoslav project. However, suddenly things changed for the worse and the wars of the 1990s came out of nowhere. We were all scared that it would 
spread to our areas. An atmosphere of fear enveloped this whole place. It is hard to find a Hungarian home in which at least one resident was not recruited by the Yugoslav People's Army to go fight in Baranje and other fronts in Croatia and Bosnia...Recruitment was disproportionate. I would know, I used to drive them out there. Thankfully, those days are gone and we all returned with are heads on our shoulders (at least in this area). Now it is quiet, but it is hard to forget those days. Today we can be proud of the correct tolerant relations we have with the Serbs. No one is touching us." (anonymous source, in discussion with author, November 19, 2018)

This same picture of tolerance is reiterated by numerous other interview subjects. One goldsmith from Backa Topola admits a "historical self-isolation of the Hungarian community in Vojvodina has always existed to a certain extent, especially cultural. The 1990s created a general attitude of distrust towards Serbs. However, now we feel safer and we can say that a climate of tolerance has been established" (anonymous source, in discussion with author, November 14, 2018). Despite feeling safer, however, members of the Hungarian community in Vojvodina vehemently reject the notion that tolerance has anything to do with integration. In fact, in the words of one mental health caretaker "tolerance means we respect ours and you respect yours... and we do respect each other's culture but we are separate" (anonymous source, in discussion with author, November 14, 2018). Instead, tolerance, for this community, is equated with "everybody being allowed to do what they want separately... after all, this is the best for peace" as one Hungarian electrician from Vojvodina concludes (anonymous source, in discussion with author, November 12, 2018). Hence, being left alone on a parallel path seems to count as 
tolerance for many representatives of the Hungarian community. As a dog obedience trainer from the area argues, "tolerance allows for isolation which is important to preserve one's national identity. This is natural. Everyone everywhere does it" (anonymous source, in discussion with author, November 14, 2018).

Empirically, this notion of parallel lives based on tolerance is shown in various facets of daily life of ethnic Hungarians in Vojvodina. The Hungarian community leads a life self-isolated from that of the Serbian community, with very little interaction and integration. As previously noted, there are numerous Vojvodinian villages that are ethnically homogenous, a concentrated effort on the part of this community to keep to themselves and preserve their ethnonational identity. Even in villages that are ethnically heterogeneous, there are finite boundaries that separate the ethnicities apart. For example, even a road running through the middle of the village is enough to define the division between the Serbs and Hungarians, if only as a symbol of separation. This is not to say, however, that interaction between the ethnic groups is absolutely non-existent. Economic transactions do happen, but even so there seems to be an unspoken trend that in each village Hungarians patronize one set of markets, butcher shops, bars, and cafes, while Serbs patronize another. The Hungarian community in Vojvodina has simply created a separate life apart from the Serbs; they read their own Hungarian newspapers (almost exclusively focused on ethnic Hungarian issues in Vojvodina interspersed with highlights from Hungary), listen to Hungarian radio and TV stations directly from Hungary, go to bilingual schools in which Hungarian is offered as main the language of instruction, apply for citizenship status in Hungary, are reliant on the kin-state for economic transactions, and travel to Budapest rather than Belgrade for all important medical 
matters. The fact that various institutions function more efficiently in Hungary than in Serbia has surely facilitated this division. However, the truth remains that the Hungarians in Vojvodina do not interact and integrate with the dominant Serb group if not essential to their survival.

\section{Parallelism Through Language}

Arguably, as previous research notes, the most vivid example of the disengagement and separateness that defines interethnic relations in Vojvodina is language (Pusic, 2008). Extreme preservation of language distinction represents the pinnacle of differentiation between the communities. In fact, 22 out of 23 subjects in this inquiry asserted that language is the focal feature for preserving their Hungarian identity. One Calvinist priest was very frank on this subject, claiming that "to defend our identity we must defend our language" (anonymous source, in discussion with author, November 14, 2018). The Hungarian music teacher at a public elementary school in Krivaja agrees with this sentiment asserting that "language is identity. You cannot choose your identity and so you cannot choose your language" (anonymous source, in discussion with author, November 12,2018). While this subject does acknowledge the importance of common language in bringing people closer together, his neighbor, a recently promoted factory foreman, admits that "many younger Hungarians do not understand Serbian. We women more so than men" (anonymous source, in discussion with author, November 7, 2018). However, the music teacher does recall previous times in which students were compelled to learn the language of the majority of their locality. This, of course, meant Serbs also 
had to learn Hungarian if that was the majority language in that said locality. As the music teacher explains:

"But, you see, while Hungarian children were and still are required to learn Serbian in schools, albeit with mixed acceptance and results. Serbian children always rejected learning Hungarian. They would make jokes, spit, and harass their Hungarian language teacher. I know that we live in Serbia and that Hungarian pupils are forced to learn Serbian, but why shouldn't Serbian pupils also learn Hungarian since they live in our areas? Them knowing the language would possibly bring us closer together." (anonymous source, in discussion with author, November 12, 2018)

Thanks in part to former Socialist Federal Republic of Yugoslavia (SFRJ) language policy that recognizes Hungarian as an official national language, the ethnic Hungarians in Vojvodina have been able to safeguard and preserve their language to a certain extent, thus ensuring the preservation of their distinct ethnic cultural identity. Prior research concludes that Vojvodinian Hungarians do not want to learn Serbian, nor do they want to speak the majority language even if they do know it (Pavlovic, 2004). Previously, compulsory military service in the former SFRJ compelled Hungarians to learn to speak Serbo-Croatian in order to function. However, with its abolition, elementary knowledge of Serbian among the Hungarians in Vojvodina rapidly declined, as demonstrated by the low rating that Hungarian elementary school students give to their mastery of the dominant language in the province (Andric, 2009, p. 38). Teaching Hungarians Serbian as a second language in public schools has been far from successful in encouraging language integration that would at least facilitate increased interactions 
between the communities (Manic, 2011, p. 354). As one mechanical engineer and educator in Subotica contends:

"the problem is not ethnic politics nor the Hungarian elementary pupils blatantly refusing to learn Serbian. Rather, it is bad education policy that requires Serbian language teachers have completed an undergraduate degree in Serbian language and literature in order to teach minority children. Which Hungarian teacher in their right mind has graduated with a degree in Serbian literature?! None. So, what you have are Serbian teachers who do not know Hungarian, teaching Hungarian children Serbian. It is comical. The Serbian teachers simply hand out good grades so as not to seem nationalistic, and the Hungarian children learn nothing." (anonymous source, in discussion with author, November 10, 2018) A few members of the Hungarian community in Vojvodina interviewed recognized the need for Hungarians to learn the Serbian language purely for instrumental purposes. The former chief ambulance driver in Backa Topola admits that many Hungarians in Vojvodina do not know Serbian and are "handicapped because they remain isolated" (anonymous source, in discussion with author, November 19, 2018). Others vehemently disagree. For example, one farmer from Stara Moravica argues that "knowing Serbian means assimilation. As a child I refused to learn Serbian and I refuse to speak it now out of spitefulness for you Serbs. You Serbs should learn Hungarian if you want to live among us. You came here. Serbia and Serbs undermine our Hungarian language" (anonymous source, in discussion with author, November 19, 2018). The majority of Hungarians in Vojvodina, however, are more balanced in their approach to the topic of language, recognizing that requiring Hungarians to learn and know Serbian 
places the minority in a subservient position since the system favors the Serbian language (anonymous source, in discussion with author, November 12, 2018). The mechanical engineer in Subotica provides a contrasting view, arguing that "you cannot expect to be equal with the majority if you do not know the language of the majority in the state that you live in" (anonymous source, in discussion with author, November 10, 2018). Despite this discourse, the overwhelming feeling shared by members of the Hungarian community is that they are second-class citizens precisely because their mother tongue is Hungarian. Regardless of their limited options, however, their language use remains important to their preservation and self-isolation. Moreover, the fact that there are many Hungarians in Vojvodina who do not know Serbian speaks volumes about the development of parallel lives.

\section{Parallelism Through Education}

While language is most important marker of Hungarian identity and a means of identity preservation, many subjects in this inquiry connected language with the high salience they place on public education in the mother-tongue. "Knowing the language is owning your identity. Being educated in your language, no matter in what country, is preserving your identity" (anonymous source, in discussion with author, November 19, 2018). The fact is that Hungarians generally choose to attend public elementary and high schools in which their native Hungarian is the language of instruction, rather than attending school in Serbian. This further supports the argument that linguistic interaction and integration into the dominant culture is not a high priority for Hungarians in Vojvodina. Even if this decision later limits their academic and economic prospects in 
Serbia, Hungarians still choose to send their children to school in which the language of instruction is their own mother-tongue (Samardzic, 1999). Such an academic legacy of separation between the communities, begun at an early age, is perpetuated later in life and only breeds further disengagement. This lack of integration later culminates and reinforces itself through political and cultural disinterest, disengagement, and isolation that is sometimes criticized by the Serbian majority as madjarizacija ("Hungarization") (Koprivica, 2008). What starts as small distinction later transforms into ignorance towards the other side through reinforced, overlapping cleavages that ends with the creation of two distinct solitudes/realities. The ultimate result is the current "voluntary exodus" of young Hungarians from Vojvodina -- with whose multiethnic peoples they have little in common on a collective level -- to Hungary, for both instrumental economic reasons and to seek intrinsic affinity. The forging of bonds, or, in this case, the lack thereof, through interaction for the sake of greater cohesion on a collective cultural level is at issue here. How far this phenomenon has progressed is best understood from the words of one young postman who describes his two children who are now attending public elementary school in Stara Moravica. According to him, his children are learning that:

"The capital city of this country they live in is Budapest...My younger son is even learning to count in Hungarian forints instead of Serbian dinars in his introductory mathematics class. They have even been learning and singing the Hungarian national anthem. They are preparing these children to leave and easily adapt to life in Hungary...I would like them to learn at least something about Serbia and 
Serbian culture like I had to." (anonymous source, in discussion with author, November 7, 2018)

The Hungarian private entrepreneur from Novi Sad sees nothing illogical with this. He recalls that he and his wife made the conscious decision to send their children to elementary and high school that enrolled classes where Hungarian was the language of instruction. For him, this step was important for the family in order to nurture their Hungarian identity, regardless whether this decision would restrict their future prospects in Novi Sad. After all, they could choose to learn and engage with other Serbian children after school as much as they wanted. Thankfully, "both daughters have finished university in London and Budapest respectively" (anonymous source, in discussion with author, November 24, 2018).

The public relations official of the National Council of the Hungarian National Minority also finds no issue with students in Hungarian classes in Serbian public schools being taught that Budapest is their capital city. This subject is especially proud of the work and progress that has been made in "developing a necessary parallel primary and secondary curriculum in the Hungarian language that is still under the umbrella of Serbia's public education system." Furthermore, this respondent highlights that the "law allows for exactly $30 \%$ of the public curriculum be dedicated to studying Hungarian national history" (anonymous source, in discussion with author, March 23, 2019). As this respondent further elaborates, Hungarian language is not included in this curriculum allocation. Furthermore, the group of subjects over which Hungarians have educational control ("national group of subjects") effectively encapsulates all the social sciences that 
students learn in elementary/secondary school, leaving only the natural sciences with the same curriculum for Serb and Hungarian pupils.

Revealingly, this respondent also stresses the amount of money the Hungarian government is investing in education for its Hungarian students in Serbia. While he is critical of the current Serbian policy prohibiting Hungarians from utilizing textbooks directly from Hungary, he is positive that Hungarians in Vojvodina will continue to differentiate their own education from the mainstream Serbian education system. As he explains:

"The Serbian Ministry of Education currently prohibits us from using Hungarian textbooks in schools, asking us to write and publish our own in cooperation with the department. This is understandable given what is happening with the Albanians in Kosovo and the Albanians in Presevska Dolina who want Kosovar textbooks that the Serbian government does not recognize. But in our case, this will change given that Hungary is a powerful state...It is simply unfeasible for us to write our own textbooks...Hungary is willing to supply us with their educational resources and given the amount of support from Budapest this will soon be a reality... For now, our teachers are going on exchange programs in Hungary, learning new modern teaching methods, and finding innovative ways to unofficially supply their students with printed chapters from Hungarian textbooks as compilation scripts...Eventually we will have our own education system that functions parallel to the Serbian education system." (anonymous source, in discussion with author, March 23, 2019) 
This council official concludes by boasting of the allure that being educated in the Hungarian language currently presents. "It is becoming very popular to study in Hungarian. We have seen an increase in Hungarian grade classes." Even mixed marriage couples are now choosing to enroll their children in grade classes where the language of instruction is Hungarian. "These students will soon become Hungarian citizens as stipulated by the Hungarian citizenship law. The Hungarian government has pledged to fully finance their future university studies in Hungary if they so wish" (anonymous source, in discussion with author, March 23, 2019).

\section{Parallelism Through Political Affiliation}

Nowhere is parallelism of the Hungarian community more apparent than in the political sphere. 20 out of 23 participants acknowledged ethnic identification is the primary factor influencing their political affiliation. Apart from holding politics in the Republic of Hungary in the highest regard (a topic for the following chapters), the majority of participants also admitted a high affinity for ethnic Hungarian minority parties operating in Serbia. An overwhelming number of subjects felt at least positive, if not wholly supportive, of the mainstream ethnic Hungarian minority party called the Alliance of Vojvodina Hungarians (VMSZ) which is now part of the Serbian governing collation. Several subjects voiced their ardent support for the historical, if not more radical, ethnic Hungarian party known as the Vojvodina Hungarians Democratic Community (VMDK). When asked why they support these parties, most respondents were shocked by this question and declared: "they are our parties and logically protect our interests. We are Hungarians and we support Hungarian parties. All other parties in 
Serbia are Serbian, regardless of ideology. Even their names proclaim this. Our place is not in these parties" (anonymous source, in discussion with author, November 10, 2018). This level of ethnonational "partiality" that the Hungarian community feels towards members of their own group also applies to local politics (Lichtenberg, 1997, p. 166). As the private goldsmith from Backa Topola assesses:

"To be honest, you cannot win a local village election that comprises a Hungarian majority if you yourself are not Hungarian. Hungarians will always vote for Hungarians not matter how good a person you are. To be heard, first and foremost you have to be identified as Hungarian. There is a historical legacy of this fact." (anonymous source, in discussion with author, November 14, 2018)

\section{Parallelism in Daily Life}

Even the supposedly trivial matters of daily life can become political, offering yet another example of parallelism for Hungarians in Vojvodina. For example, the Hungarian community in Vojvodina has recently taken a vested political interest in renaming all of the local streets to Hungarian names, even if this has come at a huge financial burden for their community. For example, streets in Kanjiza called Josip Broz Tito or Milos Obilic have been recently renamed by Hungarian historical figures such a Lajos Kosut in line with reformed legislation governing minority cultural rights in the Republic of Serbia (which will be discussed later). Even such seemingly trivial matters as names hold meaning for the Hungarian community in Vojvodina, further demonstrating a tendency towards parallel lives. These choices, focusing on or even restricted to Hungarian 
connotations, render meaning to the collective identity of the Hungarian community in Vojvodina (Wellman, 2000).

\section{Parallelism as a Result of Institutional Realities}

\section{Parallelism as Institutional Outcome Versus Berry's Self-Segregation Outcome}

On a theoretical level, the phenomenon of parallelism draws on scholarship on ethnic/national distance, also researched in Vojvodina, and acceptance/tolerance (as feeling) between personal-group relations (Bogardus, 1947; Smith \& Dempsey, 1983; Siber, 1998; Lazar, 2007). However, such research focuses on the individual in relation to the group while parallelism, on the other hand, focuses on institutionally sanctioned relations between groups. Specifically, parallelism focuses on the sociometric of indifference and detachment between groups (as both feeling and behavior) rather than tolerance as a measurement of community relations. As such, parallelism is most akin to what John W. Berry terms 'Self-Segregation' as a distinct mode/outcome of intergroup relations (Berry, 1974, p. 19). Berry's research focuses on culturally plural societies in which there is a constant balancing between issues of individual/collective community identity versus national unity, something akin to what is occurring in Vojvodina, at least as far as the Hungarian community is concerned. Berry explores the psychological aspects of cultural pluralism, focusing on the interplay between individual identity versus the need for national unity, and develops a typology concerning the modes of group relations in complex societies. When analyzing specific intergroup relations, Berry inquires whether retention of identity is sought, whether groups strive for positive relations, and whether these evidenced relations are actually the choice of the groups 
involved. Measuring the extent to which expression of identity is permitted, unity is encouraged, and freedom of choice is allowed, Berry's model of intergroup relations describes eight distinct patterns of groups relations, derived from the three psychologically significant questions outlined above and which should provide dichotomous (Yes/No) answers. Upon closer investigation, the case of interethnic relations in Vojvodina could possibly fall into this pattern that Berry terms as Rejection / Self-Segregation, which is characterized as a "decision pattern in which ethnic group(s) affirm their culture and identity, but deny the usefulness of positive intergroup relations" and such an attitude is nurtured in an open and free manner (Berry, 1974, p. 19). While this category of separation/segregation is useful in understanding relations in plural multinational societies such as the one that exists in Vojvodina, it is not sufficient in providing a complete description of interethnic relations in this province, particularly in regards to the ethnic Hungarian community.

It is difficult to discern clear, dichotomous answers to Berry's psychological questions in the case of group dynamics between Hungarians and Serbs in Vojvodina; quite simply, the answers to these questions are more complicated. Therefore, parallelism, with its focus on indifference and response to institutional realities rather than a conscious self-segregation, builds on Berry's understanding of self-segregation and is the main/dominant paradigm through which we can better understand interethnic relations. In applying a theory of parallelism, I do not reject Berry's model but rather opt for a more comprehensive approach to directly address and incorporate issues of cultural maintenance, as well as community contact and participation which may not be as choice-driven as previously supposed (Berry, 1997, p. 9). Parallelism in Vojvodina, 
specifically as it relates to the Hungarian community, is complex precisely because it comes in the subtlest ways; collective interethnic dynamics are at times neither rational nor agency-driven, but instead institutionally-driven by both push and pull factors. In this manner, self-segregation attributed to a voluntary ethnonational homogenization fails to explain the ordered lack of interactions and detachment displayed by the Hungarian community in Vojvodina - such an outcome can only be understood through sustained, institutional support.

Describing interethnic relations in Vojvodina in terms of parallelism provides an alternative approach to understanding the life of the Hungarian community in the province. Most importantly, however, if parallelism defines the life of this community in Vojvodina, the all-important question becomes: what are these institutional factors that have created this specific outcome? Previous research exploring parallelism in Eastern and Central Europe looks at various political and economic factors. The literature on parallelism in Vojvodina is confined to establishing this phenomenon, but fails to adequately analyze its institutional causes. To address this gap in scholarship, this research will focus on two specific institutional factors that have possibly led to the outcome of parallelism as it relates to the Hungarian community in Vojvodina. It is important to note that the factors under scrutiny here are specific to this community and may not be generally applicable to all other instances of parallelism. Thus, further research must be taken to determine for the generalizability of these findings to other communities. The following chapters will be dedicated to exploring two distinct institutional factors: Vojvodina's territorial and non-territorial autonomy contentions, and Hungarian kin-state influence on its kin-minority in Vojvodina. 


\section{Factors Facilitating Hungarian Parallelism in Vojvodina}

This research focuses specifically on the root causes for the existence of parallelism from the perspective of the Hungarian community in Vojvodina-a parallelism which at times can be understood both as an objective truth and a subjective perception. My findings indicate that the current level of disengagement and isolation characterizing interethnic relations for Hungarians in Vojvodina is heavily influenced by the compounding of these two distinct institutional factors. This study takes a comprehensive approach to understanding the factors facilitating the persistence of parallelism as the dominant phenomenon defining current interethnic relations between Serbs and Hungarians in Vojvodina.

The first factor under scrutiny is the complex discourse concerning territorial and, more recently, cultural autonomy in Vojvodina. Taking an initial historical approach to tracing the development of Vojvodina's territorial autonomous status, coupled with primary data analysis that gauges current Hungarian sentiments of discontent and distrust, this research finds that inconsistencies and paradoxes associated with Vojvodina's political status has led to parallelism for the Vojvodinian Hungarians. Namely, "Vojvodina as an autonomous province has always presented a problem for nationalists, since it is conceived of as territorially autonomous, civil, and non-ethnic in type" (Komsic, 2006, p. 47). Such a framework is complicated in a part of the world synonymous with ethnonational tendencies and a province in which a supranational regional identity has never fully been established. Territorial autonomy for Vojvodina has always, in one way or another, been tied to the "national question": how does the state maintain a national character while managing a plethora of national minorities residing 
within its borders? The national question thus overlaps with the Vojvodina question. Yet using territorial autonomy to resolve the national question has been less than successful. Discourse concerning the national question in Vojvodina has always been dominated by the Serb majority, with little to no regard for the minorities who are actually supposed to be the primary "beneficiaries" of policy related to self-governance. Such a somber realization naturally lends itself to investigation of more recent developments related to autonomy of the non-territorial variety taking form in Vojvodina. In particular, this study examines the implications of cultural autonomy for the Hungarian community in Vojvodina, and finds that this is yet another enabler, if not empirical expression, of parallelism as an interethnic dynamic. Ultimately, my findings indicate that policy continuity matters and policy implementation even more so. Reversing decentralization policy and backtracking on minority rights policy breeds antagonism and distrust that leads to the dissociation of the non-dominant group (Hungarians) from the dominant group (Serbs), and, ultimately, the existence of parallel lives. Furthermore, even though minority rights policy, tied to the issue of Vojvodina's autonomy, seems rather progressive on paper, the problem comes with implementation. As will be discussed in what follows, Serbian backtracking on issues have led the Hungarian community to selfseparate, focus internally, and become self-sufficient. Constant polemic over territorial versus cultural autonomy in the province has not helped matters either. As gleaned from the data, the Hungarian community in Vojvodina sees through the promises and finds policy related to Vojvodina's autonomy not only unstable, but at times deceptive. In the end, autonomy in Vojvodina, whether territorial or cultural, does not foster interaction and integration, as conventional wisdom and policy aims would have us believe, but 
instead produces the opposite effect; what should be supporting greater integration is actually an institutional barrier preventing interaction. The non-territorial cultural autonomy that is presently afforded the Hungarian community in Vojvodina is deemed by the dominant group to be a solution to resolving interethnic relations in the province. For the Hungarians, however, this is only a stage in the process of achieving ethnic territorial autonomy, which they seemingly desire.

A similar outcome can be attributed to the presence and operation of the kin-state (Hungary) on its diaspora in Vojvodina. Undeniably, the Republic of Hungary is actively supporting the life of the Hungarian community in Vojvodina, both through political support for the ethnic Hungarian parties in Vojvodina and lobbying with the Serbian government in Belgrade, as well as through continued economic assistance and investment. The Republic of Hungary is also responsible for inadvertently creating a sense of self-sustenance on the part of its kin-minority in Vojvodina, who rely on the kin state, rather than the Serbian state, for their economic and social needs. Interviews show that the Hungarian community in Vojvodina finds the role of the Hungarian state of paramount importance to its sustenance and security in Vojvodina. What the Republic of Hungary does both at home and abroad is of primary importance, covered meticulously by Hungarian media in Vojvodina, much more so than what happens in Serbia. Thus, the Hungarian community in Vojvodina looks to Budapest rather than Belgrade for their preservation in Vojvodina even though they reside across the border. The political support that the leadership in Budapest offers the Vojvodinian Hungarian political elite is undeniable. Furthermore, the legal citizenship rights that Hungary extends to its kinminority in Vojvodina are both unique and extensive for any European state, and have 
been received with open arms by this community. Finally, the financial support and economic assistance that Hungary continuously provides its kin-minority in Vojvodina is of paramount importance, as it inhibits the Hungarians in Vojvodina from forging closer relations on both an economic transactional and national level. Together, all of these forms of assistance have brought the kin-minority in closer proximity to the kin-state, in a type of national homogenization project, in turn enabling the forging of meaningful relationships of cooperation and reliance. Hungary's kin-state activism has come at the detriment of efforts to improve interactions between the Hungarian and Serbian communities in Vojvodina; quite simply, such with whom they live. Apart from the instrumental value that Hungary's support offers, the national values of solidarity that are derived and espoused through this assistance cannot be overlooked. In this case, the perception of support from the kin-state is as important as the actual support from the kin-state. The Hungarian community depends upon the power of the kin-state from across the border, instead of the actual government that is sovereign in the territory in which they reside. 


\section{Chapter IV - Historical Contentions Surrounding Vojvodinian Territorial and Cultural Autonomy}

Autonomy, defined as independence of action on the domestic level, is often believed to be a slippery slope which eventually leads to independence (Lijphart, 2002; Hannum \& Lillich, 1980). Some assert that autonomy claims can be placed on a continuum with cultural autonomy as the least extreme end and secession is the most extreme, with territorial autonomy occupying a middle ground between the two in terms of self-governing rights (Jenne, 2007). Yet even such a categorization is rather arbitrary since, bar secession, both territorial and cultural autonomy can be implemented to various degrees. While autonomy may extenuate demands for independence in certain political situations, it does not necessarily lead to secession. In fact, the "establishment of regional autonomy is not [always] a slippery slope to independence; the development of regionalism is not unidirectional; the politicization of regional identities does not necessarily stimulate conflict and secessionism but actually serves the purpose of accommodation of diversity while the existence of institutional framework does not make claims for independence necessarily the most salient and successful exit option" (Stjepanovic, 2018, p. 210). Given this novel assertion, autonomy is an important factor to consider when analyzing regional interethnic relations outcomes in terms of the precarious balancing between the state's rights, minority rights, and vested sub-state authorities.

Theoretically, autonomy as a tool of sub-state politics raises the all-important issue of territoriality and spatial boundaries within the wider context of identity politics (Stjepanovic, 2018). “Territory still remains a primary guarantor of two fundamental 
human needs: identity and security" (Hannum, 1996, p. 463). In a broader context, autonomy should be considered an alternative to statehood and a very plausible solution to managing self-determination claims. If implemented under the correct conditions, "the right to autonomy recognizes the right of the minority and indigenous communities to exercise meaningful internal self-determination and control over their own affairs in a manner that is not inconsistent with the ultimate sovereignty - as that term is properly understood - of the state" (Hannum, 1996, p. 473). In this manner, autonomy may be deemed an effective strategy to balance between preserving state sovereignty while simultaneously addressing minority self-determination demands. However, merely granting autonomy is not sufficient to ensure that self-determination demands are met. "Autonomy is not an end in itself - it is a political tool to ensure that other rights and needs are appropriately addressed" (Hannum, 1996, p. 474). Therefore, whether it be territorial or cultural, autonomy must fit the conditions of intergroup dynamics at play in that given sub-state region. In order for autonomy not to disintegrate into secession and/or irredentism it is often said that it must be driven by cultural motives that do not impede on the political and economic system as a whole. Granting cultural over territorial autonomy, and vice versa, depends solely on the spatial conditions and interethnic relations dynamics at play (Safran, 1999).

Regionalism, defined as a "political project and the processes of mobilization and identity politics," is not a unique concept confined to the province of Vojvodina and its resident Hungarian community (Stjepanovic, 2018, p. 30). Practices related to regionalism are handled very differently in different states. In Western European states with a stronger democratic tradition, it is said that autonomy generally does not 
precipitate a conflict between identity and power to such an extent as in Eastern Europe, where ethnonational homogeneity extenuates the problem. Nevertheless, in numerous cases where cultural autonomy has been implemented (Latvia, Lithuania Estonia, Aland Islands, Greenland) or territorial autonomy has been granted (Swiss cantons, Basque county, Catalonia, German constituent states, former Autonomous Republic of Crimea, Corsica), the issue of balance between rights and identity becomes more important. In this precarious process, managing interethnic relations has often come to the forefront. Autonomy, for better or worse, does ultimately affect the reordering of ethnic/territorial group relations. Many times, territorial or cultural autonomy seek to foster greater integration by answering the call to self-determination of a territory or ethnic group without comprising the integrity of the state. Yet, it can also lead to alternative interethnic relations outcomes as is illustrated from the case study of the Hungarian community in Vojvodina. Beginning with the assertion that interethnic relations in Vojvodina are defined as "multinational" and are also said to "exhibits strong groupness and historiography corresponding to national groups," this case presents an intriguing example of how instituted territorial and cultural autonomy, albeit periodically revoked, has actually enabled the definitive novel, intergroup relations dynamic of parallelism (Stjepanovic, 2018, p. 202).

It must also be stressed that autonomy, as it pertains to Vojvodina and the Hungarian community, is not so much about managing ethnonational conflict as it is about managing territorial diversity, albeit with very mixed results. The issue with autonomy in Vojvodina, therefore, is not with avoiding ethnonational conflict but rather a concern with the way in which this strategy is used to manage the national question, and 
the specific interethnic relations dynamic it has fostered in this process for its resident Hungarian community. The common sentiment is that the "Balkans experience appears to indicate that autonomy or self-governance will only take root if independence has been firmly precluded as a potential threat" (Weller, 2005, p. 72). Yet, fears of secession persist when discussing the granting of territorial or cultural autonomy in Southeastern Europe. The same holds true for any attempt at ethnic regional autonomy, which remains extremely unpopular and is rarely tolerated by the central state (Stjepanovic, 2018, p. 210). The case of Vojvodina and the pleas of its Hungarian community for selfdetermination under the banner of minority rights is no exception to the wider trend of political struggle that has had its bearing on and, for better or worse, defined interethnic relations in the province.

\section{Amplitudes of Autonomy in Vojvodina}

The story of Vojvodina's autonomy is one of struggle and volatility in which territorial autonomy and non-territorial forms of cultural autonomy are constantly in flux, in which state centrism is pitted against decentralization (autonomism), and in which the national question rises in salience periodically only to be completely neglected at other times for more technocratic or economic concerns. Amid these complexities and brought on primarily due to "drastic amplitudes in autonomy," the status of the Hungarian community in Vojvodina has been in a constant state of turmoil and uncertainty, resulting in a gradual self-separation from the dominant group (Orlovic, 2014, p. 286). The takeaway: policy continuity matters. Reneging on advancements made in the area of minority rights protection leads to self-isolation and attitudes of indifference displayed 
for vulnerable groups. Even more so, policy implementation matters. Complex and inclusive laws, as well as "good intentions," are worthless if they end up as dead words on paper. For this reason, Vojvodina's institutionalized volatile political status as an autonomous province, particularly in the manner it has affected minority protection and self-rule, has bred attitudes of disengagement among the Hungarian community in Vojvodina.

Secondary data analysis speaks to the fact that autonomy is an important issue for the Hungarian community in Vojvodina. The Minorities at Risk Dataset examines a myriad of factors, numerically coding for a variety of qualitative variables, and finds that there are ongoing "political grievances focused on creating or strengthening autonomous status" as well as "economic grievances focused an ending discrimination" among the Hungarians in Vojvodina (Minorities at Risk Project, 2019). In addition, a survey conducted by Vojvodina's Sociological Association and the Center for Sociological Investigation under the Department of Sociology at the University of Novi Sad finds that the Hungarian ethnonational community considers the laws and policies regulating minority rights to be the most important factor in the preservation of a community's national identity (Sokolovska, 2010, p. 96). The Hungarian community also considers the macro socio-political situation in which it operates as instrumental to its national preservation (Sokolovska, 2010, p. 96). Taking these findings into consideration, an indepth study of autonomy policy in the context of the Hungarian community in Vojvodina is warranted given that the issue is especially salient for the preservation of Hungarian national identity. 
This study investigates two complex interrelated autonomy issues that have episodically been in flux - territorial administrative autonomy for Vojvodina as a whole, as well as more recent autonomy for ethnic Hungarians which can be both cultural and/or territorial. Arguably, while these two autonomy issues may seem independent of one another, in this case study they are extremely interrelated and come to confluence in the development of parallelism exhibited by the Hungarian community in Vojvodina. As historical analysis will reveal, territorial autonomy for Vojvodina has time and again attempted to solve interethnic relations issues and, ultimately, promote integration, either directly or indirectly. Time and again, autonomy alone has failed to achieve these goals partly because of failed implementation, partly because of discontinuity caused by reactive state centralization, and partly because of conflicting conceptualizations of Vojvodina which have either failed to involve Hungarians in the decision-making process or were Serb-dominated. At the same time, ethnic autonomy has been looming in the background - mostly driven by Vojvodinian Hungarian political elites who have tapped into very real community sentiments of discontent and even disassociation. The question of ethnic autonomy for Hungarians is a more recent development, reaching full swing with the democratic changes that took place in Serbia in the early 2000s. While ethnic Hungarian autonomy may be considered a reaction to fickle Vojvodinian territorial autonomy, it can also be seen as the natural progression of Hungarian identity consciousness in Vojvodina which leads to parallelism. The cultural autonomy currently afforded the Hungarian community in Vojvodina comes on top of relative advances made in reestablishing territorial autonomy for the province. As will be shown in the following discussion, such a position on the issue of autonomy is seen as a compromise-- a 
compromise that may not be as stable as it first seems. The notion of ethnic territorial autonomy remains a real striving among the Hungarians in Vojvodina. One cannot help but notice that Belgrade's reactive policies are constantly playing catch-up to form an effective policy of autonomy that address ever-evolving interethnic relations. The reestablishment of Vojvodinian territorial autonomy remains plagued with a legacy of ineffectiveness and inadequacy precisely because of its instability - pushing the Hungarians in Vojvodina further away. At the same time, the cultural autonomy currently granted to the ethnic Hungarians allows for the outlet of parallelism which, if taken to its ultimate conclusion, could overlap with ethnic territorial autonomy should it ever be afforded to this ethnonational community.

\section{Preluding "Golden Age" of Vojvodinian Autonomy}

It is commonly held that 1974 marked the "golden age" of Vojvodina's autonomy, ushered in by the complex 1974 Constitution of the Socialist Federal Republic of Yugoslavia and the following Constitutional Law of the Socialist Autonomous Province of Vojvodina. These political developments not only effectively transformed the country from a federation into a confederation, but also vested the province with substantial self-governing authorities guaranteed by broad constitutional reforms. However, the idea of Vojvodina as an autonomous entity has been around since as early as the beginnings of the twentieth century, in various shapes and forms, and has introduced a myriad of issues. 


\section{Vojvodina Before 1945}

Voivodeship of Serbia and Banat of Temeschwar

In times of great power politics in the Balkans, the inhabitants of what is today the territory of Vojvodina were considered an expendable military resource in attempts to pit the Austro-Hungarian Empire and the Ottoman Empire against each other. It was only later that the territory was recognized as a political factor. It was only through a prolonged process that the Serbs, who migrated to the area during the Great Serb Migrations of 1689-1692 and 1737-1739, gained the status of a nation like their Hungarian and German counterparts in the territory which is today Vojvodina. Through the years, the Habsburg monarchy granted political compromises and concessions in exchange for guaranteed loyalty and services granted as the border militia along the Military Frontier. This was especially true for the rebelling Serbs, who were even granted the right to territorial autonomy with the establishment of what is colloquially known as Serbian Vojvodina (Djukanovic, 2016, pp. 51-52). This Serbian Vojvodina, officially named the Voivodeship of Serbia and Banat of Temeschwar, was short-lived and was quickly abolished in 1860 due to macropolitical changes that witnessed Austrian power waning and its border retracting. The existence of this Serbian Voivodeship highlighted that "Vojvodina posed an obstacle to the creation of a homogeneous and centralist state both to Hungarian nationalism in the $19^{\text {th }}$ century and Serbian nationalism in the $20^{\text {th }}$ century" (Beslin, 2017, p. 297). However minor and episodic this event in Vojvodinian history, it did shape the political realities that would grip the province and its inhabitants in the early 1900s. Quite possibly, granting territorial autonomy to Vojvodina at such an early stage shaped the political discourse that would unfold in due time. 


\section{Vojvodina and the First World War}

It was not until 1918 that the political question of Vojvodina reached the culmination of its potential as a sustainable political reality. The sudden collapse of Austria-Hungary in the First World War ushered in a new political era for Vojvodina. Facing the reality of a Habsburg monarchy in swift demise, the various nations residing in Vojvodina began to mobilize to secure as much political leverage and territory as possible to gain power in their newly forming nation-state in an unstable new global political order (Bjelica, 2015, p. 16). It was at this climactic time that the Great People's Assembly of Serbs, Bunjevci, and other nations of Vojvodina convened in the city of Novi Sad and swiftly proclaimed the unification of Vojvodina with the Kingdom of Serbia. Interestingly, during this meeting, the topic of autonomy for Vojvodina was not discussed in any shape or form; the historic yearning to recreate a Serbian Vojvodina was giving way to the grander idea of Yugoslav unification, which was abruptly realized with the creation of the Kingdom of Serbs, Croats and Slovenes. Of course, "Vojvodinian selfdetermination" would not have been possible without the Serbian military presence on the ground in Vojvodina, which the Allied powers recognized as the new status quo and later formalized through the Treaty of Trianon of 1920 (Bjelica, 2015, pp.16-17).

\section{Vojvodina in the Interwar Kingdom of Yugoslavia}

The Treaty of Trianon effectively redistributed the Hungarian kingdom's territories, gifting Vojvodina to the Kingdom of Serbs, Croats and Slovenes, in the process allocating a sizable number of Hungarians and Germans to the newly formed state. While the Treaty of Trianon recognized and reaffirmed historic Serbian nationalist 
tendencies (a striving for all Serbs in Vojvodina to finally be under Serbian rule), the reality of ruling Vojvodina in the interwar period was far more complex. The population that inhabited the territory of what is now Vojvodina during this time was split rather equally between Hungarians, Germans, and Serbs (Bjelica, 2015, p. 18; Beslin, 2017, p. 302). Governing such a multiethnic population presented a variety of difficulties for the administration of the later renamed Kingdom of Yugoslavia.

The status of minorities during this period (1918-1941) was precarious. Yugoslav leaders were not overly enthusiastic to have such a large number of non-Slavic minorities in their newly created state. The fact that the "minority" Hungarian population was actually the majority in some areas of Vojvodina actually put the government on edge. Therefore, "throughout the inter-war period the minorities in these parts were seen as a destabilizing factor and a potential danger" (Janjetovic, 2012, p. 67). To resolve this perceived threat, the Kingdom of Yugoslavia initially favored the resettlement of national minorities. This solution was curbed by the 1919 Convention on Protection of Minorities—-forced on the Yugoslav leadership at the Paris peace conference-which sought to grant basic nationality rights to minorities in accordance with international standards, especially those pertaining to "establishing and maintaining of their own schools" (Sajti, 2003, p. 144). Even though the Yugoslav government reluctantly adhered to this agreement, they were still haunted by the threat of alien minorities. Instead of remaining passive and neglecting the issue, Yugoslav policy quickly switched tactics by attempting to dictate the manner in which minority rights were to be implemented in the new state. For example, the government tried infiltrating the minority education system by passing a series of superseding domestic laws that effectively compelled "schools in 
places where minorities lived to provide parallel classes for minority children, taught in their native language but with the Serb language as a compulsory subject. The Serbian law on elementary schools conflicted with the international provisions in not recognizing the right of religious denominations or local communities to maintain schools" (Sajti, 2003, p. 146). Ensuring loyalty was the goal and the government deemed it best to nurture in the minorities, especially the Hungarian population, a loyalty to Yugoslavia that would hopefully eventually wean them away from their partiality to their maternal state (Janjetovic, 2012, p. 71). However, this was never effective, as shown by the fact that "basically all minorities [in the Kingdom of Yugoslavia] still strove to set up their national cultural organizations which would be blanket organizations for all kinds of cultural and social activities on local and national levels" (Janjetovic, 2012, p. 74). Of course, it was extremely hard to influence the minority education system when the right to use of national communities' languages was guaranteed by the constitution (Constitution of the Kingdom of Serbs, Croats and Slovenes of 1921, Article 16). Ultimately, the failure of Yugoslav interwar minority policy to secure the loyalty of members of the minorities, especially the Hungarians, would have dire consequences during the Second World War unleashing violent interethnic clashes in Vojvodina as groups struggled to secure possession of territories they inhabited.

It would be a mistake to claim that there was no debate over Vojvodina's administrative division in the Kingdom of Yugoslavia, however. On the contrary, it was during this period that the first interpretation of Vojvodina was developed. This conception of Vojvodina derives its tradition from the Serbian national movement and considers the province an "ethnically and culturally defined Serbian space" (Beslin, 2017, 
p. 339). At the time, the notion of Vojvodina as a Serbian space ran contrary to its extremely ethnically and culturally heterogeneous composition and was thus highly idealistic, if not revolutionary, in its interpretation. Surely, the Serbian national movement wanted to simplify the unique conditions in which the Serbs found themselves in Vojvodina, to more closely reflect the conditions found in the rest of Serbia proper. The Serbian political elite, finding themselves as neither the clear majority nor the historic inhabitants of this space, as they were in the rest of Serbia, were perplexed and sought to readjust the status quo and assert Serbian dominance. This ultimately meant making Vojvodina mimic (if not being wholly integrated into) the larger Serbian space. The tangible expression of this narrow Serbian nationalist conception of Vojvodina, wholly disregarding the ethnic composition of the province, came in the form of rampant state centralization which was plausibly driven by deeper political strivings for greater Serbian unity.

Simultaneously, interwar Yugoslavia witnessed increased bureaucratization and intense regional administrative reorganization. What is today the province of Vojvodina was divided across four districts, as prescribed by the Vidovdanski Ustav (Constitution of the Kingdom of Serbs, Croats and Slovenes) of 1921 (Bjelica 2015, p. 19). However, such a parceling of Vojvodina had nothing to do with minority policy and actually only further alienated the population of Vojvodina, both Vojvodinian—Serbs and minorities alike. In fact, such an administrative division triggered mass protest from Vojvodinian politicians from various political persuasions, bar the Radical Party led by Jasa Tomic. Countless Vojvodinian political groups considered that the government's underlying motive for increased state centralization was detrimental to the economic feasibility, if 
not prosperity, of the territory (Bjelica, 2015, p. 19). These progressive voices cried foul play, claiming that the unquestionable economic exploitation of Vojvodina as a direct result of state centrism could not be justified by "homogenization of the Serbs" alone (Beslin, 2017, p. 302). The fact that Vojvodina during this time experienced "accelerated pauperization, caused by the heaviest tax burden in Yugoslavia" was problematic for many. However, the state was skillful in deflecting critics by branding them all autonomous separatists and Serbian traitors (Beslin, 2017, p. 303).

What is most intriguing during the interwar period for Vojvodina, therefore, was the invigorated movement for territorial autonomy led by some Vojvodinian Serb intellectuals and landholders. Hungarians or Germans, who now found themselves vulnerable in a "foreign" state and neglected by both the state apparatus and the progressive opposition, were not concerned with autonomy or noticeably active in this political debate during that time. For all other ethnonational groups in Vojvodina, especially the numerous Hungarians who were until recently deemed the enemy by the Serbs, survival, rather than political status, was of primary concern. As the Hungarian music teacher at a public elementary school in Krivaja recollects:

“My grandfather used to tell me how fearful he was for his family's future in the new Kingdom. You cannot comprehend how it feels to wake up one morning in 1918 and no longer be part of your country. In this uncertainty, these people were only concerned with their survival and surely not with their political status or future of the province. How can you politically participate in this state of shock and in a new country in which no one wants you? Probably the only thing on my 
grandfather's mind was whether Vojvodina would be returned back to Hungary." (anonymous source, in discussion with author, November 12, 2018) Still, even Serbian calls for political self-government during this time seem rather irrational and dangerous in context of the evenly split population that could put Serbian control of the territory in jeopardy. The Germans and Hungarians were certainly dissatisfied with the status of Vojvodina in the Kingdom, but their political efforts were rather disengaged from inter-Yugoslav politics and entirely focused on border revision and nationalist irredentism (Bjelica, 2015, p. 18). On the other hand, Serbian calls for self-government came at the height of this dire economic downturn caused by perceived state exploitation and, therefore, it comes as no surprise that calls for autonomy came on the back of pressing issues such agrarian reform, tax reform, and currency regulation (Bjelica, 2015, p. 18). As such, all talk of autonomy at this time was still very much Serbian-focused (monoethnic), neglecting the status of the other national minorities, and driven by tangible economic concerns enveloped in a narrative of for economic selfdefense.

The interwar Kingdom did witness the establishment of the first ethnically Hungarian political party - the Yugoslavian Hungarian Party (Jugoszlaviai Magyar Part). The Yugoslavian Hungarian Party aspired to be the exclusive representative of all Hungarians in Vojvodina; an idealistic goal at best given the fact that Hungarians in this historically peripheral region lacked a distinct local political consciousness at the time (Sajti, 2003, pp. 30-32). Nevertheless, the Hungarian Party focused its program on "demanding full assertion and observance of the rights laid down in the [international] minority-protection treaty and the constitution" (Sajti, 2003, p. 45). From this, we see that 
this political organization was solely focused on ensuring minority rights protection, especially for Hungarian language education and progressive land reforms that were paired with tax system adjustments detrimental to Hungarians especially. ${ }^{9}$ At no point was this party principally concerned with autonomy for Vojvodina. The lack of concern for Vojvodina's autonomy reflected low salience for this issue from its party's supporters and political leaders. Of course, this matter was not helped by the systematic political ostracization that the Hungarian Party experienced during this time. Thus, the Hungarian Party's legacy is marred with political impotence as their efforts were continuously plagued by a confluence of systemic state intolerance and sporadic activism-activism which was brought to an abrupt halt with the introduction of the royal dictatorship instigated by political violence in the country (Sajti, 2003, pp. 57-121). What is certain is that the question of Vojvodina was not on the primary agenda of the Yugoslavian Hungarian Party who had other, more pressing concerns. If autonomy was ever indirectly mentioned by this party, it was packaged in the grander scheme of ensuring minority rights protection for the Hungarian community residing in this territory.

In retrospect, revived calls for Vojvodinian self-government, at least for the Serbs, during the interwar period, is arguably a case in which the tool of autonomy as a "measure to prevent the exploitation of Vojvodina" reflected a growing regional elite-led Vojvodinian nationalist movement where economic inequality and underdevelopment pitted the Vojvodinian periphery against the Serbian central core (Bjelica, 2015, p. 18). The creation of the Vojvodina Front, a "nucleus of the new anti-centralist and

\footnotetext{
${ }^{9}$ Minority rights and land reform have remained omnipresent problems for the Hungarian community in Vojvodina to this day as this research will highlight. These two issues remain contentious, fluctuating in salience at specific periods in history.
} 
supranational conception of Vojvodina," was the first expression of this disgruntled Vojvodinian periphery rising up against the perceived uneven development and exploitation by the Serbian core (Beslin, 2017, p. 341). While the Vojvodina Front gained considerable political momentum, it never evolved into a militant inter-class community strongly aware of its separate identity as Nairn (1977) postulates. Part of the reason was that it never became a cross-ethnic Vojvodinian movement, since a Vojvodinian identity did not (and never did) take foot. The fact of the matter was that the Vojvodina Front was led and dominated by the Serbian elite in Vojvodina throughout is existence. The Hungarians never showed interest nor participated in the Vojvodina Front; likely, it was seen as simply another avenue of Serb domination. Thus, the historical contribution of the Vojvodina Front remains more in its political contribution to the arising supranational conception of Vojvodina that would be a recurrent topic throughout the province's political history.

Throughout this period, however, the issue of territorial autonomy for Vojvodina was Serb-dominated. There were moments and glimpses in which a competing conception of Vojvodina was presented which considered the heterogeneous ethnic composition of the province, yet, on the whole, the dominant narrative was still of Vojvodina as a Serbian national space. The most important thing to understand is that during this time the Hungarian community was not part of the conversation regarding Vojvodinian autonomy. Solving interethnic relations through Vojvodina's territorial autonomy was subsidiary to finding an appropriate means of tying the province to Serbia proper, given the political and economic demands. As such, tensions over political centralization versus economic decentralization won over any interethnic relations 
considerations. If Vojvodina's territorial autonomy could have addressed the interethnic dynamic in the province it would have been welcomed, but at the time this consideration came second to solving more immediate concerns of regulating political relations among Serbian elites. Yugoslav interwar minority policy was a mixture of reactive centralization and neglect for alien ethnonational groups that were openly deemed disloyal.

\section{Vojvodina and the Communist Party of Yugoslavia}

While the extremely powerful Radical Party in Vojvodina consistently demonized the issue of autonomy during the period of the Kingdom of Yugoslavia, one political group rising in relevance initially wholeheartedly embraced the idea of Vojvodinian autonomy: the Communist Party of Yugoslavia (KPJ). KPJ support for Vojvodinian autonomy was motivated by the desire to induce political instability and division in the Kingdom of Yugoslavia and to threaten the monarchy, which banned all political opposition activity, especially that of the KPJ which it considered outright dangerous. Uniquely, however, for the very first time in its political discourse, the "KPJ interlinked the issue of Vojvodinian autonomy with the national question in Yugoslavia" (Bjelica, 2015, p. 21). Proclaiming their support for the universal right to self-determination and self-government for all peoples in Vojvodina, the KPJ went so far as to support the cession of northern Vojvodina to Hungary (Beslin, 2017, p. 299). The KPJ vehemently maintained this position until the beginning of the Second World War. The KPJ is credited with introducing this second conception of Vojvodina, which sought to unshackle the province from Serbia and considered it in terms of a far broader Yugoslav framework. This conception acknowledged the historical and ethnic specificity of the 
province and therefore considered Vojvodina modern, pluralistic, and, most importantly, supranational (at least in the beginning).

\section{Vojvodina and the Second World War}

The Second World War changed the social fabric in Vojvodina in many ways, antagonizing dormant nationalist sentiments on all sides. As the former chief ambulance driver in Backa Topola claims:

"WWII brought another round of conflict to this area, probably a continuation of unresolved issues from the war past. Logically, Hungarians here and back home were extremely unhappy with the result of 1918 (which we still regard as a year of collective mourning). So, you cannot blame some 'destructive' Hungarian nationalism for simply wanting to be part of our state. Serbia was on one side, we had to be on the other. Hungarians were not nationalist or fascist by ideology but out of need. Sadly, circumstances made it so that we once again came out on the losing side...We can say that a climate of uncertainty enveloped this area...uncertainty about the future for Hungarians living here." (anonymous source, in discussion with author, November 19, 2018)

While the Partisan resistance movement in Vojvodina affirmed their support for Vojvodinian autonomy in line with the official stance of the provincial committee of the KPJ, there were many Serbs in the communist leadership that looked unfavorably at the establishment of Vojvodinian provincial territorial autonomy once the war was over (despite still publicly voicing support for the principle of self-determination). While the early provincial communist leadership in Vojvodina expected Vojvodina to be a wholly 
autonomous unit within the restructured Yugoslavia that had little or nothing to do with Serbia in the legal sense, Serbian leadership in Belgrade had other ideas. When the war ended, it did not take much time for Vojvodina's provincial communist leaders to be swiftly disposed of and their vacant positions filled with hardline proponents of Serbian centralization. Once again, a solution to "Vojvodina's question" now became a completely Serbian issue, and all talk of autonomy somehow almost overnight becoming deemed separatism yet again (Bjelica, 2015, p. 25). With such a change in the political climate, other local Vojvodinian communist politicians had to carefully balance their pursuit of Vojvodinian autonomy with the need for political concessions from the KPJ, later renamed the League of Communists of Yugoslavia (SKJ).

\section{Vojvodina During the Communist Era}

Vojvodina and the National Question in the FNRJ and Subsequent SFRJ

Given the newly developing, unfavorable political attitudes towards Vojvodina's future political status, the granting of territorial autonomy to Vojvodina in 1945 at the Second Session of the Anti-Fascist Council for the National Liberation of Yugoslavia (AVNOJ) was nothing if not fragile and arguably rather nominal in content. The establishment of Vojvodinian territorial autonomy was the result of much deliberation within the KPJ, who finally favored a supranational autonomous conception of the province. After all, "a lasting solution to the national question in Yugoslavia was seen in a broader ethnic foundation of the Yugoslav federation" (Beslin, 2017, p. 315). On a pragmatic level, justification for the creation of the Autonomous Province of Vojvodina (AP Vojvodina) ranged from potential economic benefits of territorial regionalization, to 
cultural-historical differentiation of the province from Serbia proper. The general perception is that Yugoslav communists were guided by the example of regionalization that their communist counterparts in the Soviet Union had previously employed to relative success. On the other hand, some would argue that the establishment of AP Vojvodina had nothing to do with imitating Soviet-style governing practices but was a deliberate attempt by Yugoslav communists to decrease Serbian influence in the newly established Federal People's Republic of Yugoslavia (FNRJ) and subsequently renamed Socialist Federal Republic of Yugoslavia (SFRJ) (Zundhausen, 2008, pp. 412-413). More specifically, the argument is that Tito's government intentionally carved out the territorially autonomous provinces of Vojvodina and Kosovo from Serbia in order to curb Serb domination that would appease the Croats and Slovenes in the FNRJ (and the later SFRJ) and thus create a balance of political power. At the Second Congress of the Communist Party of Serbia, convened in 1949, Petar Stambolic even explicitly stated that Vojvodinian autonomy was created for the purpose of "breaking lingering Greater Serbian chauvinism that exists towards the nationalities" (Nikolic, 2011, p. 27). Regardless of this controversial debate, what seems certain is that the creation of AP Vojvodina was motivated by the underlying notion that territorial autonomy is interlinked with the national question and that it could prove useful in solving the complex status and relationship between nations and nationalities in the province.

Even the first Statute of the Autonomous Province of Vojvodina from 1948 explicitly states in Article 2 that "In the interest of realizing brotherly cooperation between the peoples [nations and nationalities] who live in Vojvodina and ensuring the rights of national minorities defined by the Constitution of the Federal People's Republic 
of Yugoslavia and Constitution of the People's Republic of Serbia, Vojvodina enjoys special autonomous rights as is the free will of the people" (Statute AP Vojvodina of 1948, Article 2). This same interlinking of the issues of territorial autonomy and the national question is further elaborated in the revised Statute of the Autonomous Province of Vojvodina from 1953, which states that "In the interest of realizing the right to selfmanagement, the working peoples of the Autonomous Province of Vojvodina rightfully choose their provincial governing bodies and through them realize their autonomous rights...in the interest of developing and solidifying brotherhood and unity between nations and nationalities who reside in the province and realizing the rights of national minorities [nationalities] as prescribed by the Constitution" (Statute AP Vojvodina of 1953, Article 2). Yet, despite the continued interlinking of autonomy with the minorities question and efforts to improve interethnic relations through the mechanism of territorial autonomy — the policy pinnacle of Yugoslav style self-management— relations between nations and nationalities were far from idyllic (Bjelica, 2015, p. 27). The political, economic, and cultural existence and status of the Hungarian community in Vojvodina remained very much hostage to the whims of antagonistic local communist officials who treated the minority very differently from village to village, depending on personal attitudes, with little attention paid to official policy (Petrovic, 2017, p. 338).

The multinational character of Vojvodina presented a variety of issues for the KPJ from the outset. The KPJ initially claimed that its granting of territorial autonomy to Vojvodina was in line with its policy of rebuilding ethnic relations in the province and finally solving the national question. Yet intolerance towards national minorities in Vojvodina existed and persisted, in no small part due to the recent, violent legacy of the 
Second World War. The atrocities committed by the Hungarian fascists who invaded Vojvodina during WWII and committed a genocide of the Serbs, Jews, and Romanies were indirectly attributed to all the Hungarians in Vojvodina, who generally welcomed Hungarian occupation (Ludanyi, 1979, p. 230). Referencing Hungarian and Jewish historical sources, the private goldsmith from Backa Topola describes a "horrific story of nationalist retaliation and retribution between ethnic communities in Vojvodina during and after the war. In a guerilla war such as the one that played out here, horrific war crimes were committed by all sides. After conflict stopped, all the ethnic communities found it extremely difficult to trust one another in a general climate of uncertainty." (anonymous source, in discussion with author, November 14, 2018)

With this anger over the extent of Vojvodinian Hungarian support for the (Hungarian) fascists during the war, calls for the mass deportation of Hungarians from Vojvodina became more vocal. While the Serbs believed Vojvodinian Hungarians' wartime loyalties to be an omnipresent threat to the newly reorganized Yugoslav state, Hungarians in Vojvodina considered their WWII support a matter of mere solidarity with their Hungarian co-nationals across the border. As the private entrepreneur from Novi Sad explains: "I can understand why they wanted us out of Yugoslavia. Many here supported Hungary during the Second World War. But this was not solidarity out of ideological reasons, but purely a desire to reunite with our people. For many Hungarians, the Kingdom of Hungary under Horthy was viewed as the liberator who was going to right the wrongs of the First World War" (anonymous source, in discussion with author, 
November 24, 2018). The former chief ambulance driver in Backa Topola agrees with this assessment and claims:

"From the perspective of my grandparents and parents, this was a civil war and not an ideological war. Sadly, many atrocities were committed that later came to haunt our people, and the communist backlash is understandable. However, very few people here were true fascists and they really did not know of the war crimes that the Hungarian military was committing. For them, at the time, that whole mess was simply an opportunity for them to reunite with their own people and not be divided between two states - a return to the pre-WWI status we had here." (anonymous source, in discussion with author, November 19, 2018)

A public elementary school teacher in Krivaja also believes that the Hungarian community in Vojvodina was not fascist-oriented. In his interview, this respondent argues that the Yugoslav communists were unfair in their judgment of Vojvodinian Hungarian participation in the war effort, generalizing Hungarian support for the fascists. This interviewee claims that "the retribution against the Hungarian community that some Yugoslav officials sought was unwarranted. Hungarians in Vojvodina protected their Serbian neighbors from the Hungarian killing squads. Do not forget that the Petefi Brigade was a partisan brigade mainly comprised of Hungarians from Vojvodina fighting against the fascists - German and Hungarian" (anonymous source, in discussion with author, November 12, 2018). According to this subject, therefore, failed plans to push the indigenous Hungarians out of their homes in Vojvodina was not only unjustified and unwarranted, but also spoke volumes about the Yugoslav communist government's failure to recognize the contributions of this community. 
Apparently, Tito and Kardelj secretly considered the option of sanctioning the collective punishment of the Hungarians in Vojvodina, which would have expelled at least 40,000 after the war (Petrovic, 2017, p. 334). However, Tito quickly reneged on this and the KPJ favored appeasement which guaranteed that most of Hungarians were allowed to remain in the province. This comes in stark contrast to the fate of Germans in Vojvodina after WWII, who were either forcibly expelled or exterminated by the regime almost immediately. Likely, the Yugoslav communists did not perceive the same threat from Hungarians and their maternal state, Hungary, post-WWII as they did from a postHitler Germany and the Germans. Instead, the KPJ made every effort to publicly differentiate Hungarian war criminals who perpetrated atrocities in Vojvodina from the regular Hungarian civilians in the province. Despite the fact that the KPJ policy approach sought to normalize interethnic relations between Serbs and Hungarians in the province, continued conflict and violence between the groups persisted (Petrovic, 2017, pp. 339340). A period of "social carpet bombing" of the Hungarian community in Vojvodina ensued (Sajti, 2003, p. 479). This hostility ultimately resulted in the systematic exclusion of Hungarians from all political life in the province, purging the KPJ of influential Hungarians on all levels - a decision whose legacy would prove terminal for integrating the Hungarian community in Vojvodina into the newly established state, instead turning them into passive bystanders in the new social order (Janjetovic, 2007, p. 64).

For many years, the KPJ remained adamant that the international character of Yugoslav communism required reconciliation between the two sides, and attributed past Hungarian antagonism and aggression to a reaction to Greater Serbian nationalist chauvinism and Greater Serbian hegemony (Petrovic, 2017, p. 341). To this effect, the 
KPJ propagated the need to cooperate with the Hungarians in Vojvodina, and proactively sought to develop a sense of "belonging and loyalty to Yugoslavia" similar to what was attempted in the former Kingdom of Yugoslavia (Bjelica, 2015, p. 29). However, this time, the KPJ was explicit in its claim that the rehabilitation of interethnic relations was to be best achieved by granting territorial autonomy for the province, proactively seeking to ease the possibility for Hungarians in Vojvodina to have and organize their own schools, newspapers, and cultural events. The Yugoslav government propagated the motto of bratstvo i jedinstvo (brotherhood and unity) to guide their policy approach, which assumed a fundamental unity of the interests of all nations and nationalities in Vojvodina (Petrovic, 2017, p. 241; Judah, 1997, p. 136). For a period of time this seemed to weaken chauvinist attitudes in Vojvodina (Bjelica, 2015, p. 32). However, the underlying interests and intentions of Vojvodinian Hungarians were viewed with suspicion by the KPJ even from the time of FNRJ's establishment. This was surely not helped either by the later falling out of Tito and Stalin, or by Hungary, an ally of the Soviet Union, becoming a potential enemy to the SFRJ (Petrovic, 2017, p. 341).

Altogether, while it would seem that KPJ policy was initially taking a step forward in addressing interethnic relations in Vojvodina, issues persisted that actually moved one step back. For sure, the KPJ did introduce the second, competing, supranational narrative of Vojvodina and finally attempted to address the national question directly through territorial autonomy for Vojvodina. However, schisms between ideology and reality persisted. How could the KPJ reconcile brotherhood and unity with a general distrust of the Hungarian community? How could they ensure the loyalty of this community once territorial autonomy was granted to Vojvodina and set it on the path to 
decentralization? The KPJ wanted the solve the national question through using territorial autonomy for Vojvodina. However, territorial autonomy for Vojvodina was still deemed dangerous among those who supported state centralization, as they were fearful of potential separatism and sought ways to reign it in. At this time, Hungarians were still barred from participating in Vojvodina's political life. This not only prevented meaningful advancement in improving interethnic relations but also made any advancement made in relation to Vojvodina's territorial autonomy rather confusing.

Offering the Hungarian community in Vojvodina limited cultural autonomy (and with it the possibility to organize their own schools, their own newspapers, and cultural events) while at the same time expressing political distrust towards this same community sent a confusing policy message. If some form of political emancipation for Vojvodina did come to fruition through the device of autonomy, social emancipation for the Hungarian community residing in the province surely did not take place, as it was still dependent on the whims of local officials. As such, the tendency to take one step forward and one step back on issues of autonomy continued. Striving to develop the Hungarian community's sense of loyalty by granting cultural and territorial autonomy for Vojvodina, only to simultaneously question their underlying aims of this foreshadows eventual problems in implementation of autonomy policy.

\section{Problem of Hungarian National Partiality in the FNRJ and SFRJ}

From the beginning of communist rule in the FNRJ and later SFRJ, Hungarians in Vojvodina did not seem to embrace the party nor the transnational character of the movement. Much historical evidence suggests that the Hungarians, along with the 
Albanians, posed the greatest problem for the KPJ (Shoup, 1963). Hungarian national partiality was apparent as early as the 1946 elections for the League of Communist Youth of Yugoslavia (SKOJ) witnessed Hungarians voting almost exclusively for Hungarian delegates/representatives. In instances such as these, "more than any other minority, the Hungarians have displayed their nationalist feelings and their lack of respect for the rest of the Yugoslavs" (Shoup, 1963, p. 80). Thus, despite the push for reconciliation and integration of nations and nationalities, especially in Vojvodina, the opposite was occurring, eventually leading to the almost complete exclusion of Hungarians from Yugoslav political life for many years. As Shoup (1963) explains:

Yugoslav communists alienated the minorities from the regime far more than alienating the rest of the Yugoslav peoples. Most of the minority populations took no national pride in the achievements of the regime, associate communism with the Slavs, and in varying degrees remain unreconciled to their position within a Yugoslav state. Communists, for their part, cannot completely avoid treating the minorities as second-class citizens. Repressive measures, carried out in the population generally to assure the security of the regime, always fall most harshly on the minorities because of their political attitudes. (Shoup, 1963, p. 79)

The autonomy as a policy tool, sought to redress this issue, but its effectiveness was tainted from the beginning. In fact, merely granting territorial autonomy and paying lip service to cultural autonomy in Vojvodina did nothing to resolve the national question since it was implicitly centered on the dominant Serbs and Serbia, hence relegated to an administrative function and arguably leading to the further isolation and alienation of the Hungarian community in Vojvodina. 


\section{Vojvodina in the FNRJ of the 1950s}

In another case of back-and-forth on Vojvodina's territorial autonomy, a notable policy shift occurred in the mid-1950s when the KPJ sought to redirect policy efforts away from broadly employing territorial autonomy in an effort to resolve the national question. Instead, they emphasized more concrete goals, specifically delivering on increased self-management which could possibly have led to further integration. However, even here the government ran into issues noting that Hungarians now simply did not want to participate in the provincial government initiatives. Even today, Hungarians still only make up $6.58 \%$ (less than $1 \%$ of all Vojvodinian Hungarians) of employees in Vojvodina's public sector (Bjelica, 2015, p. 44). Hungarians showed similarly low membership in the League of Communists of Vojvodina (SKV).

The attempt to uncouple the issue of territorial autonomy from the national question, by refocusing on administrative political self-management, and eventually to economic self-management, did not improve interethnic relations. Vojvodina's economy entered the FNRJ as one of the most developed and successful. The KPJ's decision to limit the appropriation of land in Vojvodina garnered favor with the Hungarians. On the other hand, the socioeconomic changes that were pushed through, including comprehensive agrarian reform and limited collectivization, made Vojvodinian Hungarians more skeptical. The fact that Tito's government invested three times less in Vojvodinian industry than was on average invested in the rest of the FNRJ only added to this frustration (Bjelica, 2015, p. 53). As such, the political economy that the Central Committee of the League of Communists of Yugoslavia (CK SKJ) was implementing in Vojvodina was problematic, at best. Territorial autonomy, at least on the economic front, 
was not supporting the equal economic self-management of all the nations and nationalities that it was intended to propagate. Initial Serbian political domination was reflected in the unequal levels of economic self-management between narodi and narodnosti in the province.

\section{Vojvodina - Administrative Region Versus Political Category}

Throughout the time of KPJ's governing of the province, the core question regarding Vojvodina's autonomy was whether AP Vojvodina should take the form of an administrative region or a political category (Bjelica, 2015, p. 77). As the discussion above explains, the KPJ eventually favored considering AP Vojvodina an administrative region, for fear that recognizing it as a political category would agitate the volatile and persistent national question. Considering AP Vojvodina as an administrative region ensured that all national and provincial issues were relegated to technocratic solutions and procedures, rather than becoming polarizing political issues that could possibly introduce a political-institutional dimension to the debate over rights. Paradoxically, the KPJ repeatedly failed to address, let alone reconcile, the supranational idea of a Vojvodinian autonomy based on a nationally pluralistic identity with the clearly apparent Serbian-dominated perspective concerning the province which neglected the national question apart from its own.

This debate reached its peak in 1961, when several prominent politicians in the KPJ claimed that granting Vojvodina territorial autonomy had prompted the creation of a Vojvodinian national identity. While this harsh criticism was rejected as being far too critical, it did serve to turn back and refocus the issue of autonomy on the national 
question to some extent. Yet again, however, Vojvodina's territorial autonomy was interlinked not with the national question in general but, paradoxically, with the national question for Serbs, specifically (Bjelica, 2015, p. 122). Reasserting their commitment that Vojvodina is an integral part of Serbia and not federal Yugoslavia, the SKV changed the discourse by introducing the claim that Vojvodinian autonomy is about Serbs realizing their self-governing and self-management rights and being closer to and equal to their brethren in Serbia proper. Once again, sadly, this debate not only neglected to mention the Hungarians in the context of Vojvodina's autonomy but arguably alienated them further from the dominant society.

Among continued reneging on the issues of political and economic selfmanagement and decentralization and in a climate of constant polemic over the form and meaning of autonomy for Vojvodina, the Hungarian community in Vojvodina was eventually neglected from the debate altogether. What started out as a KPJ policy to solve the national question became a debate over the extent of political and economic selfmanagement that somehow once again put the Serbs in Vojvodina in primary focus to the detriment of the status of the national minorities. While the KPJ tried to claim that Vojvodina is synonymous with national equality, the reality was quite different until 1967.

Therefore, we again take one step forward and two steps back on Vojvodinian autonomy. Uncoupling Vojvodina's territorial autonomy from the national question and re-centering it towards more concrete political and economic self-management, only to later reverse course and reemphasize the need to address interethnic relations serves to further highlight the general lack of policy continuity related to Vojvodina's Hungarian 
community. Serb domination of the discourse regarding Vojvodina's territorial autonomy not only demonstrates the destruction of Vojvodina's plural supranational conception but also provides an explanation for further Hungarian disassociation and isolation.

\section{Debates Concerning Vojvodina's Duties in 1967}

Another definitive breakthrough in the debate concerning Vojvodinian autonomy came in 1967. Finally, AP Vojvodina's overarching powers and duties were outlined. These included the self-governing right to form and terminate municipal territories in the province, the right to organize the education system, cultural activities, and health policy, and the right to oversee social security in the province. Most important, at least as far the Hungarians are concerned, was granting provincial authority to administer education in the nationalities' languages and recognizing the importance of utilizing the nationalities' languages in public administration (Bjelica, 2015, pp. 294-295). These concessions were later fortified in the 1974 Yugoslav Constitution. However, the SKV still wholly maintained that the question of Vojvodina's territorial autonomy was of a socioeconomic character and did not represent a national political question of survival, as was the case with Kosovo's autonomy. This was likely a much-needed strategy to appease the Serbian unitarists (Bjelica, 2015, p. 304).

\section{Vojvodina and the 1974 SFRJ Constitution}

The constitutional reforms heralded by the SFRJ Constitution of 1974 cannot be understated. They were instrumental in finally solidifying Vojvodina's territorial autonomy. These reforms were based on two core ideas: decentralization and self- 
management. For the first time, Vojvodina's autonomy had a clear federal framework that directly tied it to the Yugoslav federation rather than to the Socialist Republic of Serbia. It is at this time that Vojvodina gained an equal voting right to SR Serbia in the country's collective presidency, effectively becoming an equal unit member of the federation. Still these apparent gains did not stop some critics from claiming that "selfgovernment" in the form of political and economic self-determination, which the 1974 Constitution apparently granted, remained non-existent for the Hungarian community in AP Vojvodina and was relegated to "freedom to express nationality and culture through their own [Hungarian] language and script" and legal equality in front of the law (Ludanyi, 1979, pp. 244-245).

Some claim that the 1974 Constitution introduced mainly symbolic changes intended to eradicate inequality under the banner of self-determination for the nations but stopped short of doing so for nationalities. However, ample evidence presented below seems to suggest otherwise (Stojanovic, 1997). The SFRJ Constitution of 1974 developed extremely high standards in the sphere of collective rights for both nations and nationalities, and individual rights in general (Sekelj, 1990, p. 150). This Constitution finally confirmed Vojvodina's nationally pluralistic identity and hence declared the equality of all nations and nationalities in Vojvodina in front of the law. It also defined and reaffirmed the specific rights afforded all nations and nationalities in the sphere of language use, culture, education, and media (Tolvaisis, 2012, p. 65). Articles 170 and 171 of this legal document outline the extent of specific rights afforded to the nationalities that included: 
"right to opt for a nation or nationality and to express their national culture, and also the right to the free use of their language and alphabet...Members of nationalities shall, in conformity with the constitution and statute, have the right to use their language and alphabet in the exercise of their rights and duties and in proceedings before state agencies and organizations exercising public powers. Members of the nations and nationalities of Yugoslavia shall, on the territory of each Republic and/or Autonomous Province, have the right to instruction in their own language in conformity with statute." (Constitution of the Socialist Federal Republic of Yugoslavia of 1974, Articles 170-171)

Most importantly, these articles lay the parameters for the subsequent "Constitution" of the Socialist Autonomous Province of Vojvodina, that was also adopted in 1974, which further fortified the progress made in the sphere of nationalities' rights protection and built upon the province's new vested rights of self-rule.

\section{Constitution of the Socialist Autonomous Province of Vojvodina}

Arguably, the 1974 Constitution of the Socialist Autonomous Province of Vojvodina represents the zenith of the development of nationalities rights protection in Vojvodina. This document finally redirected discourse over Vojvodina's status away from mere territorial autonomy and towards national cultural autonomy as per the 1974 Yugoslav Constitution. This piece of legislation ushered in much institutional change for Vojvodina, granting the province its own Presidency, Supreme Court, Bank, and Constitutional Court (Djukanovic, 2016, p. 55). This came in addition to broadening the province's fiscal duties and authorities, as well as granting it the right to engage in 
international cooperative relations. Most pertinent to the ethnic Hungarians in Vojvodina, this document symbolized the pinnacle of affirmation of equality between nations and nationalities in the province. More specifically, the 1974 Constitution of the Socialist Autonomous Province of Vojvodina "empowered nationalities to govern their own media, language, education and cultural matters" (Tolvaisis, 2012, p. 65). This meant that no language was privileged and that the languages of the five major national groups (one being Hungarian) were to be equally used in education, mass media, and culture. Such robust affirmative policy was very much welcomed by the Hungarian community in Vojvodina. Economic expansion quickly took place, followed by extensive social and cultural development in the areas with a Hungarian numerical majority, including North Backa and North Banat (Tolvaisis, 2012, p. 65). The creation of the publishing house for Hungarian literature, Forum, along with the establishment of the Department of Hungarology at the University of Novi Sad signaled the beginnings of extensive steps towards recognizing national equality of the Hungarian community in Vojvodina championed by the underlying promise of cultural pluralism and interethnic tolerance.

The 1974 Constitution of the Socialist Autonomous Province of Vojvodina effectively enshrined national cultural autonomy for the ethnic Hungarians in Vojvodina by granting them extensive collective rights, wide cultural autonomy, and non-territorial self-determination as a defined nationality under the 1974 Yugoslav Constitution (Renner, 2005, pp. 13-40; Bauer, 2000, pp. 259-308). These changes were met with approval by the Hungarian community in Vojvodina. One survey which focuses on the desirability/undesirability of entering into social relations with other national groups in Vojvodina recorded the highest degree of group identification with Vojvodina and 
Yugoslavia as a whole during this period — the smallest interethnic distance between Serbs and Hungarians ever recorded (Tolvaisis, 2012, p. 66; Komsic, 1997, p. 22). As a professor from the University of Novi Sad notes, it was at this time that the "tradition of work and good neighborly relations took root" and Hungarians here began to identify as "Yugoslav Hungarians" on mass (anonymous source, in discussion with author, March 26, 2019). Such a tradition of work and good, neighborly relations, albeit short-lived, proved to be a vital factor of stability in Vojvodina in the early 1990s when the rest of the SFRJ was marred with ethnic turmoil (Lazar \& Marinkovic, 2003; Lazar 2007).

Numerous respondents in this study reaffirm this position, speaking highly of the "golden ages" of Yugoslavia made possible through the adoption of these seminal pieces of legislation. The local municipality official recounts:

"Everybody here finally embraced the idea of bratstvo i jedinstvo (brotherhood and unity). Hungarians finally believed in and embraced the Yugoslav dream, and I would argue that our Hungarian community in Vojvodina as a whole felt equal to all the other nations in Yugoslavia during this time... We could see that we had it better than Hungarians in Romania who were heavily oppressed by the Ceausescu regime. In fact, we had a better standard of living and more rights than Hungarians in Hungary during this time.” (anonymous source, in discussion with author, November 12, 2018)

The current director of a mental care facility in Vojvodina also believes wholeheartedly that "1974 was the peak of Hungarian equality in Yugoslavia, and especially Vojvodina. We had more than what the EU is currently offering the minorities. Sadly, this was shortlived...All good things come to a very quick end. Such liberalization that took place was 
unsustainable in the area of the world we live in" (anonymous source, in discussion with author, November 12, 2018). When pressed to expand his reasoning, this respondent merely stated "You know what Balkan primitivism is" (anonymous source, in discussion with author, November 12, 2018).

Even the private goldsmith from Backa Topola notes 1974 as the "breakthrough year when Hungarian dissatisfaction with their status in Vojvodina and in Yugoslavia changed to general content given the newly acquired rights and privileges" (anonymous source, in discussion with author, November 14, 2018). The former chief ambulance driver in Backa Topola further elaborates on this newfound collective content in 1974 arguing that "we Hungarians finally felt like we were home. Like we were in our country...like the Hungarians in Hungary" (anonymous source, in discussion with author, November 19, 2018). This idea that the Hungarian community in Vojvodina was increasingly voluntarily associating with Yugoslavia during these "special years" is echoed by the former diocesan bishop of the Roman Catholic Church for the North Backa jurisdiction (anonymous source, in discussion with author, November 10, 2018). This subject goes even further by claiming that:

"Hungarians in Vojvodina had a moral obligation and responsibility to the Yugoslavia of the 1970's. It is true that the Yugoslav communists looked rather unfavorably on me as a religious leader, but I must also say that they respected me as a human - as a minority and a religious scholar. I never experienced such respect and professionalism as in those times. Thus, I can proudly say I am a Yugoslav Hungarian.” (anonymous source, in discussion with author, November $10,2018)$ 
Despite enormous gains in rights and privileges that the adoption of these two seminal documents ensured, the gap between nations and nationalities arguably became more pronounced than ever. Specifically, less self-determination was afforded to narodnosti than to narodi. The Protestant priest addresses this directly, claiming that events that precipitated in 1974

"gave our community a false sense of security and inclusion. The reality was very different. During this time the Hungarian community in Vojvodina lost its identity, willingly embracing this illusionary Yugoslav identity for a brief moment. We did not really gain anything tangible. But we did not realize this at the time. Instead, we were lulled by economic prosperity into believing we were equal because we could afford a comfortable life" (anonymous source, in discussion with author, November 14, 2018)

Such a sentiment may hold significance given that one electrician from Vojvodina argues that "all this talk of autonomy (territorial or cultural) achieved in 1974 was as irrelevant then as it is now. The economic prosperity that was achieved then is the only real sign of equality for all nations and nationalities. Everything is about money" (anonymous source, in discussion with author, November 12, 2018).

The 1974 Constitution of the SFRJ and the following 1974 Constitution of the Socialist Autonomous Province of Vojvodina introduced a host of changes that fortified territorial autonomy for Vojvodina, and reaffirmed cultural autonomy for the Hungarian community specifically. Once again, a noticeable shift occurred in which it seemed that decentralization had trumped reactive state centralization at the expense of halting Serbian-domination on the question of Vojvodina's status. Extending collective rights, 
widening cultural autonomy, and solidifying non-territorial self-determination seemingly affirmed Vojvodina's nationally pluralistic identity. The Hungarian community in Vojvodina welcomed these advancements even though it once again broke with policy continuity on issues of autonomy. By allowing for cultural autonomy instead of simply hollow territorial autonomy, interethnic relations between Serbs and Hungarians improved. It seems that it was generally recognized that territorial autonomy, in the volatile manner in which it had been implemented, was not solving the nationalities question. Thus, territorial autonomy, made possible by rampant decentralization, enveloped and fortified a cultural autonomy which was more directly geared towards the Hungarian minority. In the process, even the most ardent critics would acknowledge that the Hungarian community at least gained the illusion of inclusion and equality, if nothing more. Sadly, such progress in interethnic relations was short-lived and was yet again reversed by renewed state centralization.

\section{Vojvodina's Status During the Milosevic Era}

What progress in interethnic relations was made in 1974 through the tool of Vojvodinian territorial autonomy and national cultural autonomy for the nationalities came to an abrupt halt with Slobodan Milosevic's rise to power in the Socialist Republic of Serbia. The rise of ethno-nationalist sentiment across the SFRJ, coupled with increasing institutional constraints, unearthed the desire to create ethnically-based, independent nation-states and thus spelled the end of the multinational federation. Vojvodina's autonomy clashed with the idea of a Serbian unitary nation-state. Arguably, "the ideology of nationalism as the dominant legitimation matrix in Serbia, with the 
nation as an organic category has never reconciled itself with Autonomous Vojvodina, holding that this implies separatism and splitting the unity of the nation, and sparing no effort to suppress such an alternative" (Beslin, 2017, p. 341). ${ }^{10} 11$ To this end, some critics argue that Serbian nationalist hardliners made every effort to reduce and then subsequently abolish Vojvodina's territorial autonomy as quickly as possible. Others contend, however, that abolishing Vojvodina's autonomy cannot be attributed to rising Serbian nationalist sentiments but rather to a rational policy planning that operated within new institutional parameters caused by the dissolution of the federation that justified centralization on purely economic grounds.

Whatever the case, it is clear that Milosevic's rise to power did change the status quo of autonomy in Vojvodina in tangible ways. What advances were made in the realm of minority protection in Vojvodina were swiftly reversed, mostly due to a rising trend and, arguably, a need for, greater centralization. This centralization eroded the institutional mechanisms that could prevent the dissolution of Vojvodinian autonomy and guard against the destruction of the previously established minority rights system. In an act of political maneuvering, President Milosevic deemed it best to suspend seats for both SAP Vojvodina and SAP Kosovo in the rotating collective SFRJ Presidency in order to ensure a stable majority in the already ethnically polarized governing body. Such "elimination of Vojvodina's political ruling top from the League of Communists of

\footnotetext{
${ }^{10}$ See also Dosije Autonomna Pokrajina Vojvodina in which Cedomir Antic offers an alternative perspective on the clash between Vojvodina's autonomy and supposed Serbian nationalism. Providing a historical analysis of Vojvodina's political developments, Antic concludes that that the autonomous status that was granted Vojvodina was not the reflection of the "democratic will of its people...nor the consequence of a unique [historical or cultural] tradition" (Antic, 2014, p. 65).

${ }^{11}$ See also Autonomija Vojvodine: Srpsko Pitanje in which Cedomir Popov and Jelena Popov present an alternative view of Vojvodina as a historically Serbian space.
} 
Yugoslavia [SKJ] implied the discrediting and the beginning of a complete delegitimization of the socialist-era approach to the national question" (Tolvaisis, 2012, p. 66). The manner in which Vojvodina's disobedient leaders were attacked and disposed of was truly astonishing. The daily narrative fed to the public was that Vojvodina's autonomy, as it stood, was moving towards state separatism.

In 1988 and 1989 anti-bureaucratic revolution gripped the republic in a political crisis and prompted mass protests on the streets of Novi Sad. Following this colloquiallynamed "Yogurt Revolution", Milosevic's government was able to pass a series of amendments to the 1989 Constitution of the Republic of Serbia that "de facto suspended Vojvodina's autonomy" (Djukanovic, 2016, p. 56). Protests erupted against the provincial government's alleged bureaucratic inefficiencies, which were supposedly undermining Serbia's position as well as Belgrade's ability to pass laws and enact policies across its entire territory, including its two provinces. When more repressive measures failed, the communist provincial leadership switched tactics and sought to appease protestors on the streets of Novi Sad by offering them bread and yogurt—hence the name "yogurt revolution." However, all efforts at political compromise were futile and Vojvodina's provincial leadership eventually collectively resigned.

While President Milosevic's maneuver was welcomed at the time, such a move put Vojvodina in legal limbo, since its autonomy was still recognized by the superseded federal Constitution of 1974. However, the newly adopted 1990 Constitution of the Republic of Serbia effectively suspended/abolished Vojvodina's status as an entity/subject of the disintegrating Yugoslav federation, and returned it back to Serbia. Renaming it once again AP Vojvodina, all that was left of the region's autonomy was a 
hollow shell. Given the very limited self-governing authorities granted to the Autonomous Province of Vojvodina, it can only be considered nominally autonomous during this period of increasing Serbian state centralization. What is important to note is the drastic policy reversal that was about to take place regarding Vojvodina's territorial autonomy, and the subsequent disintegration of advancements towards Hungarian cultural autonomy as a result of this centralization.

\section{Vojvodina's Status Suspended Under the 1991 Statute of AP Vojvodina}

Autonomy for Vojvodina and the protection of minority rights reached new lows with the adoption of 1991 Statute of the Autonomous Province of Vojvodina - a statute which may represent the apex of Serbian state centrism. Even though this new statute still upheld AP Vojvodina's authority over minorities' cultural affairs, official use of language (Article 6), education (Article 13), and public media service (Article 15), it effectively stripped away the province's legislative authority (Statute AP Vojvodina of 1991). Still, the 1991 Statute did declare the equality of all people in the Autonomous Province of Vojvodina regardless of "national identity" (Article 4, Statute AP Vojvodina of 1991). However, problems persisted given that "legislation of the Federal Republic of Yugoslavia (FRJ) and Serbia neither had a legal definition of national minorities or nationalities, nor specified them. Neither the FRJ nor Serbia had special laws on national minority rights protection; this sphere was regulated by a series of other laws applied to respective spheres" (Tolvaisis, 2012, p. 68). This meant that while existing laws prohibited discrimination and allowed national minorities to politically organize and nominate candidates for elections, there were still no laws that protected the proportional 
representation of minorities (Samardzic, 1999). National minorities, especially the Hungarians in Vojvodina, were always in a politically weaker position to the Serb majority, and faced systematic discrimination during this volatile time. Political emancipation, if it can even be called that, did not translate into social emancipation for the Hungarian community in Vojvodina. Given such cumulative, repressive measures, autonomy in all forms took a giant step backward during this time, and once again forced this community into a state of turmoil and uncertainty.

\section{Hungarian Ethnonational Mobilization in the 1990s}

Given the unfolding volatile political climate in which the Hungarian community in Vojvodina found themselves, the old dormant dynamic of interethnic relations in the province was quickly reestablished. This climate was characterized by an alarming setback in the minority protection regime previously afforded in socialist Vojvodina in no small part due to the limiting of Vojvodina's autonomy. The previous model of national cultural autonomy that was afforded the ethnic Hungarians became the basis for an ethnic Hungarian mobilization now characterized by isolationism. The Protestant priest contends that the turmoil of the 1990s was a "blessing amid tragedy given that it served to reignite Hungarian national consciousness. The Hungarian community in Vojvodina was shaken by Serbian nationalism and naturally wanted to defend its own national identity" (anonymous source, in discussion with author, November 14, 2018). Ironically, the spirit of collective action championed by the multicultural policies of the former Yugoslavia were now being utilized by the Hungarian community in Vojvodina for the creation of their very own Vojvodinian Hungarian political party, Vojvodina Hungarians 
Democratic Community (VMDK), led at the time by Agoston Andras. At its core, the VMDK was the first sign of a real, organized ethno-political mobilization effort by the Hungarian community in Vojvodina. The creation of this party is especially important for understanding the evolving dynamic of interethnic relations, since "relative deprivation experienced by the Hungarian population of Vojvodina with the reduction of Vojvodina's autonomy served as a legitimization of the VMDK's demands for Hungarian autonomy" (Tolvaisis, 2012, p. 67). In this sense, the VMDK became the representative of the Vojvodinian Hungarian community, campaigning on a platform of reformulating the minority autonomy discourse under new conditions. During the early 1990s, the Hungarian community in Vojvodina vocalized its discontent with its position in the state and vocalized its perception of ethnically-based inequality (Ilic \& Cvejic, 1997, p. 171).

\section{Vojvodinian Territorial Autonomy Versus Hungarian Cultural Autonomy}

With the destruction of the multicultural policies of the former SFRJ, the VMDK began pushing for Hungarian minority cultural autonomy specifically. Vojvodinian Hungarians clearly stressed the issue of ethnic autonomous status apart from the issue of broader Vojvodinian territorial autonomy — a clear sign that this community was drifting further and further away from the majority and that it was no longer interested in engaging with the dominant group. As early as 1992, the Hungarian political elite in Vojvodina developed a concept of autonomy, adopted by the VMDK, which focused entirely on minority cultural, political, and territorial autonomy. This specific platform propagating ethnic Hungarian territorial autonomy went further in terms of rights and duties afforded nationalities in the 1974 SFRJ Constitution by solely and specifically 
focusing on the status of ethnic Hungarians within territorial parameters. Later referring to it as "territorial autonomy under the national principle," this program sought to include Hungarians residing in seven municipalities exclusively - Subotica, Mali Idjos, Senta, Becej, Backa Topola, Kanjiza, and Ada (Laketic, 2008). The following map illustrates the envisioned demarcations of ethnic Hungarian territorial autonomy within the context of a broader ethnic map of Vojvodina.

Figure 5. Map of proposed Hungarian territorial autonomy ${ }^{12}$

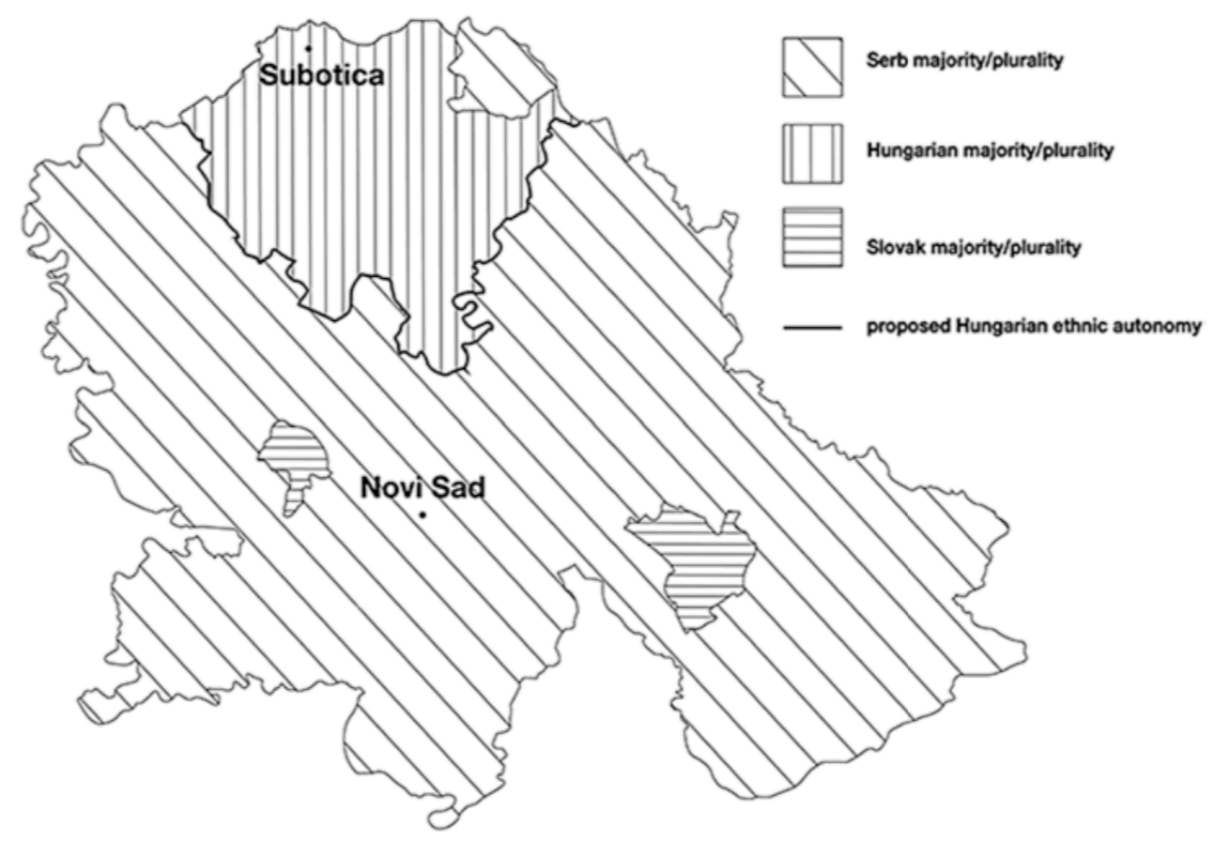

${ }^{12}$ Note. From "Multiethnic Regionalisms in Southeastern Europe: Statehood Alternatives," by D. Stjepanovic, 2018, Palgrave Macmillan, p. 152. Copyright 2018 by copyright Holder. Reprinted with permission. 
The extent to which the Hungarian community in Vojvodina sought to selfseparate from the dominant group and from Vojvodinian affairs is further illustrated by the fact that the VMDK did not engage with the autonomist parties that were gradually establishing themselves in the province. The Multinational Democratic Front of Vojvodina (SDFV), the League of Social Democrats of Vojvodina (LSV), and the Reformists of Vojvodina all developed political platforms that focused entirely on restoring full autonomy (legislative, executive, and judiciary) to Vojvodina within a very territorial framework. These autonomist parties presupposed unity based on common economic, cultural, and social interests shared among all citizens of Vojvodina. They believed that a plural, if not multicultural, Vojvodina could identify with the region primarily, and only then with their own ethnonationality. Such a view harkened back to past Yugoslav sentiments celebrating "coexistence and tolerance between communities," and reiterated the idea that a pluralistic, supranational national identity could form the basis of Vojvodinian autonomy (Stjepanovic, 2018, p. 153). However, the Hungarian community in Vojvodina did not embrace such a renewed supranational autonomist idea, and hence did not associate with these parties, deeming that their Hungarian territorial autonomy under the national principle was increasingly incompatible with a broad platform for a Vojvodinian territorial autonomy that was multiethnic in character. "The ethno-national and cultural dimension of legitimation of Vojvodina's autonomy presented an opportunity structure for the institutionalization of collective political and cultural rights of Hungarians and other national minorities in Vojvodina, as this vision created a ground for the political alliance structure of Vojvodinian Hungarians" (Tolvaisis, 2012, p. 72). Given this attitude, it comes as no surprise that the Hungarians in Vojvodina even 
distanced themselves from the controversial 1991 Memorandum Concerning Vojvodinian Autonomy which was developed by the autonomist parties for the purpose of raising international awareness about the precarious situation in Vojvodina during the Milosevic era (Djukanovic, 2016, p. 57). Hungarian constraint was even more apparent when the radical idea of complete sovereignty for Vojvodina, propagated by the slogan "Republic of Vojvodina," was proposed by the LSV. Choosing to disassociate from Vojvodina and wholly focus on and prioritize ethnic interests was the default option for the Hungarian community in Vojvodina during this time. Ultimately, ethno-territorial homogenization was key for the Hungarian community's survival in the province. As the wealthy landowner from Stara Moravica concludes: "all these autonomist parties are Serbian in character; pushing Serbian interests. There is always a couple of urbanite Hungarians who were and still are manipulated into believing these parties' ideologies but these are very rare" (anonymous source, in discussion with author, November 19, 2018).

\section{Constraints of the 1991 Statue of AP Vojvodina}

The 1990s was certainly a dire time for interethnic relations in Vojvodina. As one retried Hungarian football club manager argues: "everything that happened here during that time was analyzed through the ethnic lens...If you won a [football] game the Serbs would say that is the Hungarians preparing for war...This was the 'Wild West' in legal terms. Laws were dead letters on paper" (anonymous source, in discussion with author, November 7, 2018). Even though the 1991 Statute did afford the Hungarians ethnic equality in the sphere of education, the reality, at least from the perspective of this minority, was quite different. Very few Hungarians in Vojvodina believed that ethnic 
equality existed in the sphere of education (Ilic \& Cvejic, 1997, p. 181). The situation was no better regarding the equality of languages. The 1991 Law on Official Use of Language and Alphabet was much more restrictive than the 1976 Law on Publication of Federal Regulations. The 1990 Constitution of the Republic of Serbia declared SerboCroatian the official language and stipulated that minority languages are recognized and employed only in localities where those nationalities are more populous. The 1991 law was so restrictive that it did not even consider the publication of legal regulations in minority languages. During this period, the right to officially use Hungarian in public institutions, even in municipalities where they constituted a majority, rapidly declined. This was partially due to the fact that the ethno-national approach to personnel policy in the public administration sector had been abandoned leading to extreme underrepresentation of Hungarians in the police, judiciary, and other public enterprises even in the municipalities where they constituted the absolute majority.

The situation in regards to the minority's cultural life and media was also noticeably in decline. Much of this had to do with the dire economic situation in the country, especially during the years of international sanctions, which devastated the state. Independent minority news outlets did not exist, partly the effect of limited market demand coupled with an economically weak purchasing base of the minority (Samardzic, 1999). The two Hungarian language newspapers that did exist, Magyar Szo and Het Nap, were established by the Assembly of Vojvodina and therefore under the control of the state (Manic, 2011, p. 358). As such, it is no surprise that this, as well as other aspects of the cultural life of the Hungarian community in Vojvodina, was sorely lacking during this time, stifled by extreme state centrism. However, during this difficult period the 
institutional structures of Vojvodinian Hungarians were strengthened as a response to the increased desire for isolation and insulation from the dominant Serb society. Common hardship served as a catalyst uniting the Hungarian community in Vojvodina for defensive/protective purposes during the 1990s. During this time, the Vojvodina Hungarian Cultural Union was founded, which acted as an institutional protector of Vojvodinian Hungarian culture against perceived threats from the dominant group.

\section{Vojvodina in the Present}

Ethnic Territorial Autonomy Versus Cultural Autonomy Amid Democratic Upheaval

With the ousting of Milosevic's government in 2000, the Hungarians in Vojvodina found themselves in a new political climate yet again. Democratic changes triggered a host of dormant issues just waiting to precipitate and almost immediately instigated competing political interests in Vojvodina. "The reduction of Vojvodina's autonomy proved to be a key historical juncture that contributed to shaping significant dimensions of political cleavages, organized into political parties acting both on the provincial and the national level (Tolvaisis, 2012, p. 71). For the Hungarian community in Vojvodina, specifically, their reformed new vision for autonomy initially encompassed three interconnected elements: "territorial autonomy for Vojvodina, non-territorial autonomy for Hungarians living scattered in Serbia and territorial autonomy for the Hungarians concentrated in Northern Backa” (Beretka \& Szekely, 2016, p. 8).

Disenchanted with Serbian backtracking on policy linking minority issues with Vojvodinian territorial autonomy, the more popular Hungarian political elite in 
Vojvodina quickly settled for achieving cultural autonomy for their community, even though they still pushed for ethnic Hungarian territorial autonomy. Because of this refocus on ethnic Hungarian territorial autonomy (territorial autonomy under the national principle) the Alliance of Vojvodina Hungarians (VMSZ) split form the VMDK, becoming the biggest and most important ethnic Hungarian party in Serbia. The VMSZ immediately re-centered its policy platform to pursue the more realistic target of achieving substantial progress on minority non-territorial cultural autonomy for the Hungarian community in Vojvodina. The former chief ambulance driver in Backa Topola is clear on this subject; "cultural autonomy is the only realistic option for Hungarians in Vojvodina. We all want more. More would be good for interethnic relations. But the Serbs will never give us more" (anonymous source, in discussion with author, November 19, 2018). The 2000 regime change surely brought somewhat favorable conditions for the realization of this "realistic" goal, as the Serbian majority now deemed Hungarian cultural autonomy more palatable than ever before.

\section{Victory for Hungarian Cultural Autonomy in Vojvodina}

Possibly as a result of a genuine intrinsic change in political attitudes, or perhaps as an instrumental appeasement strategy for the purpose of forming alliances and creating a stable government, the early 2000s witnessed an increased acceptance of minority cultural autonomy from the dominant Serb political establishment. This resulted in the "gradual institutionalization of national minority rights protection on both the republican and provincial levels; the most important being the establishment of national councils of national minorities" (Tolvaisis, 2012, p. 72). The precursor to this was the passing of the 
Law on Local Self-Government and the Law on Establishing Jurisdiction of the Autonomous Province of Vojvodina (Omnibus Law) that re-vested the province with over 200 competencies ranging from culture (Article 41), to education (Article 38), to official use of languages (Article 76) and management of public media (Article 62) (Law on Establishing Jurisdiction of the Autonomous Province of Vojvodina of 2002). On the surface, this 2002 Omnibus Law represented a drastic improvement in circumstances for the Hungarian community in Vojvodina. Most importantly, the Omnibus Law stipulated adequate representation of Hungarians in provincial institutions, liberalized education programs for minority languages, proliferated official use of minority languages in municipalities where Hungarians constituted a majority (even to the point that court hearings were now held in Hungarian rather than Serbian), and established the office of Provincial Ombudsman as an independent institution overlooking the protection of human rights through the work of provincial and municipal institutions. However, the Law did not pursue systematic changes linking minority rights protection and minority cultural autonomy with the equally pressing issue of Vojvodinian territorial autonomy.

The complimentary Law on the Protection of Rights and Freedoms of National Minorities, adopted in 2002, was one of the first pieces of legislation that upheld the basic rights of minorities while also addressing the issue of minority cultural autonomy through the creation of national councils as representative bodies in the fields of education, culture, media, and the official use of language. Essentially, the "law recognized the councils as a form of autonomy, as a collective right, and rendered possible to enforce this right in practice through the election of the national minority councils" (Beretka \& Szekely, 2016, p. 9). However, the legitimacy of these councils was 
questioned from the very beginning. Neither the state nor the Hungarians in Vojvodina recognized the initial council as the legitimate representative of the community as a whole. This was partly due to the indirect election procedure for the council, and partly due to the fact that the legal competences bestowed on this body were not clearly defined. Despite its shortcomings, however, the creation of the national council for the Hungarians in Vojvodina was the first official step in achieving cultural autonomy.

Vojvodina and the 2006 Constitution of the Republic of Serbia-National or Civic?

Despite relative gains in the legislative sphere for minority cultural autonomy, the adoption of the current Constitution of the Republic of Serbia from 2006 reflects a weak compromise that resulted, yet again, in the granting of a "facade autonomy" to Vojvodina (Komsic, 2015, p. 83). Once again, policy reversal and lack of continuity define current discourse concerning Vojvodina's autonomy. In reality, the 2006 Constitution of the Republic of Serbia is the perfect example of an ethnonational constitutive act that defines the Republic of Serbia as "state of the Serbian people and all citizens who live in it, based on the rule of law and social justice, principles of civil democracy, human and minority rights and freedoms, and commitment to European principles and values" (Constitution of the Republic of Serbia of 2006, Article 1). As can be interpreted from this article, the status of the Hungarian community in Vojvodina is set apart from the dominant Serb group as the rightful "owners" of the state. Moreover, AP Vojvodina is not further fortified as a constitutional category in this document. This is clear in Article 12, which states that: "State power is restricted by the right of citizens to provincial autonomy and 
local self-government. The right of citizens to provincial autonomy and local selfgovernment shall be subjected only to supervision of constitutionality and legality" (Constitution of the Republic of Serbia of 2006). The main challenge with the 2006 Constitution of the Republic of Serbia, however, is that it does not go far enough in restoring the level of provincial autonomy granted by the 1974 SFRJ Constitution, and is more restrictive in its granting of legislative, executive, and judicial authorities to the province (Constitution of the Republic of Serbia of 2006, Articles 176-193). This stands in contrast to Kosovo, which was granted substantive autonomy, while only hollow territorial autonomy is granted to Vojvodina (Djukanovic, 2015, p. 5).

\section{Law on National Councils of National Minorities}

The 2006 Constitution of the Republic of Serbia reignited a national-civic cleavage which carried over to debates concerning the adoption of the 2009 Statute of the Autonomous Province of Vojvodina. This was expected, given the omnipresent conflict between two conceptions of the province: monoethnic and Serbian-dominated versus nationally-pluralistic and, ultimately, supranational. At this time, however, the notion of minority cultural autonomy was also gaining momentum. The Law on National Councils of National Minorities, passed in 2009, is a seminal piece of legislation that specifically addresses minority issues, finally fortifying the right to minority cultural autonomy. The law was passed thanks to the persistence of the VMSZ, which aligned itself with this concept of non-territorial cultural autonomy. This all-encompassing legislation, reaffirming the right of every national minority to elect a national council, is considered an important institutional safeguard to protect minorities. 


\section{Establishment of the National Council of the Hungarian National Minority}

The 2009 Law on National Councils, which builds on the 2002 Law on the Protection of Rights and Freedoms of National Minorities, offers much-needed specificity in defining council competencies and corrects some of the election procedures which plagued the legitimacy of the initial councils and impeded their function (i.e. election through secret ballot). The "Law on National Councils of National Minorities largely corresponded to the Common Concept of National Autonomy of Vojvodina Hungarian Parties, as nearly all the demands of the Hungarian parties regarding cultural autonomy found their expression in the provisions of the law" (Tolvaisis, 2012, p. 76). This means that the established National Council of the Hungarian National Minority (MNT) now gained input into the development of the Hungarian minority education program for public schools (Articles 12-15), control over Hungarian language media in the province (Articles 19-21), implementation of Hungarian as official language in the public arena (Article 22), oversight over Hungarian cultural affairs (Article 18), and even a measure of influence in various republican and provincial institutions (Articles 25-26) (Law on National Councils of National Minorities of 2009).

Despite increased legal competences and duties, there remain a number of problems which inhibit the MNT from functioning to its full extent. The Serbian majority constantly undermines the MNT in all areas of functioning, leading the president of the council, Dr. Tamas Korhecz, to conclude that "in the field of minority protection in Serbia "the practice of one step forward - one step backward" still prevails (HNMC, 2014). Apart from a lack of follow-through on state funding for the MNT reported by some respondents, the local municipality official also argues that "members' hands are 
tied on important issues." Taking the example of official Hungarian language use in the public arena: "the Council needs Belgrade's approval for all major decisionmaking...Even for banal things like the renaming of streets after Hungarian historical figures, the process always takes too long" (anonymous source, in discussion with author, November 12, 2018). The director of a mental care facility in Vojvodina elaborates on this point, arguing that "many times important information is not shared with the Council. We are asked about the small things, but Belgrade excludes the body from major decisions that concern our community... Their discretionary powers can overturn the initiatives and decisions made by the Council that they deem to run contrary to state interests" (anonymous source, in discussion with author, November 12, 2018). Ultimately, what both of these respondents allude to is a legacy of centralization to Belgrade that characterizes dealings with the National Council of the Hungarian National Minority. Once again, we see policy reversal on issues of autonomy, in this case cultural autonomy, which should ensure the protection of minority rights for the Hungarians. Serbian legal provisions, although progressive on paper, are not enough without adequate follow-through; the laws themselves are quite comprehensive, yet implementation remains problematic.

Primary data indicate that the Hungarian community in Vojvodina places very low importance on the role of the National Council of the Hungarian National Minority in preserving their national identity. Amidst the 2018 national council elections, the majority of Hungarian interviewees stated that they did not even vote. Secondary data indicate that only 47,316 out of an eligible 129,471 Hungarians in Vojvodina actually went to the polls on November 4, 2018 (Republicka Izborna Komisija, 2018; Beta, 2018); 
overall, Hungarian voter turnout for 2018 MNT elections was a mere 36\% (Zoric, 2018). When pressed on the reasons for their lack of political participation, the majority of subjects either claimed that the "council is a platform for pursuing personal interests, like everything else here" or that this institution is yet another "façade for VMSZ legitimacy as the collective voice for the Hungarians in Vojvodina" (anonymous sources, in discussion with author, November 12/12, 2018). However, a few respondents were fervent supporters of the MNT. These interviewees, like the private entrepreneur from Novi Sad, argues that the "council keeps us together. It is the very institution that makes us a community. Hungarians here are perpetually unhappy with the work of the council only because they are uninformed about the role and responsibilities of this body" (anonymous source, in discussion with author, November 24, 2018). The Calvinist priest even argues that this institution is important for "promoting parliamentarism among the Hungarian community in Vojvodina" (anonymous source, in discussion with author, November 14, 2018). However, the wealthy landowner from Stara Moravica vehemently disagrees with this position, as demonstrated by his claim that:

"The council is circumscribed by the Serbian government. It is surely Serbian directed when it does not include the whole spectrum of Hungarian minority parties, especially the VMDK, and allows solely VMSZ party interests to be pursued which plays into Serbian President Vucic's interests. All those claiming that it promotes parliamentarism are disillusioned puppets." (anonymous source, in discussion with author, November 19, 2018)

Whether this is the case is disputable, at best. What is intriguing, however, is that nearly all respondents participating in this inquiry assert that the MNT promotes "a distinctly 
Hungarian culture and identity" (anonymous source, in discussion with author, November $14,2018)$. One local municipality official contends that this is logical, given that the "Hungarian government is a co-financier of this council" (anonymous source, in discussion with author, November 12, 2018). Whether respondents would feel differently about the work of the MNT if they perceived this body was more attuned to the cultural preservation problems that the local community faces is beyond the scope of this research, but is worthy of further exploration. The private goldsmith from Backa Topola seems to imply that the council "needs to more directly address the issues the Hungarians in Vojvodina face, rather than more abstract unrealistic ideas" (anonymous source, in discussion with author, November 14, 2018). On the other hand, the Hungarian community in Vojvodina needs to be better versed in the workings and responsibilities of their council - their lack of knowledge on the subject seems to be a systematic problem. The interviews clearly highlight this issue, as symbolically indicated by the response of the retired industrial metallurgy worker originally from Pacir who frankly states that she has "no clue what this council is. Are you talking about the VMSZ?" (anonymous source, in discussion with author, November 14, 2018).

Vojvodina and the 2009 and 2014 Statutes of AP Vojvodina

Finally, the adoption of the 2009 Statute of the Autonomous Province of Vojvodina and the subsequent 2014 Statute of the Autonomous Province of Vojvodina have also had mixed results in clarifying the issue of autonomy for Vojvodina and its link with Hungarian cultural autonomy and minority rights protection. In regards to Vojvodinian autonomy, the 2009 Statute of AP Vojvodina still does not go as far as the 
1974 SFRJ Constitution, since it does not address the issue of AP Vojvodina's fiscal autonomy and budget control nor the question of its property ownership. It also limits the province's capacity to establish regional and international agreements of cooperation (Djukanovic, 2016, pp. 62-63). Moreover, it asserts that "AP Vojvodina is an inseparable part of the Republic of Serbia" (Statute AP Vojvodina of 2009, Article 1). At the same time, the 2009 Statute does make advances in terms of the implementation of minority rights protection in Vojvodina - a welcome change to the 2006 Constitution of the Republic of Serbia. First, this document replaces the term "national minorities" with "numerically smaller national communities" in order to do away with the pejorative reference that "minority" connotes in Eastern Europe. More specifically, this article reaffirms the national equality of "Serbs, Hungarians, Slovaks, Croats, Montenegrins, Romanians, Roma, Bunjevci, Ruthenians, Macedonians, as well as other numerically smaller national communities" (Statute AP Vojvodina of 2009, Article 6). In addition to reaffirming the equal status of Hungarian (and other minority languages) for official use, this document also upholds the principle of proportional representation in provincial bodies and institutions. Finally, and of critical importance, this 2009 Statute of AP Vojvodina establishes the Council of National Communities, which cooperates with and advises national councils (specifically the MNT for the Hungarians) on issues of minority rights. The merit of this Council of National Communities is to further solidify the institutionalization of minority rights protection in Vojvodina and broaden minority integration. However, the fact that half of the representatives of the Council of National Communities are chosen by the dominant group has been criticized by some as unfavorable to building lasting partnerships with the national councils like the Hungarian 
MNT. Still, in legal terms, this statute does seek to uphold new values of multiculturalism in Vojvodina, calling on provincial organizations and institutions to promote interethnic communication and respect (Statute AP Vojvodina of 2009, Article 7).

Yet again, however, a reversal in what little advancements have been made with the 2009 Statute of the Autonomous Province of Vojvodina quickly surfaced. A 2009 ruling of the Constitutional Court of Serbia brought into question Article 4 of the Statute, which proclaims that the "holders of the right to autonomy of AP Vojvodina are its citizens" (Statute AP Vojvodina of 2009, Article 7). The controversial ruling finds that "AP Vojvodina has not been created by its citizens but by the Constitution of the Republic of Serbia" and therefore nullifies this article (Ustavni sud Republike Srbije, 2013). Such a decision by the Constitutional Court of Serbia not only reemphasizes the continuing tradition of state centralization in reaction to the question of Vojvodinian autonomy, but also fortifies the overarching conception of "Serbia as an ethnonational state whose institutions do not recognize the regional and multicultural specificities of its citizens in its autonomous provinces" (Komsic, 2016, p. 39). Consistent with the Constitutional Court's ruling, therefore, this particular retrenchment on the issue of autonomy has been solidified by the current 2014 Statute of the Autonomous Province of Vojvodina which is simply a revised version of the 2009 Statute. The fact remains, however, that the "subtle" revisions included in the current 2014 Statute of the Autonomous Province of Vojvodina now delicately renege on Vojvodina's autonomous capacities by a continuous declarative referral to "conformity with the [Serbian] Constitution" (Statute AP Vojvodina of 2014, Articles 3-4). Hence, the legacy of taking one step forward and one step backward on issues concerning autonomy in Vojvodina 
continues, carrying complex repercussions for the current interethnic relation outcome of parallelism for the Hungarians, as will be assessed in the following chapter. 


\section{Chapter V - Current Reflections on Vojvodinian Territorial and Cultural}

\section{Autonomy}

Despite renewed advancements in the realm of minority rights protection, the question of Vojvodina's autonomy remains extremely complicated. Even today the legal status of Vojvodina is not completely clear, possibly also the result of lacking policy continuity that has led to legal confusion. "The state structure of Serbia can be best described as asymmetrically decentralized...Serbia remains a unitary state with a unitary legal system" (Beretka \& Szekely, 2016, p. 6). The question of territorial autonomy has been addressed and readdressed numerous times in Vojvodina's history. Decentralization and self-government through self-management, characterized by advancements and broadening of competencies and duties to Vojvodina's provincial institutions, has always been followed by extensive repression and reactive state centralization.

The countless cyclical reversal of policy related to Vojvodina's territorial autonomy has bred instability. At the same time, using territorial autonomy to resolve underlying non-territorial issues in Vojvodina (specifically, complex interethnic relations in the province), has resulted in further confusion, if not utter failure. Paradoxically, it seems as though addressing the national question directly in Vojvodina has always been too polarizing, instead leading government after government to rely on the device of territorial, mostly administrative, autonomy to resolve the pressing issues indirectly. But the territorial, non-ethnic, variance of autonomy afforded Vojvodina only neglects the issues and is a breeding ground for ethno-national tendencies (Djukanovic, 2016, pp. 6465). Simply claiming that the administrative territorial autonomy afforded to Vojvodina at this time is sufficient, based on the idea of a supranational Vojvodinian citizenry, 
completely misunderstands the issue; after all, the current cultural autonomy pursued and relatively achieved by the Hungarian community implies the triumph of the ethnonational individual over the aspirational supranational citizen as the primary identifier in Vojvodina. It is cultural autonomy that specifically serves the ethnonational individual who seeks to preserve his/her national culture from the imposter, in the process enabling a defensive type of solidarity that regards culture as reserved insularly for "our" people and in need of protection from the foreign "other." In contrast, if the supranational citizen had ever triumphed in Vojvodina, cultural autonomy probably would not be on the agenda and hold such a high salience, since it would be arguably irrelevant.

Even more problematic, two competing conceptions of Vojvodina exist, without any resolution or compromise in sight. The monoethnic Serbian conception has dominated over the nationally pluralistic conception that heralds Vojvodina's supranational integration, despite repeated claims that the "existing autonomy arrangement [afforded Vojvodina] is not based on ethnic foundations" (Beretka \& Szekely, 2016, p. 4). Crucially, the debate concerning territorial autonomy has nearly always been headed by the dominant group, Serbs, instead of the national communities which the policy is actually intended to influence the most. Their intentional and, at times, unintentional exclusion from the discourse has shaped the Hungarian community's attitude and posturing. What started as a national irredentist movement to unite back with the maternal state, Hungary, has transitioned into a well-organized ethnonational political mobilization movement in Vojvodina. A supranational conception of Vojvodina has not succeeded. Amid all this back-and-forth and instability, the Hungarians in Vojvodina have arguably sought to self-exclude from the dominant group; they have settled for 
cultural autonomy that has, as its ultimate end, self-segregation from the dominant Serbs, expressed through a general display of apathy and indifference towards both Vojvodina's other national groups, and Vojvodina itself as a province.

Aspirations of ethnic territorial autonomy for the Hungarians in Vojvodina were never acceptable to the Serbs. However, the cultural autonomy that is currently offered the Hungarian community in Vojvodina means two very different things for the two groupings. For the Serbs, granting cultural autonomy to the Hungarian community in Vojvodina is congruent with its effort to uphold and institutionalize its minority rights protection program by fostering an atmosphere of trust and cooperation; cultural autonomy is deemed a reflection of their tolerance and progressiveness. For the Hungarians, however, cultural autonomy means partially realized self-separation from the dominant group, a state in which the community can interact with the larger society only as much as it deems necessary, having broad competencies and self-governing rights over a multitude of subjects.

In the middle of all this stands Vojvodinian territorial autonomy, which at times clashes with and, at other times, overlaps with the cultural autonomy granted to the Hungarians in the province. Territorial autonomy has, as its ultimate goal, the state's solidifying of its minority rights protection program; the fact that Vojvodina's provincial authorities lack full autonomy in the field of national minority rights is a case in point, highlighting the hollow nature of Vojvodina's autonomy. For the Hungarian community, this has, as its end, an attitude of apathy and uncertainty resulting from the volatility and constant reversal on issues of territorial and non-territorial autonomy with which Vojvodina is associated. 
Interviews clearly indicate current attitudes of indignation mixed with apathy as regards to the topic of autonomy, both of the territorial and non-territorial variety. A private entrepreneur from Novi Sad sums it up best, stating that, "while it is true there are never enough rights, at least when the minority is concerned, certain problems persist and violations are repeated; one such area is surely the question of autonomy" (anonymous source, in discussion with author, November 24, 2018).

What this respondent conveyed in his interview is that there is a general EU trend towards granting more rights to minorities, a trend also influencing Serbian authorities; while some changes are warranted, others, sadly, are not, and are clearly part of an ulterior Western agenda. The interviewee feels that maximizing rights is generally positive for the Hungarian community in Vojvodina, but some "rights movements going on here are simply decadent," and the constant dissatisfaction some members express "undermines the collective agenda and only proves us weak in the face of those in power" (anonymous source, in discussion with author, November 24, 2018).

In the midst of all these confusing rights issues, some extremely important rights are lost; the status quo forces use the confusion to manipulate important rights issues by bargaining with, or even granting less pressing rights, while important issues are not addressed and resolved. In the entrepreneur's assessment, the Serbian authorities are guilty of trying to divert attention from the subject of autonomy by immediately branding it a betrayal of the country, and secession. On many occasions, the government in Belgrade both sidelines the issue, diverting attention to the state of the economy, or to the necessary improvements in the area of rule of law, or points to the reinstatement of territorial autonomy for Vojvodina which has no real powers nor realistic effect on the 
lives and status of the minority. Hence, in his words, "autonomy in Vojvodina is an illusion" (anonymous source, in discussion with author, November 24, 2018).

\section{(Dis)Illusions Concerning Vojvodina's Territorial Autonomy}

With regard to the issue of Vojvodina's territorial autonomy, several respondents were not even aware that Vojvodina's territorial autonomy has been legally reinstated in 2006; even when shown proof of this legal fact, one truck driver from Vojvodina sarcastically remarks, "as with all things here, everything is dead words on paper. No law applies here. You can pass all the laws you want, but what does it matter when nobody adheres to them" (anonymous source, in discussion with author, November 7, 2018). The factory foreman goes even further in claiming that "real autonomy for Vojvodina does not exist; everything is going to Belgrade" (anonymous source, in discussion with author, November 7, 2018). Even the Hungarian dog obedience trainer from Vojvodina draws on this very same notion, arguing "decentralization that is offered Vojvodina is fictive. It may meet EU standards on paper, but the truth is that real autonomy for Vojvodina does not exist" (anonymous source, in discussion with author, November 14, 2018). In this regard, the retired industrial metallurgy worker originally from Pacir goes so far as to claim that "Vojvodina's autonomy is an appeasement tool presented by Belgrade to the EU. It makes the EU believe that Serbia is fulfilling EU standards...Maybe this autonomy is also supposed to appease us minorities here by offering us 'everything...' but, actually, nothing at all" (anonymous source, in discussion with author, November 14, 2018). 
What Belgrade's underlying motives truly are is difficult to assess (especially if ulterior reasoning does, in fact, exist), but the notion that territorial autonomy granted to Vojvodina is a hollow shell, which only serves as an appeasement strategy used by Serbia to satisfy EU strategic goals, is something numerous respondents alluded to in their interviews.

\section{Vojvodina's Territorial Autonomy Lacking Economic/Fiscal Autonomy}

When pressed on the reasons why subjects believe Vojvodina's territorial autonomy is non-existent, multiple respondents linked this belief with the lack of provincial economic autonomy. Some subjects effectively retorted with questions such as, “show me where Vojvodina's money is; where is 'our' money?” (anonymous sources, in discussion with author, November $7 / 24,2018$ ). One such participant, a painter by trade, claims that "we live in centralization, which is proven by the economic policy that is in place here" (anonymous source, in discussion with author, November 7, 2018). Astoundingly, 19 out of 23 subjects tied the discussion of Vojvodina's territorial autonomy with economic policy, specifically the lack of fiscal autonomy afforded to Vojvodina. Numerous respondents asserted that Vojvodina's territorial autonomy would only mean something if the province was granted complete control over its economyspecifically, fiscal policy and budget control. As one interviewee concludes:

"Real territorial autonomy must include economic autonomy. Money is the only tangible measure of territorial autonomy for this province. It is easy for Belgrade to claim it has granted Vojvodina autonomy while being careful to retain control over its coffers. Belgrade claims it cares for Vojvodina. This is great; but now 
give us back our money. Don't tell me how much you care. Show me by your money... without this provision, you can only conclude that we live in centralization." (anonymous source, in discussion with author, November 14, 2018)

The Protestant priest agrees that the reality of Vojvodina's territorial autonomy must be heavily dependent on the level of economic autonomy afforded to the province, specifically its fiscal independence. In this case, the lack of economic autonomy afforded to Vojvodina renders "territorial autonomy useless" (anonymous source, in discussion with author, November 14,2018). He, like so many Hungarians in his community, is dismayed that Belgrade does not allow people in Vojvodina control over their purses, and provided an interesting rendition of a Christian parable to illustrate his point:

"You are surely aware of Jesus' teaching - 'Render to Caesar the things that are Caesar's; and to God, the things that are God's...' On the surface of things, you could say that Belgrade's economic control over the citizens of Vojvodina imitates this teaching; but this is not the case. Belgrade's economic control inverts this teaching. Belgrade is Caesar, who takes everything from you; then it, by itself, decides how much to give back to you to give to God. In this process, the inhabitants in Vojvodina have no control over their wallets. It is like me taking all the money from my congregation and then telling them to willingly tithe." (anonymous source, in discussion with author, November 14, 2018)

This view leads the Protestant priest to conclude Vojvodina's territorial autonomy is merely nominal and means absolutely nothing to the Hungarian community. For many subjects in this study, therefore, political autonomy must be tied to economic autonomy 
for Vojvodina's status to be rendered meaningful and worthy of its label. Participants' perception of Belgrade's unwillingness to grant Vojvodina economic autonomy shapes an extremely negative view of autonomy, if not wholly denying its existence. The wealthy landowner from Stara Moravica sums up the sentiment best: "without money, autonomy means nothing" (anonymous source, in discussion with author, November 19, 2018). Unequivocally, for the Hungarian community, Vojvodina's political autonomy without economic autonomy is pointless according to the overwhelming majority of respondents participating in this study.

Yugonostalgia Concerning Vojvodina's Status as per the 1974 SFRJ Constitution

When discussing the province's territorial autonomy, a number of older participants in this inquiry reminisced about Vojvodina's status in 1974; all these respondents expressed positive views regarding Vojvodina's territorial autonomy as granted by the 1974 SFRJ Constitution. The Protestant priest argues that Vojvodina's status in 1974 represented the "pinnacle of respecting minority rights" (anonymous source, in discussion with author, November 14, 2018). While sharing his views on the matter, the retired Hungarian football club manager solemnly recognizes that no matter how good the status of the Hungarians was, "never again will we have what we had in 1974. That was a time when we Hungarians... all of the people had it better than anyone else. But, we Hungarians knew that it would not last long; Belgrade would not allow it. At the time, Vojvodina gained the status of a republic...a state, practically" (anonymous source, in discussion with author, November 7, 2018). More specifically, this interviewee touched on the idea of how fickle Yugoslav policy concerning autonomy apparently was, 
and how quickly and easily it was abolished when Belgrade deemed necessary. The painter is extremely emotional on the topic, making sure to stress several times how "Belgrade was so quick to destroy... regress on all the progress concerning Vojvodina's territorial autonomy in the 1970s" (anonymous source, in discussion with author, November 7, 2018). Noting the ease with which territorial autonomy was stripped away from Vojvodina, a dose of indignation could be perceived in several of these subjects; many simply gesticulated with their hand that the topic requires no further elaboration.

Pressed on the reasons for such a nostalgic outlook on Vojvodina's territorial autonomy as realized in 1974, the aforementioned subjects once again all reverted to the economic factor. The retired Hungarian football manager claims that the 1974 SFRJ Constitution is a perfect example of "political and economic autonomy functioning together for the betterment of Vojvodina and all the peoples that live here" (anonymous source, in discussion with author, November 7, 2018). One Hungarian painter is even more direct: "we lived better. We could go anywhere and buy anything. Who talked about interethnic relations then? We all had what we wanted and could get along or not get along with anyone...Money gave us individual independence" (anonymous source, in discussion with author, November 7, 2018). However, such a materialistic remark is not shared by all who addressed this topic. The mechanical engineer takes a more normative approach to the subject, assessing that what Vojvodina's status in 1974 realized was a "transition from mere tolerance to respect between the narodi and narodnosti that was sadly quickly revoked" (anonymous source, in discussion with author, November 10, 2018). Peculiarly, this was the only respondent who took a rather normative understanding of Vojvodina's territorial autonomy. 


\section{Vojvodinian Hungarian Cultural Autonomy as Community Identity Preservation}

Turning to the topic of non-territorial cultural autonomy for the Hungarian community in Vojvodina, 17 out of 23 respondents shared extremely favorable views on its implementation; all of these respondents claimed that cultural autonomy that was granted to the Hungarian community in Vojvodina in the early 2000s represents the most important factor in enabling the preservation of their collective, but distinct, Hungarian ethnonational identity. The local municipality official is clear on this topic when he states, "cultural autonomy for the Hungarians in Vojvodina is of paramount importance to the survival (opstanak) of our people here" (anonymous source, in discussion with author, November 12, 2018). As a founding member of the Hungarian minority party, VMSZ, this respondent described in detail both the logic behind this belief, and the prolonged political process that marred the struggle this party underwent to achieve cultural autonomy for the minority they represent. He assesses that the Hungarians in Vojvodina as a minority are in an

"undeniably unequal position compared to that of the Serbian majority, and that the system currently in place inevitably favors the Serbs at all times. This is probably the fortune of all minorities everywhere across the world. Hence, we had to work within that system and come up with solutions that would guarantee our survival here so as to become as independent and non-reliant on Serbia as possible, within the constraints that the government would allow." (anonymous source, in discussion with author, November 12, 2018)

This subject, like so many others in this inquiry, stressed how important the realization of cultural autonomy is for the Hungarians in Vojvodina with respect to nurturing their "true 
and distinct Hungarian cultural identity" (anonymous source, in discussion with author, November 7, 2018). Furthermore, the retired Hungarian football club manager specifically addresses the areas in which the realization of cultural autonomy for the Hungarian community in Vojvodina has had an overwhelmingly positive effect on this community. "Our ability to control our print and electronic media, monitor official Hungarian minority language use, and organize the education system for this Hungarian community is vital in preserving our identity and ultimately our survival in this area" (anonymous source, in discussion with author, November 7, 2018).

The Calvinist priest wholeheartedly agrees, stressing:

"The fact that we Hungarians control our education program, and are able to organize it in our native Hungarian mother-tongue, is of immeasurable value in preserving our identity. Thank God, we are witnessing a revival of Hungarian national identity here...Preserving our language is essential in teaching our younger generations to defend our identity. After all, identity cannot be chosen, you are born with it. Thus, it is imperative to defend your nation and your identity in order to come to terms with your being and realize yourself as an individual." (anonymous source, in discussion with author, November 14, 2018)

Despite overwhelmingly positive attitudes concerning Hungarian cultural autonomy among members of this ethnonational community in Vojvodina, there also seems to be a dose of concealed discontent and indignation associated with this topic. Upon probing deeper into the subject of cultural autonomy, several respondents offered a view that alluded to what can best be described as maximining - resourcefully trying to do the best with the maximum they have achieved. In this regard, the private entrepreneur 
from Novi Sad claims that "the reality is that cultural autonomy has been, and remains to be, the easiest to realize here. For sure, we want more and strive for more, but will probably never be granted more by Belgrade. More would be good...for us and for you" (anonymous source, in discussion with author, November 24, 2018). This idea, that Hungarian cultural autonomy is the maximum that the Hungarian community can achieve for itself, highlights the feelings of indignation that are associated with this matter. The retired Hungarian football club manager is adamant on the fact that "no Serbian politician would give us more than we have now achieved. We have to be content with this...We have achieved a lot given the circumstances in which we live" (anonymous source, in discussion with author, November 7, 2018). Ultimately, the former chief ambulance driver in Backa Topola is clear to point out that:

"Cultural autonomy is the reality for the Hungarian community in Vojvodina. It is surely the maximum we can achieve. All those that tell you that we should have or that we still can achieve some other additional forms of minority autonomy are lying to themselves, and to you. We members of the VMSZ sat down with Serbian representatives and quickly saw that we cannot ask for more, or else we will lose even this that we gained through much diplomatic effort and international regional pressure." (anonymous source, in discussion with author, November 19, 2018)

\section{Pursuit of Hungarian Territorial Autonomy}

Entertaining the prospect of potentially achieving minority territorial autonomy or even individual autonomy is something that the wealthy landowner from Stara Moravica 
repeatedly stresses. This respondent proudly identifies himself as a sympathizer of the Vojvodina Hungarians Democratic Community (VMDK). He insists that the VMDK remains the only Hungarian minority party that has not compromised its principles, unlike the VMSZ - which he identifies as political sell-outs that will do anything that Serbian President Vucic wants. According to this subject:

"The VMDK is the only Hungarian minority party that is concerned with our distinctly Hungarian interests. It does not care to compromise with the Serbs, which it logically should not. After all, it is our party, not your party or any other minority's party! It should protect our interests without compromise. Most important, the VMDK is the only Hungarian party here that seeks cultural, territorial, and individual autonomy for our minority community...The fact is, regardless of what these VMSZ supporters tell you, cultural autonomy without territorial autonomy means nothing...We Hungarians need to control the money we make as a community, to fully administer the localities in which we live in, and finally, tell the Serbian colonialists that they are not welcome here. The cultural autonomy the VMSZ has compromised on, and that has inadvertently compelled our community to settle for, has resulted in Hungarians being totally relegated from politics altogether. There are no Hungarians in power at any level in our localities at all. This tells you everything...I do not care about your interests, I care about our position." (anonymous source, in discussion with author, November 19, 2018)

Pressed on the issue of minority territorial autonomy, it seems that the wealthy landowner is not alone in his attitudes, regardless of his albeit more radical stance on the 
subject. Among a number of other subjects, the retired metallurgy worker originally from Pacir also admitted in her interview that "Hungarian cultural autonomy together with Hungarian territorial autonomy would be best" (anonymous source, in discussion with author, November 14, 2018). Even the former chief ambulance driver in Backa Topola recognizes the value of what achieving Hungarian territorial autonomy would have for his community in Vojvodina. However, he quickly brushes this thought off by claiming that "individual and especially minority territorial autonomy is simply not a reality for us here in Vojvodina. This dream cannot be seriously entertained by mainstream Hungarian minority parties and the Hungarian political public in Vojvodina" (anonymous source, in discussion with author, November 19, 2018). The private entrepreneur from Novi Sad seconds this sentiment, simply stating, "minority territorial autonomy is an illusion" (anonymous source, in discussion with author, November 24, 2018). For this subject, the best that can be achieved is somehow balancing this cultural autonomy granted to the Hungarian community in Vojvodina with progress to be made on "Vojvodinian regional autonomy, if that means anything to anyone anymore... which would later serve as a stepping stone to full Hungarian territorial autonomy as the guarantee of already achieved cultural autonomy" (anonymous source, in discussion with author, November 24, 2018).

Finally, the opinion that Hungarian territorial autonomy is an illusion is summarized by the retired Hungarian football club manager who concludes: "Sure, it [minority territorial autonomy] is possible in theory, but Serbia would never grant us Hungarians territorial autonomy, regardless of whether we believe this to be a good thing" (anonymous source, in discussion with author, November 7, 2018). This sense of 
concealed discontent and indignation seems to encapsulate the vast majority of discussions regarding Hungarian minority territorial autonomy.

Interviews conducted for the purpose of this study are clearly limited in discerning the pragmatic realities and possibilities of implementing ethnic territorial autonomy in Vojvodina for the Hungarian community, but this still does not negate the sense that a majority of participants in this study feel extremely positively towards its prospect. When pressed on the issue, one postman admits that "granting cultural as well as territorial autonomy to the Hungarians would be the best." This respondent believes minority autonomy would be the optimal outcome that would ensure the Hungarians would be free to organize affairs as they deemed best "because we know what we need and want, and would not have to rely on Belgrade" (anonymous source, in discussion with author, November 7, 2018).

The notion of tying minority territorial autonomy to the concept of dependency is elaborated on by one Hungarian cattle farmer who argues that:

"Combining cultural with territorial autonomy would make us fully independent to function here...It would protect our Hungarian cultural autonomy as well as improve interethnic relations, because we could openly operate independently of one another politically, culturally, and especially economically, by law...which is the unspoken reality already" (anonymous source, in discussion with author, November 7, 2018).

It speaks volumes that only two subjects in this inquiry claimed that autonomy, in any shape or form, is not important to them, and that only two other respondents felt that Vojvodina's territorial autonomy held any meaning for them. One such respondent, the 
former diocesan bishop of the Roman Catholic Church for the North Backa jurisdiction, simply claims that he is, first and foremost, a "Hungarian of Yugoslavia...With the destruction of this beautiful country, everything has become irrelevant. Vojvodina does not stand for anything, and neither does its autonomy in any form" (anonymous source, in discussion with author, November 10,2018). The second subject in this grouping is a self-proclaimed "uncompromising Titoist communist who will not be swayed by Serbian, Hungarian, or American politics" (anonymous source, in discussion with author, November 12, 2018). Finally, the only two respondents who recorded positive views towards Vojvodina's provincial territorial autonomy once again referred to personal sentimental recollections of the golden days of Yugoslavia. For example, the mechanical engineer in Subotica reiterated his desire for "Vojvodina's autonomy to be restored to the status it had in our Yugoslavia. Nothing more" (anonymous source, in discussion with author, November 10,2018). What is most important to discern here is what connects all of these four respondents: a high degree of "Yugonostalgia" and all the associated ideas of self-management and/or idealistic bratstvo i jedinstvo (brotherhood and unity) that accompany it. Thus, for these subjects, the idea of Vojvodina's autonomy is deeply connected with personal experiences and recollections of Yugoslavia, and once again does not stand alone in value and meaning.

\section{Vojvodina as a Sovereign State}

Revealingly, respondents show an extremely high salience for the idea of Vojvodina as an independent republic. Even though the political status of Vojvodina as an independent state was not initially a component of this inquiry, the feelings freely and 
organically expressed by the respondents cannot be neglected. Arguably, it is worth addressing generally positive sentiments to the idea of an independent Vojvodina in terms of forecasting the general direction of interethnic relations and the potential evolution of the phenomenon of parallelism.

Though initially it may seem rather paradoxical that the Hungarian community in Vojvodina simultaneously displays both a low salience for Vojvodinian territorial autonomy and a high salience for a sovereign and independent Vojvodinian state, these two metrics, on closer examination, actually do fortify one another. Arguably, an independent Vojvodina is a compromise, or possibly even a sign of a political stepping stone, between Vojvodinian territorial autonomy and illusive Hungarian ethnic territorial autonomy. After all, territorial autonomy for Vojvodina still ties the province to Serbia, and hence, does not unshackle it from what this community perceives as continuous Serbian domination. The potential for policy backtracking and state repression still exists in the framework of territorial autonomy for Vojvodina; it has historically persisted, as evidenced in the above analysis. The situation changes, however, in the case of an independent Vojvodinian state, with regards to a perceived restart in interethnic relations. If all other conditions remain the same, the majority remains Serb, but the Hungarian community apparently perceives that their status changes, if only in terms of breaking with a tainted legacy that has distanced them from the epicenter of power and participation. The psychological effect of having the political, economic, and administrative capital be Novi Sad instead of Belgrade should not be underestimated. Hence, the benefits of Vojvodinian statehood must be considered in terms of the views and attitudes shared by members of the Hungarian community. 
In the words of one hostess at a local hunting lodge, "Vojvodina as a republic would solve all issues here. We would all do what we wanted without interference. We would all be equal" (anonymous source, in discussion with author, November 7, 2018). One painter from Stara Moravica arrives at the same conclusion, believing that "there would be more stability here. We could shape politics and things would not be taken away from us so easily like they always have been. Politics would be more stable" (anonymous source, in discussion with author, November 7, 2018). Pressed on the reasons why respondents believed a potential independent Vojvodina to be a "positive thing," many claimed that it would "improve interethnic relations as well as improve living conditions" (anonymous source, in discussion with author, November 14, 2018). Probing deeper into what they meant by improvement, several subjects alluded to the theme of stability, with one respondent noting that "Novi Sad, instead of Belgrade, would direct affairs" (anonymous source, in discussion with author, November 7, 2018). Another interviewee claimed that "everyone would mind their own business" in an independent Vojvodina (anonymous source, in discussion with author, November 7, 2018). However, once again, similar to the topic of Hungarian territorial autonomy, the retired Hungarian football club manager is clear to point out that "Vojvodina as an independent and sovereign state is a dream, even further realizable than Hungarian territorial autonomy... better not to talk of this anymore" (anonymous source, in discussion with author, November 7, 2018). Given the polarizing climate in Serbian politics in regards to the contested subject of Kosovo's unilateral independence, it comes as no surprise that this interviewee did not want to elaborate on this topic further. 
It would not do this topic justice, however, without also highlighting the negative feedback that the prospect of Vojvodina as an independent republic invoked among several subjects in this study. The construction entrepreneur from Stara Moravica argues that "Vojvodina could not function alone. It is simply unsustainable independently. Maybe it would be good from a social standpoint, even though I am even skeptical of that, but from a pragmatic economic standpoint it is simply impossible" (anonymous source, in discussion with author, November 12,2018$)$. The economic feasibility of such an independent state is problematic, as noted by the private entrepreneur from Novi Sad, who inquires:

"Do you know how much building new institutions would cost Vojvodina as a new state? Vojvodina could not support this economically now. This model is neither positive from an interethnic perspective nor sustainable from an economic perspective. All who tell you otherwise are uneducated on economic matters." (anonymous source, in discussion with author, November 24, 2018) Digressing from mere economic reasoning opposing Vojvodina's independence, the former diocesan bishop of the Roman Catholic Church for the North Backa jurisdiction was the only respondent to directly rebuke its prospects on the grounds of interethnic instability. This respondent reasons that an independent Vojvodina would "be the precursor to war in this area" that would bring unprecedented ethnic upheaval that the rest of former Yugoslavia has not seen (anonymous source, in discussion with author, November 10, 2018). Instead, this interviewee was sure to advise the importance of nurturing state unity at all costs. The uneasiness of the former Catholic bishop's words were lost on the private goldsmith from Backa Topola, who rhetorically inquires: "What 
interethnic conflict are you talking about? Who would fight this war, when there are no people here anymore? A Republic of Vojvodina is not good simply because it does not matter; having a country without people has no significance" (anonymous source, in discussion with author, November 14, 2018).

\section{Autonomy as an Institution Fostering Parallelism}

On the surface of things, it would seem that the territorial and non-territorial elements of Vojvodina's autonomy are progressive and could complement each other rather well in resolving national tensions and fostering interethnic interaction and integration. The comprehensive minority rights protection program instituted in Vojvodina would seem to imply the same. The problem however, is the constant backtracking and drastic oscillations that characterize Vojvodina's policy of territorial and/or cultural autonomy. Many have lost trust in the stability of Vojvodina's provincial territorial autonomy, a policy that has constantly failed to solve interethnic issues, leading the Hungarian community to look inwardly, relying on themselves in isolation from tremulous provincial politics. Current cultural autonomy for the Hungarian community in Vojvodina plays into this apparent trend, despite what Serbian policy shareholders hope to achieve. For the Hungarians in Vojvodina, (ethnic) minority territorial autonomy seemingly remains the underlying ultimate goal.

Policy continuity matters. Policy reversals related to autonomy have led to the distancing of the Hungarians in Vojvodina. Additionally, the fact that discourse concerning Vojvodina's autonomy has always been Serbian-dominated is even more 
problematic, and further alienates the Hungarian community, who feel they have no place in this debate.

A pluralistic, supranational, autonomous Vojvodina has continuously clashed with the nation concept as an organic category to which Serbian nationalists have always aspired. In such a vision for Vojvodina, Hungarians have been compelled, for the sake of survival, to look inwardly and disengage from the dominant group.

The unstable provincial territorial autonomy that the Serbs have repeatedly addressed has not solved the interethnic issues in Vojvodina; securing cultural autonomy for their community is the most realistic goal the Hungarians in Vojvodina have achieved. Through this type of cultural autonomy, this community hopes to be left alone, disengaging from the volatility of Vojvodinian politics altogether, but all the while aspiring to acquire the elusive minority territorial autonomy as arguably the ultimate logical outcome of parallelism.

In retrospect, Vojvodina's territorial autonomy has not brought them much good, and even when it did in 1974 it was quickly revoked. Ethnic cultural autonomy, when distinct and separated from territorial autonomy for Vojvodina, has proven more stable for the Hungarian community in Vojvodina; however, the breeding of parallelism, instead of integration, has been its outcome.

Whether granting ethnic Hungarian territorial autonomy represents the pinnacle of parallelism for this community is debatable, but plausible. Hungarians in Vojvodina are distrustful of, and seek to dissociate from, Serbian-dominated Vojvodinian politics altogether. The claim is that Vojvodina's provincial territorial autonomy is not, and does 
not need to be, ethnic-based. But the reality is that it not only seeks to resolve interethnic issues, but is also further dominated by the majority ethnic group.

More interestingly, the Hungarians in Vojvodina have discerned underlying Serbian objectives. Serbian authorities boast of developing progressive policy that upholds minority rights protection and fosters interaction and integration, but the Hungarian community is skeptical — they see and understand the lack of policy implementation in the province when it comes to managing interethnic interaction and integration. For the Hungarians, Vojvodinian autonomy, as offered by the Serbs, has a tainted legacy and is considered merely a façade created for the outside world, catering to dominant Serbian national interests.

True integration requires the Serbian establishment put laws and words into action; according to the Hungarians, nothing short of granting ethnic territorial autonomy will convince them otherwise. This sad state of affairs has led the Hungarians in Vojvodina to become apathetic, looking inwardly and engaging with the dominant group only to secure the maximum possible level of cultural autonomy for themselves. 


\section{Chapter VI - Kin-State Phenomenon}

There are numerous ways in which international law allows for the protection of minority rights. Of course, the state in which the minority resides is chiefly responsible for the protection of minority rights which are considered human rights and a topic of inter-state activity. However, the resurgence of nations (and hence, nationalism) in Eastern Europe, particularly with the dissolution of the Soviet Union, has introduced new issues into the discourse on ethnonational minorities residing outside their politicocultural sphere. The kin-state, as the entity concerned with reaching out to its co-ethnic population across borders, also can play an important role in the protection of minority

rights of its community in a foreign host state. The manner in which the kin-state postures itself in relation to its kin-minority in other states can have a significant impact on interethnic relations in the host state.

Until recently, kin-state activism, defined as a "nationalist strategy that aims to create, institutionalize, and mobilize ethnonational kindship across territorial boundaries, usually without redrawing borders or initiating population exchanges," has often been overlooked as a factor in minority politics (Liebich, 2017, p. 4). Conventional understanding would have us believe that minority affairs are the product of a simple direct relationship between the given minority and the nation-state in which it resides. However, current global discourse on human rights and liberal multiculturalism has pledged an international commitment to minority rights. This pledge has opened the floodgates, and vested legitimacy to a host of new actors, with regard to tailoring minority politics and, ultimately, influencing interethnic relations outcomes. No longer 
are minorities constrained to domestic political institutions to vie for recognition; instead, ethnonational minorities are now presented a myriad of avenues through which to seek assistance and sustenance from seemingly oppressive national governments.

Within this new minority rights agenda, kin-state activism has become an immensely influential factor steering minority "agency." In fact, the kin-state should be considered in terms of the historical process of minoritization - a "project of emancipation and empowerment" whereby minority politics becomes the product of relations between multiple actors inclusive of national governments, nationalizing states, and even regional powers engaged in kin-state politics (Buyuksarac, 2017, p. 22).

Kin-state activism in minoritization proceeds by "eschewing territorial objectives and instead seeking rights within existing national borders, developing a reformulation and alternative to an explicitly nationalizing project" (Cowan, 2001, p. 156). Minoritization fueled by kin-state activism is evidenced among Turkmen in Iraq, the Mongols in the People's Republic of China, Malays in Indonesia, Lao in Thailand, and most noticeably, the Hungarians in Romania, Slovakia and Serbia's Vojvodina (Buyuksarac, 2017; Liebich, 2017; Cribb \& Narangoa, 2004).

Theoretically, kin-state nationalism, even more so than autonomy, challenges Gellner's (2006) modernist sociocultural approach to the theory of nationalism, which argues that nation-building occurs solely within state boundaries. If the kin-state phenomenon is conceptualized as a unifying and inclusive factor that "involves states reaching out to co-ethnics beyond the border, cultivating border ties, and including these populations in the nation both culturally and institutionally," then it is surely proving 
effective in transcending conventional nation-state borders by fortifying a cohesive irredentist-type of virtual nation-building effort (Liebich, 2017, p. 2).

In the face of an imperfect international nation-state system, where state borders do not correspond with national limits, so-called trans-border nationalism or cross-border homeland nationalism of external national homelands is gaining traction (Brubaker, 2000, pp. 4-6). Such a rising trend has inevitably created an intricate and interconnected triadic relationship between the kin-state, kin-minority, and host/resident state (Brubaker, 1996; Stjepanovic, 2013). With the host state inclined towards diffusing a nationalizing nationalism across its entire territory, the kin-state pursuing a competing homeland nationalism, and the kin-minority possibly nurturing a complementary minority nationalism, the possibilities for conflict arguably abound in this relational nexus (Liebich, 2017, p. 3; Brubaker, 2000, p. 1). Despite these rising securitization concerns, however, kin-state activism does provide an alternative way for "virtual" nation-building to occur that does not implicitly question fixed borders (not matter how arbitrary they are), does not clash with the norm against territorial conquest, and does not erode the norm of territorial integrity (Liebich 2017; Fazal \& Griffiths, 2007; Zachar, 2001). In this process of virtual nation-building, enveloped in minority rights discourse, kin-state activism presents an undeniably important factor in reordering interethnic relations outcomes between its kin-minority and the host-state in which it resides.

\section{Role of Kin-State Activism}

In relation to their kin-minority in a host state, the kin-state can take four types of transnational actions. These four types of actions can be categorized as "actions in the 
context of international bodies and mechanisms, actions in co-operation with the home state, actions vis-à-vis other states, and domestic legislation on the relationship with its kin minority" (Kardos, 2006, p. 130). The first category focuses on the manner in which the kin-state appeals to international institutions and uses established institutional processes for achieving foreign policy goals related to expanding minority rights protection for their kin-minority. The second and third categories actions involve cooperative bilateral agreements or joint declarations between the kin-state and the home state in which their kin-minority resides. These types of actions are understood to be the most cooperative but difficult to come by, especially in Eastern Europe where states are skeptical of other states meddling in domestic affairs particularly related to their minorities. The fourth category related to unilateral actions of the kin-state in relation to its kin-minority can come in the form of domestic constitutional provisions that provide some framework for assistance and preferential treatment to members of its kin-minority. This last category of actions is very common, but since they are unilateral they are also often frowned upon by the international community and the host state in which the minority resides, because they are seen as encroaching on the sovereignty of the host state.

The influence of the kin-state, the Republic of Hungary, on its kin-minority in Vojvodina is a major factor in producing the interethnic relations outcome of parallelism. The Republic of Hungary, the kin-state, has worked tirelessly through international institutions to internationalize the plight of the Hungarian community in Vojvodina, and, more controversially, to pass unilateral legislation that offers preferential treatment and benefits to its kin-minority — an act which the Serbian host state has at times deemed 
disconcerting, characterizing it as meddling in domestic interethnic affairs. Conversely, Hungary has portrayed Serbia's sporadic counter-efforts to integrate the Hungarian community into society as a nationalizing Serbian nationalism effort, and has internationalized the issue as a human rights violation of its kin-minority (Hagan, 2009).

The Republic of Hungary has a myriad of interconnected interests in actively engaging with, and increasingly supporting, its kin-minority in Vojvodina. Certainly, ethnonational kinship sympathies lay the foundation for the close relationship between the Republic of Hungary and its Hungarian community in Vojvodina. However, apart from that, the Hungarian community in Vojvodina fits in well with the current Hungarian government's renewed "virtual" nation-building effort that seeks broader Hungarian national unification without necessarily border revision (Ieda, 2006). Trying to right the post-WWI wrongs that saw millions of Hungarians left scattered across newly established neighboring states, the Budapest government has seized on the opportunity, under the guise of the European Union, to rekindle relations with its Hungarian populations now living across its sovereign borders.

Instrumental reasons for such an inclusive nationalist policy maneuver include, on one hand, the economic benefits and connections the Republic of Hungary has been able to develop with its kin-minorities in all these neighboring countries, beneficial to its fragile domestic economy; on the other hand, the political benefits of including "Hungarians outside borders," has proven advantageous for the current Hungarian government in tapping into a new base of loyal supporters. These new supporters have now been granted voting rights due to the unique extension of citizenship rights offered 
by the kin-state. Together, the benefits and opportunities of forging this close relationship between the kin-state and the kin-minority seem endless for both parties.

Questioning Liebich's assertion that Hungarian kin-state activism has "put a strain on interethnic relations and has led to some perceptions of Hungarian minorities as a security risk," this research finds that Hungary's involvement is perceived as crucial for the preservation of the Hungarian community in Vojvodina (Liebich, 2017, p. 10). From the perspective of the Hungarian community in Vojvodina, the political, economic, cultural, and even mere moral support it receives from the kin-state is of critical importance to their survival and sustenance in the province.

When compared to secondary data, primary data indicates that the Hungarian community may slightly exaggerate the extent to which the Republic of Hungary provides assistance. What is vital to emphasize is the Hungarian community's perception and attitudes towards the kin-state and the resulting uneasiness it produces in the Serb dominant group, which ultimately leads to the outcome of parallelism. The Vojvodinian Hungarian community perceives that they can wholly rely on the kin-state for its sustenance, and that its existence is wholly independent and separated from the Serbs and Serbian state. Put simply, the very presence and activism of the kin-state provides an "exit option" for the Hungarian community in Vojvodina, enabling them not to interact with the dominant group without existential repercussions (Baubock, 2007, p. 2396). Thus, with the involvement of the kin-state, the Hungarian community in Vojvodina feels it is able to lead a parallel life, being afforded the possibility not to interact or engage with the Serbs for the sake of survival in the province. 
The role of the kin-state in influencing interethnic relations in Vojvodina, specifically inducing the outcome of parallelism, has to be first understood in the context of Hungarian cross-border homeland nationalism and the potential risk it poses to the Serbian host state. After all, "support of kin minorities is based on the idea of the nation as an ethnocultural entity, not on the political conception of the nation. It is thus assumed that co-nationals have, or should have, a special relation with the kin-state" (Kantor, 2006, p. 41). In this manner, the involvement of the kin-state, particularly one that invokes appeals to trans-border nationalism, seems to always involve a redefinition of boundaries whether real or perceived. In many cases, kin-state activism with its kinminority necessarily causes the redefinition of the nation from a political one into an ethnic one, thereby challenging the status quo in the international order. In fact, analyses of kin-state politics are consistently faced with the dangers of state-led transnationalism: the instrumental use of ties to those abroad to justify irredentist ambitions and exclusionary, nationalist politics; the security dilemma created by cross-border violations of sovereignty when a homeland state claims residents of neighboring states as their national members; and the potential negative effects on inter-ethnic relations created by fears of minority disloyalty ton their state of residence (Waterbury, 2008, p. 8).

Therefore, including a kin-minority across borders is surely a primary source for concern, since it involves a renewed national building effort based on what Hungarian Prime Minister Viktor Orban has termed "national reunification without borders," an effort which inadvertently challenges the interethnic status quo in the host state (Waterbury, 2008, p. 11). 
The previous chapter of this dissertation thoroughly explored the omnipresent problematic of territorial autonomy versus non-territorial forms of cultural autonomy and what this means for the Hungarian community in Vojvodina. Several of the discussions regarding Vojvodina's autonomy, from the Serbian perspective, posed a threat, and were either a reaction to or a solution to addressing or suppressing sub-state/minority nationalism. The Hungarian community in Vojvodina was always viewed with suspicion, a legacy that has historically persisted; such a view should not come as a surprise, given that the ideal of the nation-state in Eastern Europe never quite fully realized the ideology of "one language, one nation, one state" (Kymlicka, 2002, p. 5). In such a climate, minority nationalism is viewed as a threat to national solidarity, and autonomy is viewed as the ultimate concession - one that, if not strictly controlled, can lead to erosion of both the sanctity of the state, and the unity of the nation. Thus, diversity is viewed as a factor contributing to instability, directly opposing the establishment of the community that fosters an insular common identity.

In fact, diversity is deemed a problem to be managed, rather than celebrated (as it is supposed to be in the liberal plural model). Instead, all those who support this minority diversity (in the form of minority nationalism, the kin-state and its complementary transborder nationalism - a prime source of concern that can actively or passively factor into the equation), are deemed a threat.

The traditional view of minority groups throughout Eastern Europe is that they are not only disloyal, but even prone to working with the neighboring enemy, especially when this entity is their maternal state (Kymlicka, 2008, pp. 26-29). On many occasions, the kin-state has claimed the right to intervene and protect its minority in the neighboring 
state. Given the reoccurrence of such scenarios, ethnic relations in this part of the world can be considered a securitization issue (Waever, 1995); or, as Kymlicka observed, "relations between states and minorities are seen, not as a matter of normal democratic politics to be negotiated and debated, but as a matter of state security, in which the state has to limit the normal democratic process in order to protect itself" (Kymlicka, 2007, p. 589). From this perspective, the Hungarian community in Vojvodina has often been considered as an ally of, or even worse, a collaborator with the Hungarian state, one that has repeatedly been presented as a direct threat and challenger to the Serbian state. Such an outlook frames the Hungarian community in Vojvodina as a danger to the state and an oppressor of the Serbian majority, constantly seeking concessions in order not to turn fully and collaborate with the enemy - their kin-state. In such a climate, it comes as no surprise that Eastern European countries affirm the position:

(a) that minorities are disloyal, not just in the sense that they lack loyalty to the state, but in the stronger sense that they collaborated with former oppressors, and continue to collaborate with current enemies; therefore,

(b) a strong and stable state requires weak and disempowered minorities. Put another way, ethnic relations are seen as a zero-sum game: anything that benefits the minority is seen as a threat to the majority; and therefore

(c) the treatment of minorities is, above all, a question of national security. (Kymlicka, 2002, p. 20) 


\section{Historical Role of the Hungarian Kin-State}

Previous analysis has shown the distrust which multiple governments — the former Kingdom of Yugoslavia, Federal People's Republic of Yugoslavia (FNRJ), Socialist Federal Republic of Yugoslavia (SFRJ), and the Federal Republic of Yugoslavia (FRJ) - exhibited towards its nationalities, especially the Hungarians. Multiple factors (including historical irredentist tendencies, calls for secession, questions over minority rights protection, and contentions over autonomy) ended up woven together into the complex fabric comprising the national question. This question that has continuously haunted interethnic relations in Vojvodina.

The Second World War, which witnessed the collaboration of Vojvodina's Hungarians with the fascists in Hungary, was the zenith of animosity and distrust between the two communities. The communist years tried to reset the dynamic, and, at least on the surface of things, foster integration between the communities amidst a backand-forth on policies regarding autonomy which yielded resoundingly negative consequences.

Of equal historical significance has been the evolving role of the Republic of Hungary in supporting its kin-minority across the border, through the diffusion of crossborder homeland nationalism. Until signing the Treaty of Trianon that effectively ceded Hungary's South County (Vojvodina) to the Kingdom of Serbs, Croats and Slovenes, the Hungarian government had "continued to proclaim a right to maintain and direct the public administration, the judiciary and the school system, levy taxes and conscript soldiers" (Sajti, 2003, p. 12). However, even after Hungarian administration was ousted from its annexed South County, the Hungarian government remained committed to its 
kin-minority. Given Hungary's weak international position and tense relationship with the South Slavs post-WWI, Hungary was initially forced to rely on secret channels of communication to maintain contact with its Hungarian community in Vojvodina.

Throughout this volatile period, until the Second World War, affairs of the Hungarians residing abroad were a primary concern of the Prime Minister's Office (Sajti, 2003, 35). Essentially, Hungary's main objective in supporting its kin-minority abroad at this stage was to break out of international isolation brought on by defeat in the First World War. Most important, even though Hungary sought to nurture a national consciousness among its kin-minority across borders, its foreign policy generally sought to be peaceful in its endeavor by ensuring not to provoke neighboring state retaliation (Sajti, 2003, p. 38). ${ }^{13}$ This tradition of pacifist kin-state activism, crowned by the aptly called Treaty of Eternal Friendship signed between Hungary and Yugoslavia, was only episodically marred by the Second World War (arguably a violent reaction to "oppressive, nationalistic minority polices of the royal Yugoslavia" (Sajti, 2003, p. 199)). However, apart from this, Budapest continuously strived to develop "closer cooperation and more frequent contact" with its Hungarian community in Vojvodina (Sajti, 2003, p. 69). This program involved maintaining relations with Hungarian minority leaders, no matter their ideological persuasion, all for the greater purpose of nurturing the "kin question" as a major piece of Hungary's collective national narrative" (Liebich, 2017, p. 7).

\footnotetext{
${ }^{13}$ This assertion runs contrary to Alexandra Liebich's conclusion, presented in her aptly entitled piece The "Boomerang Effect" of Kin-state Activism: Cross-border Ties and the Securitization of Kin Minorities, in which she argues that Hungarian kin-state activism has had a boomerang effect that has actually led to the increased securitization of the Hungarian minority across borders.
} 
Sensing the growing intolerance, general uncertainty, and political defenselessness characterizing the status of its kin-minority in Vojvodina, consecutive Hungarian governments considered it their responsibility to maintain a nationality policy that utilized various strategies to support their kin-community. For an extended period during the Cold War, Hungarian kin-state activism went into decline, due to escalating adversarial relations between Belgrade and Budapest which compelled both the kin-state and kin-minority to accept politically-intrusive Yugoslav policy; this all changed with the more-recent violence that gripped the former SFRJ, and inevitably weakened the position of this host state.

\section{Evolving Role of the Hungarian Kin-State}

While the conflicts in the former SFRJ in the 1990s put the kin-minority Hungarian community in an ever-more-precarious position, it did result in one other consequence - it reintroduced and elevated the Republic of Hungary to a central position in regards to regulating the status of the Hungarian community in Vojvodina. During this period of political turmoil, former Prime Minister Jozsef Antall announced that he was "in spirit" the prime minister of all Hungarians throughout the world. Even more controversially, specifically related to the Hungarian community in Vojvodina, Antall claimed that "Hungary's southern border applied to Yugoslavia but not to Serbia, implying that Hungary might make territorial claims on the region if Yugoslavia experienced complete dissolution" (Jenne, 2007, p. 166). In light of such rhetoric, Antall called into question Serbia's sovereignty over Vojvodinian territory in a time of largescale Yugoslav turmoil. However, even during the later 1999 NATO bombing campaign 
of Yugoslavia, Budapest always stopped short in claiming it would intervene on the behalf of its kin-minority in Vojvodina, even if it were to experience ethnic cleansing by the Serbian majority. Refraining from alluding to a certain responsibility to protect its kin-minority, the government of the Republic of Hungary seemed more concerned with a responsibility to assist the Hungarian community in Vojvodina while still wishfully seeking an avenue to pursue border revision without outright conflict, if the opportunity presented itself.

For the Hungarian community in Vojvodina, however, such a stance taken by Budapest in the 1990s was interpreted as passivity amid growing Serbian repression that placed the minority in an increasingly vulnerable position. However, this apparent schism between the kin-state and kin-minority in Vojvodina was short-lived, soon to be rectified by a confluence of events - a changing government in Budapest, and increased vulnerability of the Serbian position after democratic changes. These events laid the foundation for the more active involvement of the Republic of Hungary in kin-minority affairs in Vojvodina.

Presently, Hungary is an active participant and stakeholder in interethnic relations in Vojvodina - at least as far as the Hungarian community is concerned. Up until the 1990s, Hungary was a rather passive actor in the complex relationship between its Hungarian community in Vojvodina and the Yugoslav state (in all its forms). Its allegiance with the USSR was considered dangerous by the SFRJ, but the Yugoslav government was merely weary of Hungarian meddling, rather than being outright fearful of its active presence in the province, influencing its Hungarian community in political and economic ways. Certainly, historical irredentist efforts have existed, but this is far 
from the outright foothold that the Republic of Hungary gained in Serbia's province and among its kin-minority during the period of instability and conflict that was unfolding (Waterbury, 2005). Surely, the rekindled ethnonational mobilization effort headed by the Hungarian intelligentsia in Vojvodina during the early 1990s helped in bringing the Hungarian community in Vojvodina closer with the kin-state. The political, economic, and social decline of the SFRJ coincided with the rising international prestige of the Republic of Hungary, which was ascending to European Union (EU) membership, and was once again becoming a major player in Eastern European affairs. The international political, economic, logistic support the Republic of Hungry has provided its kin-minority during this time cannot be denied. The political, financial, and organizational support it continues to provide for its community in Vojvodina has surely facilitated the development of parallelism.

The Republic of Hungary has been instrumental in bringing the status of the Hungarians in Vojvodina to the attention of the international community; some would even go so far to argue that Hungary was shrewd enough to manipulate the situation occurring in the rest of the SFRJ, and to claim that the plight of the Hungarian community in Vojvodina was a human rights issue. Once the status of the Hungarian community in Vojvodina was presented as a human rights concern, it was immediately elevated to the level of a securitization issue. In fact, turning the status of the Hungarian community in Vojvodina into an "internationalized issue" is deemed a success of Hungarian foreign policy (Hagan, 2009, p. 631). This increasing concern on the part of the Republic of Hungary for its kin-minority coincided with the mounting international case calling for Serbia to develop a robust minority rights protection program. 
As previously discussed, there are numerous reasons for the Republic of Hungary's vested interest in its kin-minority. Generally, "shifts towards increased kinminority engagement are considered in large part by the interests and perceptions of homeland state political elites. These motives can be grouped into three main sets of interests: the extraction of material resources for economic gain, the creation or maintenance of domestic and international political legitimacy, and the utilization of those abroad as a culture-linguistic resource to be used in defining and redefining the boundaries of national identity" (Waterbury, 2008, p. 12). In the case of the relationship between the Republic of Hungary and its kin Hungarian community in Vojvodina, the motives for engagement seem to be wholly driven for the purpose of redefining national identity and broadening the boundaries of the Hungarian nation. To a lesser extent, Hungary's active involvement with the Hungarian community in Vojvodina can be attributed to Hungary's pursuit of international prestige, seeking to once again become an important factor in the Balkans.

Hungary's renewed interest in its Hungarian kin-minority in Vojvodina is part of its large program of societal security promotion (Butler, 2007). Even the “country’s constitution claims that the Republic of Hungary has a responsibility for the destiny of Hungarians abroad, including, of course, Hungarians in Vojvodina” (Korhecz, 1999, p. 159). This all leads to the conclusion that the Republic of Hungary is dedicated to diffusing its kin-state activism to its kin-minority in Vojvodina, instigating a wide variety of consequences. 


\section{Legal Basis for Hungarian Kin-State Activism}

Legally, Hungary's kin-state activism finds its strength in Europe's commitment to minority autonomy rights under Article 11 of the European Framework Convention for the Protection of National Minorities, which states: "In areas traditionally inhabited by substantial numbers of persons belonging to a national minority, the Parties shall endeavor, in the framework of their legal system, including, where appropriate, agreements with other States, and taking into account their specific conditions, to display traditional local names, street names, and other topographical indications intended for the public also in the minority language when there is a sufficient demand for such indications" (Council of Europe, 1995). Overall, Hungary has preferred that its neighboring states take a collective-rights approach to protect Hungarian minorities; however, Hungary's support for minority rights for its kin in neighboring countries has had a polarizing effect. On the one hand, it has signaled to neighboring states, especially Serbia, that its concern for its kin-minority does not overextend to the point of directly intervening in Serbian domestic affairs (thereby posing a security threat). Simultaneously, this has had the effect of signaling to the Hungarian kin-minority that it must fight for its minority rights solely through political means, with no chance for forceful kin-state intervention. On the other hand, however, the simple matter of fact that Hungary is the force behind this minority rights struggle has made the kin-minority increasingly reliant on the kin-state. Thich has. inevitably, introduced a hardened attitude and nationalistic undertone into the already-complex discourse (Dimitras \& Papanikolatos, 2002, p. 196). Interestingly, the rise of such "minority nationalism" in the late 1990s in Vojvodina has coincided with increasing kin-state involvement (Varga, 2015 p. 84). 


\section{Hungary as a Factor of Stability}

Out of 23 subjects interviewed in this study, 22 agree with the statement that the Republic of Hungary is the chief factor of stability for the Hungarian community in Vojvodina. The local Hungarian municipality official is adamant that the "Republic of Hungary is a factor of stability by providing our community with multiple sources of assistance... The Republic of Hungary has helped us become important once again. Our community was forgotten in the 1990s. Hungary has changed all this" (anonymous source, in discussion with author, November 14, 2018). Out of 23 subjects, 21 also recorded extremely positive attitudes towards kin-state involvement, whether in the realm of politics, economics, or culture; respondents shared overwhelmingly positive attitudes toward Hungary's activism in promoting Hungarian culture in Vojvodina, providing much needed economic assistance through investment relief programs (specifically tailored to their kin-minority), promoting and supporting the political agendas of the Hungarian minority parties, and safeguarding and preserving the survival and sustenance of Hungarians in Vojvodina amid mass economic emigration. Even the more reserved former diocesan bishop of the Roman Catholic Church for the North Backa jurisdiction admits "what a blessing it is to see the unity and support that Hungarians in Hungary are showing their Hungarian brothers in Vojvodina" (anonymous source, in discussion with author, November 10, 2018). Possibly, the head of a mental care facility in Vojvodina sums up sentiments concerning kin-state activism best by stating that the "Republic of Hungary is our insurance policy — political, economic, and cultural" (anonymous source, in discussion with author, November 12,2018$)$. In this regard, primary data analysis lends to the conclusion that the kin-state is considered by the Hungarian community in 
Vojvodina as the single most-important institution in supporting their communal sustenance; simply put, for the Hungarian community in Vojvodina, Hungary's kin-state activism is equated with survival.

\section{Hungarian Kin-State Legal Activism}

Hungary and Citizenship Rights - Proliferation of the Hungarian Status Law

Probably the zenith of Hungary's kin-state activism has been its aggressive policy of repatriation of its kin-minority in neighboring countries, as part of its broader clientelist nemzetpolitika, or "nation policy" (Waterbury, 2005, p. 3). The passing of the so-called Hungarian "Status Law" in 2001 marks the tangible policy outcome and culmination of this striving which aims to "ensure that Hungarians living in neighboring countries form part of the Hungarian nation as a whole and to promote and preserve their well-being and awareness of national identity within their home country" (Hungarian Status Law, 2001). Under the law, "ethnic Hungarian citizens of Romania, Slovakia, the Republic of Serbia and Montenegro, Croatia, Slovenia and Ukraine can apply to the Hungarian government for a 'Hungarian identity card' which would make the bearer eligible for certain transportation, health, and employment benefits in Hungary. The law also provides for educational benefits inside and outside Hungary, as long as the study is conducted in Hungarian" (Deets \& Stroschein, 2005, p. 300). In this way, the Status Law has had the specific purpose of reconnecting and tying the ethnic Hungarians to the Hungarian state (Verhegyi, 2001).

While critics claim that the Status Law has inevitably sought to repatriate three million ethnic Hungarians through a resurgence of Hungarian nationalism, policy 
supporters argue that the law's sole intent is to "promote the prosperity [of the kinminority] in the country of residence" by providing primarily economic/financial support for communities as well as political logistical support to mobilize the kin-minority (Halasz, 2006, p. 258). Whether the kin-minority decides to (and, actually is allowed to) immigrate back to the kin-state is investigated only to a limited extent as part of this research, but it is worth mentioning that the Hungarian government has vehemently rejected this accusation; instead, it reaffirms that the Status Law is designed in accordance with the "ethnizenship" model that offers "external quasi-citizenship for those who don't reside in the country granting the status, as a form of symbolic membership and nation-building that may or may not translate into real benefits and mobility" (Waterbury, 2008, p. 18). According to Hungarian legislators, the Status Law should be thought of as citizenship without resettlement.

\section{Hungarian Status Law and Reclaiming of Ethnonational Identity and Unity}

The gathered interview data presents a more complex picture than the official Hungarian government narrative. The overwhelming majority of respondents in this study recorded extremely positive views in regards to the Hungarian Status Law. Of the 23 Hungarians in Vojvodina interviewed, 20 subjects stated that they have taken advantage of the various benefits and entitlements that the Status Law and the subsequent 2011 Hungarian citizenship law by ancestry offer; middle-aged respondents, especially males, recorded the most positive attitudes towards the Status Law. The municipality official proudly declares: "I am now a Hungarian citizen. I am a citizen of the EU. My papers allow me to travel and work in a number of wealthy countries, not just Hungary" 
(anonymous source, in discussion with author, November 12, 2018). The Protestant priest contends that through the Status Law "our people here have regained their dignity" (anonymous source, in discussion with author, November 14, 2018). Elaborating further, this interviewee explains that the Status Law has accomplished two things: it has finally acknowledged the Hungarian community in Vojvodina as equal to, and part of, the Hungarian nation; secondly, it has "made our people aware of their true identity and heritage... and where our loyalty should lie - with our own" (anonymous source, in discussion with author, November 14, 2018). The wealthy landowner from Stara Moravica agrees, proclaiming that "we are now finally united with our own. We have waited for the correction of this historic injustice from 1918" (anonymous source, in discussion with author, November 19, 2018). In addition to claiming the intrinsic worth of Hungarian citizenship, this subject also emphasizes that his newly acquired legal status under the 2011 Hungarian citizenship law by ancestry (which builds on the Status Law) has indirectly increased/guaranteed collective community security. He feels that his legal status ensures "physical safety from potential Serbian attacks and economic security from ongoing Serbian exploitation" (anonymous source, in discussion with author, November 19, 2018). He also feels that the Hungarian community in Vojvodina is no longer forgotten, and will never again be held hostage to Serbian interests. This sentiment is shared by the retired Hungarian football club manager who claims that Hungarians' shared identity keeps this Vojvodinian community safe. "Hungarians in Hungary are keeping us Hungarians in Vojvodina safe, politically and economically. We have shown that we care for each other, even though we are split across borders" (anonymous source, in discussion with author, November 7, 2018). 


\section{Hungarian Status Law and Economic Self-Interest}

Some respondents, however, are less inclined to link the Hungarian Status Law and the 2011 Hungarian citizenship law by ancestry with a prophetic re-embrace of Hungarian national identity on both sides of the border. As one postman shares:

"My interest in Hungarian citizenship is purely out of rational economic selfinterest; they are all logical [instrumental] reasons. I want to secure a better life for my wife and children. The EU offers this. I could care less about reintegrating back with Hungarians in Hungary. This status gives me a chance to work outside, in Austria and Germany which has better living standards than Hungary which are similar to here... Regulating your legal status is also required to participate in Hungarian economic assistance programs that pertain to Hungarians living in Vojvodina." (anonymous source, in discussion with author, November 7, 2018)

This younger respondent is just one of many who associate the Status Law with economic benefits guaranteed through the freedom of movement that this provision bestows.

Likewise, the construction entrepreneur from Stara Moravica also views the Status Law in terms of pure economic interests and transaction, just with different ramifications to their conflated identity.

"The Hungarians here are taking Hungarian papers purely out of economic interests. These people were never harboring some secret love for Hungary, nor do they wish to live in Hungary even today. They all dream of Austria and Germany. But now all of them are apparently big Hungarians. On the other hand, the equally sad truth is that the Hungarians in Hungary see us as second-class citizens and do not recognize us as equals to them. We are villagers to them. The 
majority of Hungarians in Hungary do not even know where Vojvodina is. Giving these Hungarians in Vojvodina papers is a loss for Hungary and is not supported by the ordinary Hungarian citizen. I am not sure why Orban's government still supports this." (anonymous source, in discussion with author, November 12, 2018)

\section{Hungarian Status Law and Loyal FIDESZ Diaspora Voters}

The only skeptic of Hungary's kin-state activism among its kin-minority in Vojvodina, the mechanical engineer in Subotica, agrees that the positive reception of the Status Law and the revised Hungarian citizenship law by ancestry is due to purely transactional, economic reasons. Yet, he questions whether the Hungarian state does not have something to gain from all this:

"Frankly, Orban has bought the loyalty of people here by giving them Hungarian papers. All of a sudden, they are all Hungarian nationalists, 'liking' images of Greater Hungary on their Facebook page...Orban has bought three million Hungarians across borders who are now loyal supporters and active voters for his FIDESZ party. When there are Hungarian elections, everyone shows up. When there are Serbian or local Vojvodinian elections all the people here shut themselves in their homes and refuse to go to the polls." (anonymous source, in discussion with author, November 10, 2018)

Buying loyal voters among the Hungarian community in Vojvodina is corroborated by the data from the 2018 Hungarian parliamentary elections. Statistics show that in the last parliamentary elections in Hungary an overwhelming $96.24 \%$ of the Hungarian diaspora 
voted for the FIDESZ-KDNP coalition compare this with a mere $47.36 \%$ who voted for this very same coalition inside Hungary, and there seems to at least some truth behind the mechanical engineer's claims (Hungarian National Election Office, 2018). These Vojvodinian Hungarian FIDESZ supporters are also active voters, which adds even more weight to the claim — of the approximately 54000 registered Hungarian voters in Serbia (99\% from Vojvodina), an impressive $67.07 \%$ actually showed up and voted in these Hungarian elections (Trivic, 2018; Isakov, 2018; Nemzeti Valasztasi Iroda, 2018). It should come as no surprise, therefore, that the mental health caretaker claims she has witnessed firsthand how "Orban has made my neighbors huge FIDESZ loyalists and extreme Hungarian nationalists, ever since their two daughters got Hungarian papers and moved to Budapest" (anonymous source, in discussion with author, November 14, 2018). Orban has surely bought loyal active voters among the kin-minority, who are now acutely aware of their politically-infused Hungarian national identity.

Clearly, this policy has elevated the Republic of Hungary to a central role in the lives of the Hungarian community in Vojvodina, shaping their perceptions of the value the kin-state represents, Whether the Hungarian Status Law has more of an intrinsic or instrumental worth is debatable; still, a compelling argument can be made that the Hungarian Status Law hinges on an instrumental rationale that has ramifications on longterm intrinsic prospects.

The Hungarian community rationally benefits from the Status Law's provisions, calculating the economic benefits and potential EU job opportunities that this "ethnizenship" offers; the Hungarian Status Law and the subsequent 2011 Hungarian citizenship law by ancestry opens many doors for the Hungarian community in 
Vojvodina that would otherwise remain closed. At the same time, Orban and his FIDESZ party are benefiting from unequivocal diaspora support, acquiring loyal voters through this popular policy; such transactionalism implies the instrumental worth of the legal provision. In the long-term, however, the intrinsic worth of the Hungarian Status Law and the Hungarian citizenship law by ancestry is evident in the implied national solidarity between the Hungarian community in Vojvodina and the Hungarians in Hungary. The political-legal gambit has given impetus to strengthening an ethnonational consciousness, bringing the kin-minority in Vojvodina ever-closer to its Hungarian kin-state, and demonstrating that a grand ethnonational homogenization now transcends borders through shared citizenship rights.

\section{Hungarian Status Law and Resettlement Deliberations}

The issue of whether the Status Law has led to increased resettlement of the Vojvodinian Hungarians back to Hungary is also debatable, as evidenced by the divergent sentiments of the interviewees. The former chief ambulance driver in Backa Topola asserts:

"It is a fact that our people are leaving from these areas, irrespective of Hungary's politics. It is only logical that everybody wants a better life from themselves. Yes, the Status Law has probably eased the process for our people, but it is not chiefly responsible for it. Economic hardship is pushing people from this area. People have and would continue to find alternative avenues for immigrating, regardless of laws." (anonymous source in discussion with author, November 7, 2018) 
Even the wealthy landowner from Stara Moravica solemnly agrees that "people are simply leaving. Every day there are fewer of us. God let it be true that it is because of Hungary's politics. But the truth is that people here cannot make a decent living to sustain themselves and their families and are hence forced to leave - to Hungary, Germany, Austria, Ireland" (anonymous source, in discussion with author, November 19, 2018). The Hungarian electrician from Vojvodina completely agrees with this assessment, attributing the outflow of Hungarians from Vojvodina to a global migration trend evidenced across Serbia, the Balkans, Europe, and even the world. "People are leaving. No population controls can stop this; no laws can regulate this. Movement is the destiny of the modern man. This place will one day be inhabited with Syrians" (anonymous source, in discussion with author, November 12, 2018). Reflecting on experiences in his own household, he rejects the claim that the Status Law and the subsequent 2011 Hungarian citizenship law by ancestry is responsible for the outflux of Hungarians from Vojvodina to Hungary. "This trend is all a result of economic hardship," the electrician contends. "Be sure, none of these people are leaving for Hungary just because they have Hungarian papers now. The economic situation in Hungry is nearly as bad as it is here. All are going further West. My son lives in Vienna. My daughter moved to Budapest, married, and then they both left together for Dublin Ireland" (anonymous source, in discussion with author, November 12, 2018). By their own account, the subjects involved in this inquiry feel the Hungarian Status Law is not primarily responsible for the outflow of Hungarians from Vojvodina; it provides legal support for this seemingly economically driven emigration. In their view, the Status Law 
has not motived people to move to Hungary per se, it has provided them with the option of pursuing their lives in other more economically-developed Western countries.

\section{Hungarian Status Law and Hungarian Irredentism}

With one exception, all subjects in this study vehemently rejected the common Serbian accusations that the Hungarian Status Law and the subsequent 2011 Hungarian citizenship law by ancestry are a precursor to Hungary's pretentions to annex Vojvodina. The factory foreman resolutely states that "Hungarians in Vojvodina would never want to unite with Hungarians in Hungary. My other female colleagues and I discussed this once, and none wanted such an outcome" (anonymous source, in discussion with author, November 7, 2018). The Hungarian painter also rejects this accusation, stating, "Hungary's interest in keeping Vojvodina peaceful, and its Hungarian community safe, should not be construed as Hungary's wish to take back Vojvodina. Hungary simply wants to help its people, wherever they are" (anonymous source, in discussion with author, November 7, 2018). The private goldsmith from Backa Topola is even more astounded by this question, laughing at this accusation and rhetorically inquiring: "How many people are left here? Our numbers are so small, and constantly declining, that all talk of nationalist irredentist aspirations is merely another example of Serbian political hysteria" (anonymous source, in discussion with author, November 14, 2018). Finally, the current director of a mental care facility in Vojvodina shares similar insight, attempting to explain further the Hungarian policy rationale; he concedes that Hungary's strong ties with its kin-minority is naturally a cause for concern for the host state, and recognizes that there are increasingly vocal voices from political authorities in Belgrade 
who are concerned with Hungary's meddling in what they consider internal interethnic affairs. However, in this case, he believes there really is no cause for concern, since the mere

"realization of our low numbers here renders Hungarian pretensions illusionary. There are simply too few Hungarians here for Hungary to be interested in something like this. All Hungarian policy is peaceful, and points to the fact that Hungary wants Vojvodina to remain complete and a part of Serbia." (anonymous source, in discussion with author, November 12, 2018)

Ultimately, what seems to unify all these views refuting Hungary's prospects for annexing Vojvodina is a focus on Hungary's concern for its people, rather than mere territory; the underlying premise shared among these respondents is that Hungary is primarily concerned with Vojvodina's Hungarian people, and not with its land. These subjects believe Hungary's policy is a people-before-land dynamic. As the local municipality official concludes, "All Hungarian policy points to the fact that it is in Budapest's interest for us to stay here in Vojvodina" (anonymous source, in discussion with author, November 12, 2018).

The hostess at a local hunting lodge is far more skeptical, however, providing some valuable alternative reasoning on this subject; after being surrounded by a multitude of visitors, predominantly wealthy Hungarian hunters from Hungary's major cities, she claims that she has heard discussions among "drunk patrons who make jokes how all this land in Vojvodina will soon be theirs once again, how they are hunting on territories their grandfathers inhabited, and how they will soon be taking this all back" (anonymous source, in discussion with author, November 7, 2018). Referring to the saying, "what the 
sober man thinks, the drunk admits," the hostess argues that the issue of Vojvodina's annexation is not something in which the Hungarians in Vojvodina have a say: "Hungarians here are weak. Nobody asks us anything. Ask the Hungarian politicians in Budapest if they will take back Vojvodina" (anonymous source, in discussion with author, November 7, 2018).

\section{Ramifications of Status Law on Hungarian Parallelism in Vojvodina}

Of primary concern to this study is that the Status Law has tied the kin-minority to the kin-state, to the direct detriment of fostering integration with the dominant Serb society with which this community co-exists on a daily basis. As this data and interviews demonstrate, Hungarians in Vojvodina have replaced the option for solidarity with a community within which they live, opting instead for allegiance to a "virtual nation" with which they associate through shared cultural symbols, myths, and perceived motherland/homeland (Csergo, 2005).

The Status Law, the tangible product of kin-state politics, has propagated the notion of the "unified and single Hungarian nation which in the government's interpretation refers to a spiritual and symbolic unification of the nation, without any revisionist (territorial) claims, and in which there is room for all Hungarians, regardless of their residence" (Herner-Kovacs, 2014, p. 62).

Arguably, the Status Law has influenced Vojvodinian Hungarian perceptions of self-sufficiency and, consequently, a decreased need for interaction with the dominant Serb group. Now, according to members of the Vojvodinian Hungarian community, it is the Republic of Hungary, not the Republic of Serbia, that is key to their sustenance - the 
kin-state is taking primacy over Hungarian community affairs in Vojvodina, by providing the necessary public goods, which the Serbian government is failing to supply at a satisfactory level. In their eyes, the Status Law has afforded the Hungarian community in Vojvodina the ability to opt-out of interacting with (and, integrating with) the Serbs, instead freely disassociating from the dominant group without any costs. The law has, in fact, solidified Hungarian resilience in Vojvodina; the result is parallelism.

\section{Hungarian Status Law and Survival of the Hungarian Community in Vojvodina}

It is extremely revealing that 21 out of 23 interviewees included in this research claim that the Republic of Hungary is responsible for ensuring the survival of their kinminority in Vojvodina; the municipality official is clear on this subject, concluding that "without the Republic of Hungary, we could not sustain our lives here. We are still here thanks to Hungary's support" (anonymous source, in discussion with author, November 12, 2018). The wealthy landowner proudly adds to this idea: "Thanks to Hungary, not only are we safer, but our Hungarian citizenship now allows our people to be independent from Serbs and Serbia" (anonymous source, in discussion with author, November 19, 2018). The general sentiment gathered from respondents is that Hungarian citizenship represents a type of "life vest" or, better yet, an "insurance policy" for the Hungarian community in Vojvodina. The Hungarian community perceives that it is more independent from Serbia and, as a result of this policy, more resilient. However, such resilience also comes with an increased partiality towards their own ethnonationality, if not a redirected reliance upon Hungary. The retired Hungarian football club manager best reveals this partiality when he judges that "we do not have to rely upon Serbia anymore. 
We are free because our people are helping us" (anonymous source, in discussion with author, November 7, 2018). A significant majority of participants in this study share these same views.

\section{Legal Controversies Over Hungarian Status Law}

Critics have argued that the 2001 Status Law expresses the Republic of Hungary's favor for cultural communities over legal-political communities, a position which threatens the very heart of the current international system (Deets \& Stroschein, 2005, p. 300). Others criticize the Status Law for mobilizing the kin-minority on solely ethnonational grounds, and lament the negative repercussions this policy is producing. After all, the Status Law "realizes a type of ethno-territorial nation definition by connecting the ethnocultural and the territorial principle" (Halasz, 2006, p. 266). The ethnocultural element is explicit in its focus on Hungarian (Magyar) identity that transcends the borders of the Hungarian state. By definition, the Status Law "operates with the ethnocultural conception. It extends the borders of the nation beyond the borders of the state" (Kantor, 2006, p. 44). This territorial element enters the equation by specifically labeling the countries wherein the benefits and preferential treatment apply —Romania, Slovakia, Serbia, Croatia, Slovenia, and Ukraine.

Finally, in terms of pragmatics, the law propagates Hungarian national identity by requiring individuals to profess their ethnic belonging, self-declare their Hungarian identity, and find an associate Hungarian organization in their community to attest their declaration. By these requirements, as the Protestant priest and many others have admitted in interviews, the Status Law has made the Hungarian community acutely aware 
of their ethnicity as a marker of identity/ belonging, and underscored the importance of ethnicity and "their" collective as a precursor for survival. In this study, numerous respondents expressed a rekindled national partiality (triggered by the Status Law), invoking the need to declare and "own" their distinct identity, separate from the majority in Vojvodina.

By providing political logistical organizational support with its Status Law, the kin-state has inadvertently enhanced the internal solidarity of the Hungarian community in Vojvodina which was already mobilizing on ethnonational grounds, as a response to ethnic tensions precipitating elsewhere in the former SFRJ. It has also furthered the schism between Serbs and Hungarians, who are now not only fully aware of their separateness, but also have a venue to develop their separate lives, thanks to the support of the kin-state.

Under EU pressure — based on the perspective that the 2001 Status Law both violates principles of individual autonomy that denies individuals to self-declare ethnic identification without external corroboration, and undermines the obligation of states to protect minorities within their own borders - the Hungarian government was compelled to revise the law (Deets \& Stroschein, 2005, p. 301). The revised 2003 law affirms individuals' right to self-declare identity, while restricting its kin-minority support to matters of education and nurturing culture, thereby upholding the principle of state sovereignty. To a certain extent, this revised law has also curbed the outright influence of the kin-state and attempts to settle concerns of neighboring states that the Republic of Hungary is meddling in their domestic affairs by proclaiming its supposed "positive discriminatory intention" (Halasz, 2006, p. 267). In spite of this limited policy reversal, 
the initial Status Law cemented Hungarian kin-minority perceptions regarding the kinstate; in their eyes, the Republic of Hungary has gained paternal-like status. Moreover, the revised law has continued in the same spirit of national fervor, failing to unshackle itself from an ethnocultural basis by keeping (if not even further elevating) the Hungarian language as the fundamental marker of inclusion. The revised law still defines as its chief goal "to ensure the well-being of Hungarians living in neighboring states in their home state, to promote their ties to Hungary, to support their Hungarian identity and their links to the Hungarian cultural heritage as an expression of their belonging to the Hungarian nation" (Kantor, 2006, p. 50).

All the participants in this study were not even aware of the changes the Hungarian Status Law has undergone. However, several did note that they had heard that the law became more stringent because "people who were not pure Hungarians were taking advantage of Hungarian citizenship" (anonymous source, in discussion with author, November 7, 2018). Of those that were aware of such restrictions, all welcomed such a move because they feel that the law should serve to benefit "loyal Hungarians, and not foreign manipulators" (anonymous source, in discussion with author November 19, 2018). As the wealthy landowner from Stara Moravica contends, "we must distinguish who is 'ours,' and who is just here for personal profit" (anonymous source, in discussion with author November 19, 2018).

\section{Hungarian Kin-State Political Activism}

Probably the closest link between the Republic of Hungary and the Hungarian community in Vojvodina has been achieved in the realm of political activism. Arguably, 
the close political relationship between the kin-state and its kin-minority has monopolized Hungarian minority politics outside Hungary. This is in no small part due to active, if not aggressive, kin-minority policies pursued by past Hungarian governments, culminating with the ruling Hungarian Civil Alliance (FIDESZ) led by Victor Orban. Hungarian governments prior to that of FIDESZ had involved themselves in the political affairs of HTM ['Hungarians beyond the border'] parties and organizations by offering advice or funding. FIDESZ, however, formalized these cross-border connections and took diaspora clientelism to a new extreme.

Beginning with its campaign promises made in front of HTM communities...FIDESZ allied itself with like-minded ethnic Hungarian leaders, in particular those who focused on autonomy demands and had little hope for accommodation from the majority governments. The party and its allies actively opposed the moderate wing, which pursues a strategy of small steps and legal security attainable through the tools of a constitutional state. The encouragement of the radical wing of the ethnic Hungarian organization has subsequently been blamed for the deterioration of relations between the HTM and the majority governments, a result that seems to be at direct odds with FIDESZ's stated intent in engaging with the HTM issue. (Waterbury, 2005, p. 19)

In this manner, the Republic of Hungary has managed to agitate, if not antagonize, host states (and its own national majorities) while simultaneously pulling its kin-minority further and further away. Such posturing on the part of the Republic of Hungary, a posture that openly favors and strategically and financially supports the mainstream Vojvodinian Hungarian political parties, has arguably given the Hungarian community in 
Serbia an opt-out option from interacting with (and, possibly integrating with) the dominant Serbian population.

In terms of tangible policy output, the political support that the Republic of Hungary has provided Hungarian minority parties is undeniable and is part of a grander policy approach that Hungarian Prime Minister Viktor Orban has now formulated and termed "Minority SafePack," an initiative that aims to protect minority rights throughout Europe. "Hungarian MP Gergely Gulyas said the protection for ethnic communities is a [Hungarian] national cause, irrespective of party politics. He insisted that the initiative is symbolic of the principle that "each Hungarian has a responsibility for every other Hungarian"' (Patricolo, 2018). While this initiative is focused on promoting the free use of minority language and symbols, equal legal treatment of minorities, and the cultivation of national cultures and traditions, the underlying nationalist Hungarian undertone is more than apparent. Minority SafePack has the purpose of building solidarity among Hungarians across borders with appeals to cultural nationalism in which the Hungarian state is presented as the paternalistic safe-keeper of its people.

Hungary's Minister of Foreign Affairs and Trade, Peter Szijjarto, has stated that Vojvodina's major Hungarian minority party, the Alliance of Vojvodina Hungarians (VMSZ), is the Republic of Hungary's strategic partner. Minister Szijjarto is also on record for claiming that the VMSZ is the vital link connecting the Republic of Hungary with the Republic of Serbia through a mutual interest - supporting the Hungarian community in Vojvodina. Noting the vast investment in agriculture and tourism that the Republic of Hungary has made through the years, Szijjarto has praised the ever-growing bond and coordination between the Hungarian government and the VMSZ. The party 
leader of the VMSZ, Istvan Pastor, has continuously responded with equal gratitude for the political and financial support the Hungarian government has provided, stating that the "promotion of Hungarian interests is not simply the promotion of its Hungarians in Vojvodina but also of Hungary" (Autonomija, 2016). Moreover, the VMSZ leader has also publicly acknowledged that "not only is FIDESZ our guarantor of close relations with Hungary, but we must also acknowledge the enormous benefits we as the Hungarian community in Vojvodina have received from the Hungarian government led by this very same party" (Trivic, 2018). Therefore, the close political relationship between the dominant Hungarian minority political party and the government of Hungary is difficult to overlook. Budapest's public political acknowledgment of Pastor as the "legitimate leader of the local Hungarian community in Vojvodina" only further solidifies this point (Szijjarto, 2017).

Numerous interviewees included in this inquiry enthusiastically shared how closely FIDESZ is working with the VMSZ, especially noting the close personal relationship between Orban and Pastor. The cattle farmer asserts, "people here vote overwhelmingly for the VMSZ precisely because they are the favored and chosen party by FIDESZ and Orban himself, and not the other way around. VMSZ's support is dependent on Orban's blessing" (anonymous source, in discussion with author, November 7, 2018). Hence, the impression gathered is that VMSZ's support is surely a result of Hungary's political activism. In fact, VMSZ successes are not so much the result of mass support among the Hungarian community in Vojvodina, as much as political favoritism from Budapest's political establishment. The former chief ambulance driver argues that the "VMSZ is the dominant party among Vojvodinian Hungarians not so 
much because we favor it, but because the Hungarian government favors it" (anonymous source, in discussion with author, November 129, 2018). From such statements, it may be surmised that the government in Budapest wholly directs Hungarian minority politics in Vojvodina, and Serbia, with little to no input or influence from the Hungarian community in the province; the local Hungarian municipality official, however, stresses the danger of such a claim that considers this relationship in such a direct and banal manner. Yet, rather than refuting this conclusion, he emphasizes that the "relationship is more complex" (anonymous source, in discussion with author, November 12, 2018). He implies that, rather than outright direction of Hungarian minority politics in Vojvodina, the government in Budapest steers Hungarian minority politics in Vojvodina by offering much-needed assistance and positive incentives.

“VMSZ's policy program complements FIDESZ's strategic assistance plan for Hungarians outside Hungary's borders. Hence, it is natural for the two parties to work in harmony. We are all Hungarians and we want what is best for us on both sides of the border. We are working together for the betterment of our nation in total. The VMSZ has proven a reliable partner and Pastor has become Orban's good and loyal friend. But Orban would not favor the VMSZ if people here did not support it...But, yes, popular support for our party has considerably increased with Hungary's backing... but that is because we provide results with the help of Hungary." (anonymous source, in discussion with author, November 12, 2018) This respondent, however, was adamant that the Hungarian government would assist any Hungarian minority party in Vojvodina (as it had assisted the VMDK in the 1990s) as long as it enjoys majority support of the Hungarian community. While this fact seems to 
be heavily disputed among several current supporters of the VMDK (such as the wealthy landowner from Stara Moravica), the fact remains that the direction of Hungarian political consciousness and activism in Vojvodina is heavily influenced, if not wholly dependent, on Hungary's kin-state political support.

Regardless of whether VMSZ successes are the direct result of Hungary's support, or whether Hungary's political establishment necessarily favors this party because it already enjoys the majority of support among Hungarian voters in Vojvodina, the fact remains that, to a certain extent, the FIDESZ has monopolized Hungarian minority politics in the province. Orban is able to use the VMSZ (who now works with, and relies on the FIDESZ) to push a distinct Hungarian political agenda.

If some of the arguments these respondents shared prove to be true, even to the extent of implying personal nepotism between Orban and Pastor, the VMSZ can be considered no longer fully accountable to the Hungarian community in Vojvodina, and even less accountable to the governing structures in Belgrade. Instead, all political focus has now turned to the political establishment in Budapest, an entity deemed the most important factor steering Hungarian minority political party successes in Vojvodina. The effect has also been to pull the average Hungarian voter further and further away from political life in Vojvodina, and from Serbia. For the average Hungarian in Vojvodina, such a political dimension of kin-state activism translates to necessarily deeming the Republic of Hungary the primary safekeeper and responsible sustainer of life for the Hungarian community in Vojvodina. The political aims and objectives that the government in Budapest places on the agenda have become the primary concerns of not only the Hungarian minority parties in Vojvodina but also the Hungarian community in 
Vojvodina. Over time, the Hungarian voter has become detached from his Serb counterpart with whom he no longer shares common political interests.

The most vivid and acute proof of parallelism that the kin-state has produced among the Hungarian community in Vojvodina can be gleaned from responses to the very pointed question asking whether political events in Belgrade or Budapest are considered more important to them. The majority of respondents in this study perceive political events in Budapest and Belgrade as either equally important, or deem events in Budapest to be more important to their lives than those unfolding in Belgrade.

The cattle farmer acknowledges that it is "very important for me to hear what Orban and the government in Budapest think about Serbia, Vojvodina, and our Hungarian community here. What Orban says and does has a direct impact on us here." (anonymous source, in discussion with author, November 7, 2018). The wealthy Hungarian landowner from Stara Moravica is even more resolute on this topic:

"Look at my TV behind you - all Hungarian channels; I do not have, nor would I want to watch, Serbian channels. For my life and livelihood, only events in Budapest are important. As a Hungarian why would I care about events in Serbia, let alone Belgrade? What have Serbs ever given me? I only care about my people here and across the border... Hungary is helping me here. I want to be informed about what is happening with us." (anonymous source, in discussion with author, November 19, 2018)

The private goldsmith is rather more balanced in his approach, however, arguing that “this community's interest in events unfolding in Budapest arises out of thankfulness for all that the Hungarian government and the people have done for us here" (anonymous 
source, in discussion with author, November 14, 2018). The director of a mental care facility in Vojvodina further explains, "people naturally gravitate towards those that help them. Hungary has helped us a lot here, funding and supporting a variety of assistance projects. It is natural for people here to be more interested in political events in Budapest, therefore" (anonymous source, in discussion with author, November 12, 2018). The retired metallurgy worker originally from Pacir agrees, stating that she sees all the "economic support Hungary has provided this village...I want to be informed about the things that are relevant to my family's life. Belgrade has forgotten us. We are not a part of their news. I always hear something about us here in Vojvodina on Hungarian radio and tv stations [coming from Hungary].” (anonymous source, in discussion with author, November 14, 2018) The dog obedience trainer from Vojvodina, however, does not consider his equally vested interest in political events in Belgrade and Budapest as a balance between which country is helping him more, or which provides more news coverage of his community, but rather a mere reality and reflection of his identity in the complex geopolitical position in which members of the Hungarian community find themselves; therefore, this subject admits that "of course I am equally interested in political events in Budapest as I am in happenings in Belgrade, since I am both Hungary's Hungarian and Serbia's Hungarian" (anonymous source, in discussion with author, November 14, 2018). Despite the fact that many find themselves in the same situation, both the retired Hungarian football club manager, as well as the Protestant priest, claim that events in Hungary should be more important to every Hungarian in Vojvodina because it is 
"Hungary that protects us" and because "we must be partial to those that show concern for us" (anonymous sources, in discussion with author, November 7/14, 2018).

The fact that interviewees were more vested in (and even expressed duty to) events in Budapest compared to those in Budapest may, at first, seem peculiar. But, considering the extent of kin-state activism that this community perceives, it is not surprising that people have conflated interest with adoration. An overlap surely exists between these subjects' objective interests and their subjective perceptions regarding Hungary's concern for its kin-minority in Vojvodina — resulting in attitudes that equalize, or even elevate, events in Budapest over those in Belgrade. These attitudes, the direct product of kin-state activism, highlight the extent of detachment that this community perceives, and the inevitability of "being partial to one's own." if institutional parameters allow it; that the Hungarian community still lives within the borders of the sovereign Serbian state, yet regards events across the border as more pertinent to the personal lives it leads, reveals the level of dissonance these respondents experience.

Numerous interviewees also freely shared opinions regarding the close personal relationship developing between Hungary's Prime Minister Orban and Serbian President Vucic; all respondents claim positive attitudes toward this growing relationship. These statements seem to contradict the subjects' previously-asserted detachment from Serbian politics; when asked why subjects deemed this relationship "good," many of them explained that the two leaders' relationship simply demonstrates how important their Hungarian community has become, and the strength of the Republic of Hungary: "Hungary was always lagging behind Yugoslavia. Now things have changed; Hungary is a member of the EU. Good relations between Orban and Vucic help us 
here, but also Serbia on its path towards EU membership. For Serbia, we are now the link between the governments in Budapest and Belgrade. We are now Vucic's ticket to the EU, all through Orban...Orban's international prestige has helped our community in Vojvodina increase in importance, both here and across the border." (anonymous source, in discussion with author, November 12, 2018)

The private entrepreneur from Novi Sad further elaborates on the good relations between Vucic and Orban, stating they are "only important to us from the perspective of Hungary's long-term plan for our community here...That Vucic has had to bow down to Hungary and recognize our rights" (anonymous source, in discussion with author, November 19, 2018). Therefore, this dynamic concerning the interpersonal relationship between the two leaders seems to be important insofar as it elevates the importance of the Hungarian community and benefits a perceived uneven power dynamic that benefits Hungary's position.

\section{Hungary's Kin-State Economic Activism - Prosperitati}

Arguably, strategic economic support directed by the government of the Republic of Hungary towards its kin-minority in Vojvodina has been instrumental, if not paramount, in supporting the outcome of parallelism. In 2016, the Hungarian government announced an economic assistance program, appropriately termed Prosperitati (Prosperity), which is designed and intended for the economic revitalization of the Hungarian community in Vojvodina. The government in Budapest has pledged 160 million euros, the majority of which are credits, to be specifically appropriated to the Hungarian community in Vojvodina in consultation with the VMSZ (Irsevic, 2016). This 
is the largest economic assistance/stimulus plan the Republic of Hungary has ever allocated to Hungarians residing outside Hungarian borders; the Hungarian community in Vojvodina is the pilot group for assistance programs which the Hungarian government hopes to replicate for its kin-minority residing in other neighboring host states. To date, over 34 million euros have been dispersed to Hungarians in Vojvodina, the majority of whom are private entrepreneurs and farmers.

Hungary's Minister of Foreign Affairs and Trade, Peter Szijjarto, has been a major advocate and propagator of the Prosperitati program. The Hungarian minister has repeatedly stated that this economic assistance program reflects Hungary's increasing political and economic prestige on the international level. Addressing the Hungarian community in Vojvodina as part of the Hungarian nation, Minister Szijjarto declares: "The whole nation is winning, thanks to Hungary's increasing strength, because the fact that Hungary has become a strong country and the Hungarian economy is on a stable growth trajectory is enabling both Hungarians living in Hungary, and cross-border Hungarians, to gain strength to an outstanding extent." (Szijjarto, 2017).

The minister has also been vocal in presenting this economic development program as a success story, with that success precisely due to the joint coordination efforts between the Hungarian government, the Serbian government, and the kin-minority in Vojvodina. According to Minster Szijjarto, "we regard it as our duty to do everything possible to ensure the prosperity of cross-border Hungarians" in all respects (Szijjarto, 2017).

The Prosperitati program allows Hungary, the kin-state, to assist its community across the border by offering preferential economic treatment. In fact, this economic 
development program demonstrates how Hungary's national partiality is diffused through a tangible economic policy targeting the kin-minority in Vojvodina, wholly catering to that community. Including the Hungarian community in Vojvodina in Hungary's economic success underscores the level of national partiality between Budapest and its Hungarian kin-minority in Vojvodina; as Szijjarto clearly acknowledges, "the success and strength of the Hungarian economy make it possible for all members of the nation to also profit, whichever side of the border they live on" (Szijjarto, 2017).

Hungary's motivation for such seemingly altruistic inclusiveness of its community in Vojvodina should not be overlooked — through such a powerful pull factor as economic aid, it feeds the parallelism evident among these people. This economic development program is not wholly altruistic: it was promulgated based on the premise that supporting Hungarian microbusiness entrepreneurs and farmers in Vojvodina will not only assist the kin-minority, but also help the rehabilitation of Hungary's fragile economy. Prime Minister Orban hopes that increasing economic investment in its kin-minority in Vojvodina will prove profitable for the Hungarian economy, which is apparently in crisis; after rejecting IMF recommendations, Hungary has found itself economically isolated, having to find new avenues for funding (Djurkovic, 2011). Thus, it comes as no surprise that the government in Budapest is heavily distributing funds to the agribusiness sector in Vojvodina (primarily agriculture and food industry), the core branches of the province's economy and Vojvodina's top export products. This economic development program does come as a blessing, given that an overwhelming number of Hungarians in Vojvodina are involved in the agricultural 
industry already; the plan is to expand the Prosperitati program, supporting not only agriculture and small enterprise, but also tourism in Vojvodina.

Respondents exhibit overwhelmingly positive attitudes towards the Prosperitati program. Support for this program is near unanimous, the exception being one respondent who questioned the long-term feasibility and economic sustainability of this development package, given the state and size of Hungary's economy: “for now it is great. But how long will it last is the question...Is this really economic help for us or Orban's investment in loyal voters?" (anonymous source, in discussion with author, November 14, 2018). Such a skeptical view equating economic assistance with ulterior political interests is perceptive, but a position shared by only one subject involved in this inquiry.

Many interviewees in this study seem to equate kin-state support with words of praise for the Prosperitati program. The private entrepreneur from Novi Sad notes that the "160 million euros of preferential loans that our Hungarian community here has, and will continue to receive, is no minor thing" (anonymous source, in discussion with author, November 24, 2018). The private goldsmith from Backa Topola admits that he is "extremely thankful" for the monetary stimulus he has received from Hungary: "without this money we [Hungarians] realistically could not survive here any longer" (anonymous source, in discussion with author, November 14, 2018). Guaranteeing the material substance for the Hungarian community is something that the director of a mental care facility in Vojvodina also addresses as he lists the various community projects to which the government in Budapest has contributed money; he highlights how much money Hungary has gifted the mental care facility he oversees: 
"On paper, this is a Serbian public institution. It should be financed by the state and from the partial resources the provincial apparatus should control. However, every year they are decreasing the funds that are supposed to be appropriated to us...We are forgotten. They tell us, you [Hungarians] should solve the financial issues. That is impossible for me alone... Thankfully, Hungary has saved our institution from closing." (anonymous source, in discussion with author, November 12, 2018)

The interviewee also discusses a similar state of affairs when it comes to public elementary school education; faced with dilapidated school infrastructure, limited teaching resources, and aging faculty, this same mental care facility director describes how the much-needed investment Hungary has "voluntarily gifted without strings attached" has helped revitalize these institutions (anonymous source, in discussion with author, November 12, 2018). The director makes it clear that the Prosperitati program has been instrumental in assisting the lives of the Hungarian community in Vojvodina who, in his own words, were in dire need of economic salvation. The retired Hungarian football club manager expresses a similar view, arguing that the "economic assistance Hungary is providing clearly translates to economic stability. The three thousand contracts the Republic of Hungary has made with Hungarian farmers and businessmen here means three thousand lives helped" (anonymous source, in discussion with author, November 7, 2018).

Numerous respondents in this inquiry emphasized that the Prosperitati program is the one element that is helping them survive and stay in Vojvodina. One interviewee clearly states that: 
"The economic program offered by Hungary is completely revitalizing the farm industry here in Vojvodina and is supporting small private businessmen like myself sustain our families. Serbia seems to not have the resources or political motive to help us. They are concerned with their people... Hungary's help has guaranteed our survival here for sure. Things were extremely bad here until they came.” (anonymous source, in discussion with author, November 14, 2018) Even the more politically-reserved construction entrepreneur from Stara Moravica agrees that the " 10,000 forint Hungarian pensioners are receiving from Hungary every month is helping these people survive. You see the constantly decreasing pensions these people are receiving from Serbia...Hungary is giving them something, no matter how small it is" (anonymous source, in discussion with author, November 12, 2018).

The local municipality official is arguably the most versed respondent to discuss the merits and community effects of the Prosperitati program, given that he has firsthand experience with the development of the program, going as far back as 2010. He also claims to have first-hand field experience with the effectiveness of the program; he has been the technocratic link between the officials in Budapest directing the program, and the Hungarians in his municipality who apply for the various packages within the program. As he states, "this program has become a necessity. I have seen it help people in desperate financial need. Anyone who is Hungarian can apply for it" (anonymous source, in discussion with author, November 12, 2018).

While many respondents highlight agricultural sector and small business assistance received from Hungary, this interviewee stresses the encompassing help Hungarian families in Vojvodina are also getting: 
"This is not only about economic revitalization; this program is also about helping ordinary people. Helping families survive. For example, young newlyweds [where both spouses are Hungarian], Hungarian families with three children, as well as single mothers, receive up to ten thousand euros to renovate or buy a property in Vojvodina. Also, Hungarian pensioners usually receive some type of care package, or a one-time money gift from the Hungarian government, just to help them with their regular bills here; it is not a lot of money but it means a lot to our elderly." (anonymous source, in discussion with author, November 12, 2018) Most importantly, this public official emphasized that all the Hungarian government assistance is designed to help the Hungarian community remain in, and sustain their life in Vojvodina. "They are helping us stay in Vojvodina. This Serbian fear that the Prosperitati program is designed to empty Vojvodinian villages, and make us independent from Serbia, is a common misconception" (anonymous source, in discussion with author, November 12, 2018).

That the Prosperitati program is designed to assist the Hungarian community in remaining in Vojvodina is both the official declaration of the Hungarian government, and the opinion of several subjects included in this study. These subjects point to the fact that Hungary is explicitly providing funds for their kin-minority to buy property, modernize their agricultural equipment, and even purchase land in the province as empirical proof that Budapest wants this community to stay in Vojvodina. As the Protestant priest explains, "If they wanted us to move to Hungary, it would not be helping us invest and buy in Vojvodina" (anonymous source, in discussion with author, November 14, 2018). 
The case for Prosperitati being designed to compel Hungary's kin-minority to remain in Vojvodina, and not migrate across the border, seems very plausible. Prosperitati's design makes the argument that it is actually in the Hungarian government's interest for its kin-minority to stay in Vojvodina and prosper as a valuable asset to both Hungary and Serbia. This is a very compelling argument; after all, Hungary is strategically investing in agriculture in Vojvodina, since it is both the current primary economic branch and historical occupation of the majority of the Hungarian community in Vojvodina. The program's aim is to help the majority of the kin-minority become profitable agricultural entrepreneurs, by assisting them in buying new equipment to become competitive in the modern agricultural market. It also provides them with funds to afford a decent family home, which eventually incentivizes them to stay in Vojvodina. The indirect result has also been that the Serbian state profits from this program, seemingly making it a win-win situation for everyone. As the private goldsmith from Backa Topola observes, "Let us not forget, Serbia is profiting from Prosperitati also. Serbia receives the prescribed $20 \%$ VAT tax on all business commerce that is stimulated by this program. Everybody is happy. We are receiving, we are buying, we are staying, Hungary's economy is profiting, and Serbia is taxing" (anonymous source, in discussion with author, November 14, 2018).

Despite this sound logic, this program alone does not fundamentally alter many of the underlying issues for Hungarians involved in agriculture in Vojvodina. Prosperitati evolved within the complex legal, social, political and economic parameters of the region; while the wealthy landowner from Stara Moravica is adamant that the economic assistance Hungary is providing is extremely beneficial, he does admit that Hungarians 
are being indirectly pressured to leave their homes due to the ever-declining economic situation.

"For all the economic assistance Hungary is providing, it is not enough to get this agricultural sector back on its feet. Serbia has been robbing us far too long for this one program to work miracles. Also, while the program helps young Hungarians renew their agricultural machinery and invest in new modes of production, it has been ineffective in helping us buy more land. This is due to a variety of tedious bureaucratic obstacles and banking hurdles." (anonymous source, in discussion with author, November 19, 2018)

For this respondent, therefore, the long-term success of the Prosperitati program is necessarily dependent on its effectiveness in helping Hungarians in Vojvodina purchase more land. "You need a considerable amount of land to be profitable and self-sufficient" explains this interviewee (anonymous source, in discussion with author, November 19, 2018). Furthermore, there seems to be a common misconception that the majority of Hungarian farmers in Vojvodina already own large/sizable plots of land. "What qualifies as a lot of land by former Yugoslav standards is nothing compared to what is needed by EU standards. These people here do not understand this" (anonymous source, in discussion with author, November 19, 2018).

Agreeing with the private goldsmith's assessment that the "swift communist appropriation of land in Vojvodina soon after the Second World War destroyed the sustainable Hungarian aristocratic landowning class," the wealthy landowner from Stara Moravica touches on the very complex and controversial history of Vojvodinian land ownership post-1945 (anonymous source, in discussion with author, November 14, 
2018). Importantly, this respondent assesses that "Serb communists purposefully appropriated land in Vojvodina among Hungarians in such a way that nobody here could be completely economically independent and self-sufficient," and, therefore, had to rely on the communist structures and planned farming collectives already in place (anonymous source, in discussion with author, November 19, 2018). Even with the arguably unsuccessful program of restitution in the late 1990s, very few landholders can boast of being self-sustainable by European standards, according to this subject. Consequently, it comes as no surprise that this interviewee emphasizes the need for Prosperitati to better address Hungarians' land purchasing needs. "New machinery is worthless if people here do not have enough land to utilize these machines successfully" (anonymous source, in discussion with author, November 19, 2018). Gone are the days when small farms were considered sustainable and profitable; with macro-farming as the apparent key to a stable economic future for the Hungarian community in Vojvodina, the wealthy landowner from Stara Moravica concludes that Hungary's Prosperitati program must make it easier for Hungarians to get loans for the purpose of purchasing land, and the Hungarian government must exert pressure on the Serbian government to dismantle barriers that supposedly make it difficult for Hungarians to acquire the land. When pressed to provide examples or experiences of such systematic Hungarian disenfranchisement, this respondent refused to go into further detail but resolutely ended his comments on this topic by stating:

"What we need here is that the Republic Hungary commits to, and provides us with a comprehensive and long-term agricultural subsidies program that also includes provisions to help us buy all of this land that is currently not being used 
in the area. Only then will people be able to stay here, as well as become free to fully function without external manipulation from Serbia, as far as the agroeconomy is concerned" (anonymous source, in discussion with author, November 19, 2018).

While the wealthy landowner from Stara Moravica raised practical concerns about the actual success of Prosperitati in helping people stay in the province, incentives for the Hungarian community to migrate still abound. Despite official claims from Budapest several interviewees expressed their belief that this program may be evolving - an evolution that has the potential to change Hungary's interests from helping this community stay and sustain in Vojvodina, and instead provide them with incentives to move across the border. The municipality official, for example, referenced a recentlypassed amendment that expands on the Prosperitati program, adding an economic provision that commits funds to assist young Hungarian families relocate to Hungary if they so choose. As the respondent explains, this legislation, passed by Hungary's National Assembly, has the "government pledge 47,000 euros to any young Hungarian married couple or family that seeks to relocate to Hungary. This money can be used to either purchase a new home or renovate an older home in Hungary" (anonymous source, in discussion with author, November 12, 2018). This legislation has surely redirected the initial goals of Prosperitati and possibly foreshadows that Hungary may be shifting its interests to repatriating its kin-minority to Hungary rather than assisting them to stay across the border. Long-term, the project would supersede support for parallelism, and instead support separation between the Hungarians and Serbs in Vojvodina. 
For now, at least, Hungary's Prosperitati program has indirectly served to increase perceptions of self-isolation among the Hungarian community in Vojvodina, something that the Protestant priest directly addresses:

"It does not take much knowledge to see that Hungary has strategically chosen to primarily invest in the agricultural sector in Vojvodina. Certainly, it is the major economic branch for our people. But agriculture is also a powerful factor in the historical self-sustainability of our Hungarian community here...With the additional help of these loans, we are becoming all the more self-sufficient. People here are becoming increasingly aware that they do not need Serbia to get their basic needs met." (anonymous source, in discussion with author, November 14, 2018)

The value of the Protestant priest's statement strikes at the heart of the matter: Hungarian kin-state economic activism has fostered parallelism within the Hungarian community in Vojvodina, who now proclaim their perceptions of self-sustainability.

As an economic assistance package, Prosperitati has undeniably offered economic relief and presented an attractive macroeconomic stimulus program for its kinminority in Vojvodina who find themselves in a dire economic situation. The help the program has provided — in terms of revitalizing the agricultural industry in Vojvodina as a whole, assisting Hungarians farmers modernize their farming equipment and invest in new technologies, helping families purchase or renovate their homes, and even providing pensions for the elderly Hungarian populace — should not be underestimated. However, feelings of gratitude for assistance have transformed into an evolving attitude of overreliance on the kin-state; the Hungarian community in Vojvodina now attributes its 
survival to Hungary, and to its popular economic policies relating to its kin-minority. In effect, this redirects reliance of this community onto their kin-state. Simultaneously, the ethnonational homogenization promoted by the Hungarian kin-state has resulted in the further divergence and separation of Serb and Hungarian communities in Vojvodina.

Logically, the importance of Serbia and Serbs as an economic factor is becoming even more marginal for the Hungarian community in Vojvodina; now, their focus is on the "hand that feeds." In this sense, Prosperitati can be considered both an economic insurance policy and an opt-out option for the Hungarian community in Vojvodina, many of whom feel they do not have to interact with the Serbian majority. After all, incentives for interacting are clearly decreasing, costs for self-isolating are lowering, and the Hungarian minority is now able to sustain a life separate from that of the Serbian majority. In short, Prosperitati, facilitated by Hungary's kin-state economic activism in the form of a tangible policy, produces parallelism. As the wealthy landowner from Stara Moravica revealingly concludes:

"Look outside my window here. All that I have comes from Hungary and thanks to Hungary’s [economic] assistance. This car I bought last year came from Hungary. If you look closer, the number plates on the car are Hungarian. I did not even import it to Serbia, even though I only drive here in Moravica. Look at that tractor and new combine; that was bought with funds from the Prosperitati program. Look inside my kitchen here; all these appliances were bought by Hungary. Look at my living room...virtually everything! Next year when I retire and leave all my land to my son, I will get assistance from Hungary. Plus, they guarantee me an EU healthcare standard...Who needs Serbia now? Name me one 
Hungarian here who needs to wait on Serbia now that Hungary is helping us." (anonymous source, in discussion with author, November 19, 2018)

\section{Intertwinement of EU Initiatives and Hungarian Kin-Sate Activism}

In addition to unilateral economic efforts in bringing the kin-state and the kinminority closer together for mutual benefit, the European Union has also been instrumental in indirectly making the Republic of Hungary a more active participant in the life of the Hungarian community in Vojvodina. From the perspective of the EU, this is logical, since Hungary is part of the EU's supranational organization, while Serbia remains a candidate country. The EU considers the neighboring Republic of Hungary instrumental in aiding and supporting the Republic of Serbia in its path to full EU membership; in the process of forging closer links between the two states, the Hungarian kin-minority in Serbia has become the focus of much attention.

One of the major initiatives promoted by the EU has been the so-called Danube Region Strategy (DRS). Officially, "the goal of DRS is to grow sustainably the economy and competitiveness of the region and so the welfare of its people and to create a flourishing, developing and attractive region. The DRS helps to strengthen the feeling of belonging and to decrease the differences within the region" (Csaszar, 2012, p. 77). The tangible aims of the Danube Region Strategy are to support the overall sustainable development of all countries of the Danube basin (Sarcevic \& Karanovic, 2012, p. 7). Recognizing the value of the Danube River as a natural water resource, international trading corridor, and a cultural-exchange link between the countries, this initiative takes advantage of historically-formed relations between nation-states for the sake of furthering 
new economic and cross-cultural cooperation under the umbrella of the EU. Practically, the European Union Strategy for Danube Region (EUSDR) has been instrumental as a mechanism for Serbia's path to EU integration. The whole "aim of the strategy is to strengthen the implementation and coordination of EU policies as well as coordination of EU legal norms" (Meseznikov, 2012, p. 18). Simultaneously, this macro-regional strategy has had the effect of sizably increasing economic exchanges between Serbia and Hungary (which have seen continual increases in recent years). Currently, Hungary is Serbia's fifth-leading import country. Most important, thanks to this initiative, Hungary and Serbia are forging closer relations on both the economic and political front. In this relationship, the Hungarian community in Vojvodina has taken a central role, acting as both a link and shared interest between the two states and the EU. Minister Szijjarto is even on record stating that "both Hungary and Serbia look upon one another's national communities as resources" (Szijjarto, 2018). Hungary's consideration of the Hungarian community in Vojvodina as a "resource" surely has been made possible through more pronounced efforts on the part of the EU to foster equal regional development. In this sense, the EU has indirectly fostered the closer relationship between the Hungary and its kin-minority in Vojvodina.

Alongside macro-regional strategies that the EU has employed to primarily assist Serbia's integration into this supranational organization, micro-projects have been even more instrumental in indirectly bringing the Republic of Hungary and its kin-minority in Vojvodina closer together. A prime example is the Hungary-Serbia IPA Cross-border Cooperation Programme, implemented by the EU between 2007 and 2013, which focused on specifically strengthening integration across seven territorial units in both Hungary 
and Serbia - units that include the overwhelming majority of Hungarians on both sides of the border. While the aim of this EU program is designed to deliver focused support to cross-border cooperation, under the EU mission of fostering equal regional development, the specific initiatives have ultimately brought Hungarians on both sides of the border closer together.

The joint-initiatives and programs that the two states have carried out, under EU monitoring, have had the goal of facilitating the development of a harmonic and cooperating region with a sustainable and safe environment, where common cultural and natural heritage is successfully managed. In such a regional setting, the opportunities for economic and cultural growth are induced and encouraged through closer and strengthened business, educational, research and cultural ties, resulting in the creation of job opportunities, and minimizing the isolating effects of the Schengen external border situation. (Hungary-Serbia IPA Cross-border Co-operation Programme, 2015, p. 14)

Among other things, the program has had a strong emphasis on helping manage common cultural heritage, promoting cultural values, and intensifying educational exchange. Arguably, both the Hungarian community in Vojvodina and the Hungarian state have openly welcomed such objectives, since it plays into the state's general kin-minority policy outlook. The various projects that the EU has helped finance and sponsor have simultaneously had the effect of bringing the Hungarian community in Vojvodina closer to the kin-state. The generally successful positive results this whole program has had should not be considered a surprise, given the level of affinity and partiality the 
Hungarian community in Vojvodina already expresses towards Hungary, if not necessarily the EU. As such, the EU has paved the way for the further association and cohesion-building between the Hungarian community in Vojvodina and the Republic of Hungary. In a way, therefore, the EU has given its blessing for the further integration of Hungary and its kin-minority in Vojvodina, not necessarily realizing how this has also led to this community's detachment from Serbia and its Serb majority in the province. Interviews indicate a low salience for EU initiatives in Vojvodina. Many respondents certainly share positive attitudes towards the EU, especially all those that have Hungarian citizenship, claiming that they, too, are "EU citizens" (anonymous source, in discussion with author, November 7, 2018). However, interviewees interpret EU-sponsored initiatives in Vojvodina as Hungarian-led initiatives; it seems that their views of the EU are heavily influenced by their primary loyalty to the Republic of Hungary. As the younger postman argues, "none of these EU projects would be possible without Hungary's blessing. Hungary is in the EU. The EU consults Hungary on what to do and invest here" (anonymous source, in discussion with author, November 7, 2018). The central role that Hungary already plays in the life of the Hungarian community in Vojvodina makes it all the more logical for these people to assume that it is Hungary, and not the EU, who is responsible for the strategic projects that are developing in their areas. The retired Hungarian football club manager summarizes attitudes best, admitting that "we Hungarians look to Hungary for our future. The EU is important here, but its path goes through Hungary. We are only important to the EU thanks to Hungary. It is not simply random chance that Hungary has a major role to play in all these EU projects. The EU wants us Hungarians here, and Hungarians in Hungary, to be 
together as we used to be, historically." (anonymous source, in discussion with author, November 7, 2018)

It appears that, regardless of motive, the EU is playing into Hungary's kin-state activism. Members of the Hungarian community in Vojvodina perceive EU-sponsored programs as a type of EU blessing for further cohesion-building and integration with Hungary, all at the indirect expense of their no longer having to interact with the Serbian majority.

\section{Reflections on Hungarian Kin-State Activism}

Kin-state activism is a very real and powerful factor and presence in the lives of the Hungarian community in Vojvodina. Most importantly, kin-state activism has prompted ethnonational homogenization and ultimately facilitates the development of parallelism on the part of the Hungarian community in Vojvodina. It would not be farfetched to claim that kin-state activism is the enabler, if not the cause of the currently evidenced parallelism of the Hungarian community in Vojvodina.

The Republic of Hungary's ever-increasing involvement and interest in its kinminority is undeniable, especially when surveying the extent to which it provides political, economic, and organizational support to its Hungarian community in Vojvodina. Whether it be through the extensive, yet controversial, clientelist nemzetpolitika (whose pragmatic expression has been the Hungarian Status Law), its organizational and logistic support and preferential treatment for the Hungarian minority party (VMSZ), the economic stimulus package carefully tailored to Hungarian needs in Vojvodina, or. even its central partnering role in various EU strategic devolvement 
initiatives, the Republic of Hungary's presence in the lives of its kin-minority in Vojvodina has become extremely relevant and influential.

Hungary has successfully engaged in trans-border nationalism, effectively including the Vojvodinian Hungarian community in the Hungarian nation outside of Hungarian borders. Simultaneously, Hungarian kin-state activism has managed to tap into feelings of Hungarian (minority) nationalism in Vojvodina. These feelings are quite evident in the interviews performed as part of this research, as respondents displayed a high level of partiality, solidarity and loyalty expressed towards the kin-state.

The concentrated effort on the part of the government in Budapest to engage in a renewed Hungarian supranational nation-building effort invokes distinctly Hungarian ethnic and cultural elements at the expense of political consideration, only adding further complexity to the current interethnic status quo in the border province of its neighboring host state - Serbia. As reviewed in this inquiry, Budapest's engagement in aggressive kin-state politics in Vojvodina is not wholly altruistic - a mutual economic interest has brought the Hungarian community in Vojvodina and the kin-state closer together, especially considering the economic downturn Hungary has experienced due to its recent international financial ostracization. Furthermore, inclusion of the Hungarian community in Vojvodina as part of the Hungarian national electorate has produced astounding political rewards for the ruling FIDESZ in Hungary. The ruling party has gained a very loyal and faithful group of political supporters, and especially voters, in Vojvodina precisely because of this government's preferential support for, and active engagement with, the cross-border community. 
Past research suggests that Hungarian kin-state activism in Romania and Slovakia was counter-productive, "contributing to more unstable precarious conditions in the resident state" by "failing to unify the trans-border Hungarian nation and improve their situation" (Liebich, 2017, pp. 10-14). However, this research suggests that the exact opposite is true in Serbia's Vojvodina. This study shows that the Republic of Hungary is undeniably an active stakeholder in the lives of the Hungarian community in Vojvodina, who elevate its current role to that of savior and sustainer of the kin-minority. The kinminority actually perceives Hungary as the stabilizing factor in Vojvodina, considering the political, economic and financial support Budapest offers to be crucial to its ethnonational community's survival, and to its sustenance in the province. In fact, given the preferential treatment and continual benefits the Hungarian community in Vojvodina receives from Hungary, a transfer of reliance is apparent; quite simply, the Hungarian community in Vojvodina now perceives Hungary as invaluable to its sustenance and relies on Hungary, not Serbia, for its daily functioning.

In the process, interethnic relations in Vojvodina have now been reframed, and this re-alignment has been fortified into a relationship of parallelism. Therefore, when considering the role of Hungarian kin-state activism, what is of crucial importance is the manner in which Hungary has provided a type of opt-out option for its kin-minority, fully enabling the Hungarian community in Vojvodina to choose not to interact with the dominant group without fear of existential repercussions. Through Hungary's active involvement with its kin-minority, the Hungarian community in Vojvodina is not only being realigned and reunited into one homogenized Magyar force, it is also being led to believe and feel that it is able to lead a parallel life to its Serb counterpart; they have been 
afforded the option not to interact with, nor even engage with, the majority. Instead, feeling united with, and dependent upon, their Hungarian co-nationals across the border, the Hungarian minority is now secure to self-isolate and self-separate from the Serb majority in Vojvodina. The kin-state provides an alluring and incentivizing pull factor for the Hungarian community in Vojvodina to self-separate without fear for its survival. As long as Hungary extends its apparent "responsibility to assist" to its co-nationals across borders, the Hungarian community in Vojvodina can continue to forge a life in parallel to, rather than with, its Serbian neighbors. The very presence of the kin-state decreases Vojvodinian Hungarians' incentives for interacting, and lowers costs for self-isolating and sustaining a life separate from the Serbian majority.

Hungarian kin-state activism provides a powerful pull factor for the Hungarian community in Vojvodina, who already feel ostracized and disillusioned by the institution of Vojvodinian autonomy, which acts as a counter push factor, as noted earlier in this inquiry; the kin-state fills the void left by those pressing issues of autonomy. Hungarian kin-state activism (as evidenced by the evolving Prosperitati policy and other government statements and actions) is clearly responsible for the increased development of parallelism exhibited among the Hungarian community in Vojvodina-in a complex situation, it has fostered increased ethnonational homogenization, while simultaneously offering an already-estranged community an alluring opt-out clause for disengagement. 


\section{Conclusions - Parallelism as Interethnic Relations Optimality}

What can be gleaned from this research is the manner in which two institutional factors, Vojvodina's territorial and non-territorial autonomy and Hungarian kin-state activism, have facilitated the development of parallelism as the interethnic relations outcome currently present in the Hungarian community in Vojvodina. These two factors have increased Hungarian ethnonational homogenization, which has ultimately led to the development of parallelism on the part of the Hungarian community in Vojvodina.

Contentions over autonomy in Vojvodina, in both its territorial and cultural forms, has acted as the push factor for the facilitation of parallelism. As has been previously assessed, Vojvodinian territorial autonomy has come with a continual backlash of state centralization. What progress has been made in terms of guaranteeing and protecting Vojvodina's territorial autonomy has always been followed by SFRJ, and subsequent Serbian state, repression. A legacy of "one step forward, one step backward” has had repercussions on interethnic relations in Vojvodina. As such, amid many political contentions, Vojvodinian territorial autonomy is unstable at best, if not nominal in reality. What is more, debates concerning Vojvodina's autonomy have traditionally excluded the minorities - precisely the principal group that this policy should serve the most. In such conditions, the Hungarian community in Vojvodina has become disillusioned and isolated, causing it to look inwardly and dissociate with Vojvodina as a province. The simple fact that the Hungarians in Vojvodina primarily identify as Hungarians is a case in point. Most certainty, linking the national question with Vojvodina's territorial autonomy has been unsuccessful, and continual polemics over the substance of such autonomy 
granted to the province have only alienated the Hungarian community in Vojvodina to the point of indifference.

On the other hand, the current cultural autonomy that has been re-granted the Hungarian community in Vojvodina addresses the status of this community more directly, vesting it with a certain degree of control over a multitude of cultural affairs. Arguably, the cultural autonomy that the Hungarian community in Vojvodina has now achieved is simply the current expression of parallelism. In this manner, cultural autonomy afforded the Hungarian community in Vojvodina acts as both the reflection of current interethnic relations, as well as the enabler for further deeper parallelism. Problems over autonomy policy implementation persist. Laws are arguably comprehensive and progressive, but there is a discrepancy between formulation, adoption, and most importantly, lack of implementation.

In such an unstable climate, the Hungarian community has gradually disassociated from territorial autonomy, while at the same time maximizing the cultural autonomy that is afforded them. The high salience for ethnic territorial autonomy or "territorial autonomy under the national principle" emphasized in the interviews, which would overlap with cultural autonomy, surely symbolizes a future end-phase of a project of parallelism. If this were to occur, the Hungarian community would be institutionally insulated and lead a life wholly separate from the dominant group. Ultimately, the waffling over Vojvodina's territorial autonomy was the initial push factor for the promotion of parallelism, and has evolved to the point of enabling parallelism through the state's recognition of cultural autonomy for the Hungarians. Such a driver could 
eventually lead to complete ethnic homogenization, and detachment through ethnic territorial autonomy.

Kin-state activism, as the other powerful institutional factor facilitating the development of parallelism for the Hungarian community in Vojvodina, has acted as the counter pull factor for the development of parallelism. Hungarian kin-state activism has filled the void left by contentions over autonomy in Vojvodina. In other words, what the issue of autonomy started for the Hungarian community in Vojvodina, kin-state activism has now completed - the result is the current interethnic relations dynamic of parallelism. Autonomy, especially of the cultural variety now granted to the Hungarian community in Vojvodina, opened the door for the Republic of Hungary to step in and become a powerful factor in the life of the Hungarian community in Vojvodina.

At present, the Republic of Hungary is perceived as the provider and guarantor of stability and sustenance for the Hungarian community in Vojvodina. The undeniable political, economic, and logistic support it provides its kin-minority has caused ethnonational homogenization. Whether it be through the extensive, yet controversial, clientelist nemzetpolitika, its organizational and logistic support and preferential treatment for the Hungarian minority party VMSZ, its carefully tailored economic stimulus package Prosperitati, or even its central partnering role in various EU strategic devolvement initiatives, the Republic of Hungary's presence in the lives of its kinminority in Vojvodina has become extremely relevant and influential. Today, Hungary is an active stakeholder in the lives of the Hungarian community in Vojvodina. Surely, there is an interest-based transactionalism taking place between the Hungarian kin-state and its kin-minority in Vojvodina, but the more important fact remains the extent to 
which Hungary has become an extremely powerful institutional actor influencing the lives and relations of this community.

Hungary's active presence among the Hungarian community in Vojvodina has been able to redirect relations of reliance, and to decrease the costs of not interacting with the Serb majority, by offering the Hungarian community an opt-out clause. Therefore, issues over autonomy in Vojvodina and Hungarian kin-state activism mutually support one another, and act as the prime enablers of parallelism.

This research has wider theoretical implications that transcend the boundaries of this singular case study. Arguably, that two institutional factors foster parallelism speaks to the complex ontological relationship between the individual and collective versus the institution. The liberal construction of politics and policy is very much hinged on the notion of consent - the people freely choose how to associate (Hazony, 2018, p.33); much policy literature is dedicated to celebrating individual choice and rational decisionmaking models, which all point to the idea that consent is at its foundation. What this research has highlighted, however, is that choice is very much secondary compared to compounding institutional mechanisms.

In this sense, Berry's idea that the collective self-chooses, or consents to, selfsegregation, becomes subsidiary to the broader scope of understanding the manner in which institutions shape behavior and intergroup dynamics. After all, parallelism is about institutionally-driven segregation through induced ethnonational homogenization; liberal consent to such an interethnic relations outcome is very much on the sidelines. To put it another way, free individual choice in forming or, in this case, hindering relationships is peripheral rather than central. Instead, both internal obligations and external obligations 
imposed by institutions define meaningful relations. Therefore, asking the question "why don't people choose to integrate?" is consequently unimportant because it does not address the core issue. Free unobscured consent is not the foundation of such affairs; instead, the better question would be "how, and why, do institutions support or hinder the choosing of relationships?”

The Hungarian community in the Serbian province of Vojvodina is an ethnonationality. The Republic of Serbia and the neighboring Republic of Hungary are both ethnonational states. Nationalist discourse implies that the presence and persistence of the national element lends to the "natural" solidarity of people and interests between the Hungarian community in Vojvodina and the Hungarian state. This comes at the expense of this same community's relationship with the Republic of Serbia and its Serbian majority. To fully comprehend this community's natural inclination towards their "own" Hungarian co-nationals (and subsequent disassociation from the Serbian majority), one must truly understand and recognize the centrality of the "national element" to the community's sense of self. Without descending into basic, primal dynamics of nationalism, it might be more constructive to comprehend nationalism's role in engendering parallelism, examining how nations effectively restrict members' choices while simultaneously conferring meaning to the limited choices that remain (Wellman, 2000, p. 121).

While much time has been spent critiquing a supposed multicultural conception of Vojvodina, and inquiring whether a liberal plural model of Vojvodinian citizenry is even possible, the simple fact of the matter is that all these models seem increasingly less relevant in the empirical reality of world politics. These models are alluring, offering a 
freedom to choose and form relationships that one would be hard-pressed to reject. But, sadly, they are not a reality in Vojvodina, a community with a particularly high salience for both national identity and national preservation. This heightened importance of both national identity and national preservation is a possible reflection of the community's "defensive solidarity" with their “own" (Znaniecki, 1952, p. 98). The ethnonational conception of our world, and our basic collective model of organizing into nations, is the status quo precisely because it considers the functional value of the nation in directing people to a certain "choice", and then ascribes special meaning to that outcome. For the Hungarian ethnonational community in Vojvodina, the two institutions under scrutiny in this study (autonomy and kin-state activism), have achieved that goal - they have restricted the number of interethnic relations choices, thereby giving special meaning to the one choice left (if they can be even called that anymore). In this situation, parallelism for the Hungarian ethnonational community is the recognition of the "responsibilities that are intrinsic to both inherited and adopted membership in collectives of this kind, establishing demands on individuals that do not arise as a result of consent and do not disappear if consent is withheld" (Hazony, 2018, p. 31).

This case study highlights the manner in which (state) institutions influence national choices. In this particular case, institutions of autonomy and kin-state activism are directing collective choice, homogenizing the ethnonational group, and rendering meaning to group solidarity, all of which have direct ramifications for interethnic relations. Discourse on nations and nationalism commonly addresses self-determined will, while neglecting the push-and-pull of institutions that direct, if not confine, a nation's behaviors and actions and weigh heavily on group-relations dynamics. In 
contrast, this research focuses on two mutually-reinforcing institutions which have acted as distinct pull- and push- factors to facilitate the development of parallelism. In terms of generalizability, therefore, this study shows that instances of parallelism may arise in cases where institutions of autonomy and strong kin-state activism are present.

It must be acknowledged that issues of uncertainty persist in this inquiry. Parallelism is presented as a contemporary phenomenon within a real-life context in Vojvodina. If the phenomenon of parallelism is understood as institutionally-sanctioned detachment of a community, this case study has been successful in unearthing two extremely influential institutions enabling this interethnic outcome for the Hungarian community in Vojvodina. Extensive primary and secondary research corroborate the fact that these two mutually reinforcing factors have enabled parallelism. However, the crucial question remains whether the subjects included in this study were honest in their responses to the semi-structured interview questions. The possibility that the interviewees had undisclosed motives is always present; both the internal and external validity of this study is heavily dependent on the truthfulness of the subjects interviewed, as the interview method composed the bulk of the primary data collection and analysis portions of this research study. Care was taken to ensure that demographic characteristics of the sample corresponded with the demographics of the minority population, bar the underrepresentation of female respondents.

Additionally, this study could have benefited from providing further indicators of parallelism to demonstrate causality. Gathering additional empirical and statistical data to corroborate the fact that parallelism is the current dominant interethnic relations outcome for the Hungarian community in Vojvodina proved extremely difficult; literature on the 
Hungarian community Vojvodina is scarce, and data pertaining to this group is limited. Nevertheless, statistical data illuminating Vojvodinian Hungarian behavioral trends would have been extremely beneficial for enhancing the overall validity of this study.

The degree of confidence in the internal validity of this study, demonstrating that (only) these two dominant institutions are causing parallelism, remains open for further research. Other subsidiary factors or institutions may be indirectly fostering parallelism. For example, agricultural self-sufficiency in this Hungarian community in Vojvodina may be fueling parallelism. In this case, the premise would be that communities who are economically self-sufficient have less incentive to interact with the external world, and may interact with institutions in a very different manner, compared to if they were being constrained by economic survival. Furthermore, both the macropolitical climate in the Balkans and the rising influence of the EU (apart from its association with the Republic of Hungary), have not been fully explored. Finally, this inquiry did not undertake an extensive investigation of the salience of Hungarian ethnonational solidarity, let alone a comparison of its salience to other groups in the area. It may perhaps be that heightened Hungarian ethnonational solidarity alone provides the breeding ground for these institutions to be utilized in the manner in which they have, whereas other groups may have responded differently to the same institutional forces.

This study asserts that, for the Hungarian community in Vojvodina, the phenomenon of parallelism is currently the dominant lens through which to understand interethnic relations. This research does not claim that such a dynamic has persisted throughout history, nor that it will continue in this shape and form. However, this inquiry 
does posit that if all other factors remain the same, and if these institutions continue to evolve in their current direction, parallelism will persist.

Ultimately, it must be conceded that this is only one case study within one specific context, and as such, its generalizability to other instances of parallelism is still limited. Other cases of parallelism surely exist, and further investigation of those specific communities is necessary to ascertain whether the occurrence is similarly institutionally sanctioned or whether it represents a different phenomenon altogether. Care must be taken to recognize that not every community living seemingly parallel lives with the "other" can necessarily claim to experience the parallelism that is defined here as an institutionally-induced detachment.

Finally, what are we to make of parallelism in terms of state sovereignty? Arguably, minority rights infringe upon the classical conception of sovereignty as the rights ascribed to the entity termed the state (Krasner, 1991). Granting Vojvodina territorial autonomy, and expanding cultural autonomy to its Hungarian community, has naturally undermined the classical understanding of domestic sovereignty as authority and control within its borders. At the same time, Hungarian kin-state activism infringes on the traditional conception of Westphalian sovereignty as exclusion of foreign actors (i.e., kin-state) from interfering in domestic affairs; clearly, sovereignty, as the world has known it, is being eroded by both of the institutions fostering parallelism. This is, however, a logical outcome given that the underlying foundation of interethnic relations of parallelism is the Hungarian ethnonational community's festering communal selfdetermination and struggle for their right to determine themselves as a separate people to the more dominant "other." 
However, in a world in which sovereignty is said to now ultimately lie with the people, and must be reframed in terms of responsibility by the state to its people, should we really be concerned? Concerned, yes; shocked, no, especially considering the manner in which "legality" is being replaced by "legitimacy" as the dominant principle of international law implementation — a principle swiftly being applied to issues of sovereignty. The global shift in discourse makes parallelism all the more palatable as a conflict-avoidance alternative to messier border revision. Parallelism, in this sense, provides one more avenue through which a nation can be united with its own, and in the process realize the self-determination of peoples while keeping the status quo of sovereignty intact.

This inquiry, therefore, closes by contemplating the pressing normative question: can (and, should) anything be done to curb the parallelism exhibited by the Hungarian ethnonational community in Vojvodina? This study shows that people of the same nationality gravitate towards their "own" when their kin-nation's institutions pull them in and, the institutions of the "other" alienate them and push them away. Arguably, if the institutions investigated here remain in place, and continue on their current trajectory, parallelism will continue and, could eventually achieve the desired (but elusive) "territorial autonomy under the national principle" — an outcome that would combine ethnic territorial autonomy with cultural autonomy granted to the Hungarian community in Vojvodina. Couple this with an even-more aggressive, nationalist, clientelist kin-state policy pursued by Budapest, and the prospects for parallelism continuing to be the dominant interethnic relations paradigm are near-certain. The question of whether 
anything should be done (or, can be done) to curb this outcome is difficult to answer, at best.

The ethnic democracy that seems to have taken root across Eastern Europe makes integration of minorities near impossible and multiculturalism all the more implausible. Parallelism provides a peaceful status quo solution for rising minority nationalism, a sentiment rekindled thanks to increasing kin-state national reunification efforts without border revision, allowing national minorities to detach from the state in which they reside and, instead, reconnect with their kin-state nation across the border. Across Eastern Europe, the elusive goal of forming clearly-defined national states is still a work-inprogress; the fact remains that states rarely encapsulate the entirety of their nations, as has been ideally envisioned. In such an unstable situation, parallelism may just provide the optimal interethnic outcome/solution for people to remain living side-by-side without having to live with one another. Parallelism does not call into question border revision (and hence, international legal sovereignty), even though it does remap interethnic dynamics in a very different manner. For groups who have managed to preserve their culture as distinct from the "other," parallelism just might be the most peaceful means to reunite with their own kin-state when de facto state sovereignty would have it otherwise. Equally, for all those ethnonational groups who have sought autonomy (with various degrees of success), and for whom their kin-state has shown a vested mutual interest, parallelism is a very plausible outcome of relations with the dominant group in their host state. 


\section{Bibliography}

Anderson, B. (1991). Imagined Communities: Reflections on the Origins and Spread of Nationalism. London, UK: Verso.

Andric, E (2009). Dvojezicnost madjarskih djaka. Filozofski Fakultet Univerziteta u Novom Sadu, 37-55.

Antic, C. (2014). Istorijske Tradicije AP Vojvodine. In Antic, C. (Eds.), Dosije Autonomna Pokrajina Vojvodina (pp. 46-84). Belgrade, SRB: Napredni klub.

Antonic, S. (2014). Antisrbizam Kao Sredstvo Etnoinzenjeringa i Secesionizma. In Antic, C. (Eds.), Dosije Autonomna Pokrajina Vojvodina (pp. 174-237). Belgrade, SRB: Napredni klub.

Armstrong, J. A. (1994). Nations before Nationalism. In Hutchinson, J., \& Smith, A. D. (Eds.), Nationalism (pp. 140-147). Oxford, UK: Oxford University Press.

Autonomiija. (2016, April 5). Sijarto: SVM i Madjarska vlada su strateski partneri.

Retrieved from http://www.autonomija.info/sijarto-svm-i-madarska-vlada-sustrateski-saveznici.html

Baubock, R. (2007). Stakeholder Citizenship and Transnational Political Participation: A Normative Evaluation of External Voting. Fordham Law Review, 75(5), 23932447.

Bauer, O. (2000). The Questions of Nationalities and Social Democracy. Minneapolis, MN: University of Minnesota Press.

Beretka, K., \& Szekely, I. G. (2016). The national councils of national minorities in the Republic of Serbia. Autonomy Arrangements in the World, 1-33. 
Berger, P. (1967). The Sacred Canopy: Elements of a Sociological Theory of Religion. Garden City, NY: Doubleday \& Company.

Berry, J. W. (1974). Psychological Aspects of Cultural Pluralism: Unity and Identity Reconsidered. Institute of Education Sciences, 2, 17-22.

Berry, J. W. (1997). Immigration, Acculturation, and Adaption. International Association of Applied Psychology, 46(1), 5-68.

Beslin, M. (2017). Vojvodina in Yugoslavia: The Struggle for the Autonomy. In Petrovic, L., Roksandic, D., Velikonja, M., Hoepken, W., \& Biber, F. (Eds.), Yugoslavia from a Historical Perspective (pp.295-345). Belgrade, SRB: Helsinki Committee for Human Rights in Serbia.

Beta. (2018, November 8). RIK objavio konacne rezultate izbora za Nacionlne savete. N1. Retrieved from http://rs.n1info.com/Vesti/a434378/Konacni-rezultati-naizborima-za-Nacionalne-savete.html

Bieber, F., \& Winterhagen, J. (2006). Ethnic violence in Vojvodina: Glitch or Harbinger of Conflicts to Come? European Centre for Minority Issues, 27, 1-46.

Bjelica, S. (2015). Sporovi oko autonomije Vojvodine (Kjniga prva: 1961-1974). Novi Sad, SRB: Sluzbeni Glasnik.

Bogardus, E. (1947). Measurement of Personal-Group Relations. Sociometry, 10(4), 306311.

Breuilly, J. (1994). Nationalism and the State (2nd ed.). Chicago, IL: University of Chicago Press.

Brubaker, R. (1996). Nationalism Reframed: Nationhood and the national question in the New Europe. Cambridge, UK: Cambridge University Press. 
Brubaker, R. (2000). Accidental Diasporas and External "Homelands" in Central and Easter Europe: Past and Present. Institute for Advanced Studies, Vienna, 1-19. Brubaker, R. (2004). Ethnicity without Groups. Cambridge, MA: Harvard University Press.

Budakov, S. (2006). Vojvodjanski identitet danas. In Domonji, P. (Ed.), Vojvodjanski identitet (pp. 96-99). Belgrade, SRB: Helsinski odbor za ljudska prava u Srbiji.

Butler, E. (2007). Hungary and the European Union: The political implications of societal security promotion. Europe-Asia Studies, 59(7), 1115-1144.

Buyuksarac, G. B. (2017). Trans-border Minority Activism and Kin-state Politics: The Case of Iraqi Turkmen and Turkish Interventionism. Anthropological Quarterly, $90(1), 17-54$.

Centar za Politikolsko istrazivanje i javno mjenjene. (2003). Retrieved from http://www.idn.org.rs/index_lat.php

Centar za Slobodne Izbore i Demokratiju. (2006). Retrieved from http://www.cesid.rs/istrazivanja/

Cerovic, L. (2014). Narodi na tlu Vojvodine: Od praistorije do sredine dvadesetog veka. Novi Sad, SRB: Prometej.

Constitution of the Kingdom of Serbs, Croats and Slovenes (Vidovdanski Ustav), 1921. Retrieved from http://projuris.org/RETROLEX/Ustav\%20kraljevine\%20SHS_Vidovdanski\%20u stav\%20(1921).pdf 
Constitution of the Republic of Serbia, 2006. Retrieved from https://www.ilo.org/dyn/natlex/docs/ELECTRONIC/74694/119555/F838981147/ SRB74694\%20Eng.pdf

Council of Europe. (1995). Framework Convention for the Protection of National Minorities and Explanatory Report. Strasbourg, FRA: European Union - Council of Europe.

Cowan, J. K. (2001). Ambiguities of an ema emancipatory discourse: the making of a Macedonian minority in Greece. In Cowan, J. K., Dembour, M. B., \& Wilson, R. A. (Eds.), Culture and Rights: Anthropological Perspectives (pp. 152-177). Cambridge, UK: Cambridge University Press.

Cribb, R. \& Narangoa, L. (2004). Orphans of Empire: Divided Peoples, Dilemmas of Identity, and Old Imperial Borders in East and Southeast Asia. Comparative Studies in Society and History, 46(1), 164-187.

Csaszar, Z. M. (2012). Danube Strategic Significance for Serbia. In Sarcevic, N. J. \& Karanovic, E. S. (Ed.), Danube Strategy - Strategic Significance for Serbia (pp. 71-80). Belgrade, SRB: The Institute of International Politics and Economics.

Csergo, Z. (2005). Kin-State Politics in Central and Eastern Europe: the case of Hungary. George Washington University.

Deets, S., \& Stroschein, S. (2005). Dilemmas of autonomy and liberal pluralism: examples involving Hungarians in Central Europe. Nations and Nationalism, 11(2), 285-305. 
Dimitris, P., \& Papanikolatos, N. (2002). Reflections on Minority Rights Politics for East Central European Countries. In Kymlicka, W. \& Opalski, M. (Ed.), Can Liberal Pluralism be Exported?: Western Political Theory and Ethnic Relations in Eastern Europe (pp. 186-199). Oxford, UK: Oxford University Press.

Dinic, M. (2014). Politicki Aspekti Pitanja AP Vojvodine. In Antic, C. (Eds.), Dosije Autonomna Pokrajina Vojvodina (pp. 16-44). Belgrade, SRB: Napredni klub.

Djukanovic, D. (2016). Vojvodina u post-jugoslovenskome kontekstu: nastavak suspendiranja autonomije. Politicka misao, 53(1), 51-70.

Djurkovic, M. (2011). Madjarska: Orbanov netipican pokusaj izlaska iz krize. Institut za evropske studije, 63(2), 297-319.

Domonji, P. (2006). Konkurirajuci projekti i vojvodjanski identitet. In Domonji, P. (Ed.), Vojvodjanski identitet (pp. 88-90). Belgrade, SRB: Helsinski odbor za ljudska prava u Srbiji.

Fazal, T. M. \& Griffiths R. D. (2014). Membership Has Its Privileges: The Changing Benefits of Statehood. International Studies Review, 16, 79-106.

Garabaye, R. (2010). Toward a European Policy of Integration?: Divergence and Convergence of Immigrant Integration Policy in Britain and France. In d'Appollonia, A. C., \& Reich, S. (Eds.), Managing Ethnic Diversity After 9/11: Integration, Security, and Civil Liberties in Transatlantic Perspective. New Bunswick, NJ: Rutgers University Press.

Gellner, E. (2006). Nations and Nationalism (2nd ed.). Ithaca, NY: Cornell University Press. 
Goncz, L., \& Voros, O. (2005). Hungarian in the former Yugoslavia (Vojvodina and Prekmurje). In Fenyvesi, A. (Ed.), Hungarian Language Contact Outside Hungary: Studies on Hungarian as a minority language. Philadelphia, PA: John Benjamins Publishing.

Grubacic, A. (2012). Balkanization of Politics, Politics of Balkanization. Globalizations, 9(3), 439-449.

Guibernau, M. (1996). Nationalisms: The Nation-State and Nationalism in the Twentieth Century. Cambridge, UK: Polity Press.

Hagan, M. D. (2009). The Transnational Ethnic Activism of Vojvodina Hungarians. Nationalities Papers, 37(5), 613-640.

Halasz, I. (2006). Models of Kin Minority Protection in Central and Eastern Europe. In Ieda, O. (Ed.), Beyond Sovereignty: From Status Law to Transnational Citizenship (pp. 255-279). Sapporo, JPN: Slavic-Eurasian Studies.

Hannum, H. (1996). Autonomy, Sovereignty, and Self-Determination: The Accommodation of Conflicting Rights. Philadelphia, PA: University of Pennsylvania Press.

Hannum, H., \& Lillich, R. B. (1980). The Concept of Autonomy in International Law. The American Journal of International Law, 74(4), 858-889.

Hazony, Y. (2018). The Virtue of Nationalism. New York, NY: Basic Books.

Hechter, M., \& Levi, M (1994). Ethno-Regional Movements in the West. In Hutchinson, J., \& Smith, A. D. (Eds.), Nationalism (pp. 184-195). Oxford, UK: Oxford University Press.

Hechter, M. (2000). Containing Nationalism. Oxford, UK: Oxford University Press. 
Herner-Kovacs, E. (2014). Nation Building Extended: Hungarian Diaspora Politics. Minority Studies, 17, 55-67.

Hobsbawm, E. J. (1990). Nations and nationalism since 1780: Programme, myth, reality. Cambridge University Press.

Hodson, R., Sekulic, D., \& Massey, G. (1994). National Tolerance in the Former Yugoslavia. American Journal of Sociology, 99(6), 1534-1558.

Horowitz, D. L. (1985). Ethnic Groups in Conflict. Berkeley, CA: University of California Press.

Hungary - Serbia IPA Cross-border Cooperation Programme. (2015). Project Catalog. Budapest, HUN: Joint Technical Secretariat.

Hungarian National Election Office. (2018). Országgyülési képviselők választása 2018 országos listás szavazás eredménye [Data file]. Retrieved from http://www.valasztas.hu/orszagos-listak-eredmenye

Huntington, S. P. (1996). The Clash of Civilizations and the Remaking of the World Order. New York, NY: Simon and Schuster.

Hutchinson, J. (1994). Cultural Nationalism and Moral Regeneration. In Hutchinson, J., \& Smith, A. D. (Eds.), Nationalism (pp. 122-131). Oxford, UK: Oxford University Press.

Hutchinson, J. (2000). Ethnicity and modern nations. Ethnic and Racial Studies, 23(4), 651-669.

Ieda, O. (2006). Ideological Background of the Amendment Status Law Controversy in Hungary. In Ieda, O. (Ed.), Beyond Sovereignty: From Status Law to Transnational Citizenship (pp. 185-213). Sapporo, JPN: Slavic-Eurasian Studies. 
Ilic, S. (2009). Manjinske zajednice i multikulturnost. Migracijske i etnicke teme, 25(4), 363-386.

Ilic, V., \& Cvejic, S. (1997). Nacionalizam u Vojvodini. Zrenjanin, SRB: GNB Zarko Zrenjanin.

Irsevic, S. (2016, February 5). Madjarska kreditira vojvodjanske Madjare sa 160 miliona evra. $R T V$. Retrieved from http://www.rtv.rs/sr_lat/vojvodina/madjarska-kreditiravojvodjanske-madjare-sa-160-miliona-evra_686584.html

Isakov, A. (2018, March 24). Izbori u Madjarskoj, glasacka kutija i u Vojvodini. Politika. Retrieved from http://www.politika.rs/sr/clanak/400691/Izbori-u-Madarskojglasacka-kutija-i-u-Vojvodini

Janjetovic, Z. (2007). Polozaj Madjara u Vojvodini na kraju Drugog svetskog rata i njegovi uzroci. Institut za Noviju Istoriju Srbije, 53-64.

Janjetovic, Z. (2012). National Minorities in Yugoslavia 1918-1941. Review of Croatian History, 1, 61-75.

Jenne, E. K. (2007). Ethnic Bargaining: The Paradox of Minority Empowerment. Ithaca, NY: Cornell University Press.

Judah, T. (1997). The Serbs: History, Myth, and the Destruction of Serbia. New Haven, CT: Yale University Press.

Kantor, Z. (2006). The Concept of Nation in the Central and East European 'Status Laws'. In Ieda, O. (Ed.), Beyond Sovereignty: From Status Law to Transnational Citizenship (pp. 37-51). Sapporo, JPN: Slavic-Eurasian Studies. 
Kardos, G. (2006). Role for the Kin-states? In Ieda, O. (Ed.), Beyond Sovereignty: From Status Law to Transnational Citizenship (pp. 127-137). Sapporo, JPN: SlavicEurasian Studies.

Kohn, H. (1994). Western and Eastern Nationalisms. In Hutchinson, J., \& Smith, A. D. (Eds.), Nationalism (pp. 162-165). Oxford, UK: Oxford University Press.

Kolsto, P. (2002). Territorial Autonomy as a Minority Rights Regime in Post-Communist Societies. In Kymlicka, W. \& Opalski, M. (Ed.), Can Liberal Pluralism be Exported?: Western Political Theory and Ethnic Relations in Eastern Europe (pp. 200-215). Oxford, UK: Oxford University Press.

Komsic, J. (1997). Sanse interkulturalizma i iskusenja etnodemokratije. Subotica, SRB: Otvoreni Univerzitet.

Komsic, J. (2006). Vojvodjanski identitet u tranziciji: Nacrt jedne sociolosko-politikolske analize. In Domonji, P. (Ed.), Vojvodjanski identitet (pp. 44-67). Belgrade, SRB: Helsinski odbor za ljudska prava u Srbiji.

Komsic, J. (2015). Demokratsko upravljanje kulturoloskim razlicitostima: Vojvodina u svetlu iskustva. Novi Sad, SRB: Centar za regionalizam.

Komsic, J. (2016). Demokratska tranzicija i identiteti. In Biserko, S. (Ed.), Potka Srpskog Identiteta: antizapadnjastvo, rusofilstvo, tradicionalizam ...(pp. 1-54). Belgrade, SRB: Helsinki Committee for Human Rights in Serbia.

Koprivica, P. (2008, November 18). Madjarizacija Stare Moravice. Politika. Retrieved from http://www.politika.rs/scc/clanak/63637/Madarizacija-Stare-Moravice Korhecz, T. (1999). Vojvodina-The Next Stage of the Dismantling Process?. Cambridge Review of International Affairs, 12(2), 153-167. 
Kostres, B. (2006). Vojvodjanin je stanje duha. In Domonji, P. (Ed.), Vojvodjanski identitet (pp. 9-10). Belgrade, SRB: Helsinski odbor za ljudska prava u Srbiji. Krasner, S. (1991). Sovereignty: Organized Hypocrisy. Princeton, NJ: Princeton University Press.

Kymlicka, W. (2002). Multiculturalism and minority rights: West and East. Journal on Ethnopolitics and Minority Issues in Europe, 4, 1-24.

Kymlicka, W. (2007). Multicultural Odysseys. Ethnopolitics, 6(4), 585-597.

Kymlicka, W. (2008). The internationalization of minority rights. International Journal of Constitutional Law, 6(1), 1-32.

Kymlicka, W., \& Opalski, M. (2002). Can Liberal Pluralism be Exported?: Western Political Theory and Ethnic Relations in Eastern Europe. Oxford, UK: Oxford University Press.

Laketic, M. (2008, March 28). Traze autonomiju kao iz 1974. godine. Blic. Retrieved from https://www.blic.rs/vesti/vojvodina/traze-autonomiju-kao-iz-1974godine/8s 1 gx33

Law on Establishing Jurisdiction of the Autonomous Province of Vojvodina, 2002. Retrieved from http://www.skupstinavojvodine.gov.rs/Strana.aspx?s=aktrs1\&j=EN

Law on National Councils of National Minorities, 2009. Retrieved from http://fer.org.rs/wp-content/uploads/2018/03/Law-on-National-Councils-inSerbia.pdf

Law on the Protection of Rights and Freedoms of National Minorities, 2002. Retrieved from http://www.refworld.org/pdfid/4b5d97562.pdf 
Lazar, Z. (2007). Ethnical Distance in Vojvodina. In Lazar, Z. (Ed.), Vojvodina Amidst Multiculturality and Regionalization (pp. 61-73). Novi Sad, SRB: Mediterran Publishing.

Lazar, Z. (2010). Kolektivne percepcije uloge i znacaja nacionalnih saveta nacionalnih manjina u AP Vojvodini. In Marinkovic, D., Lazar, Z., Sokolovska, V., \& Ristic, D. (Eds.), Kolektivna Dinamika Ethnickih Zajednica u Vojvodina (pp. 11-40). Novi Sad, SRB: Mediterran Publishing.

Lazar, Z., \& Marinkovic, D. (2003). Regionalni, lokalni i globalni identitet Vojvodjana. Sociologija, 45(2), 155-166.

Lichtenberg, J. (1997). Nationalism, For and (Mainly) Against. In McKim R., \& McMahan J. (Eds.), The Morality of Nationalism (pp. 158-175). New York, NY: Oxford University Press.

Liebich, A. (2017). The "Boomerang Effect" of Kin-state Activism: Cross-border Ties and the Securitization of Kin Minorities. Journal of Borderlands Studies, 1-20.

Lijphart, A. (2002). The Wave of Power-Sharing Democracy. In Reynolds, A. (Ed.), The Architecture of Democracy: Constitutional Design, Conflict Management, and Democracy (pp. 37-54). Oxford, UK: Oxford University Press.

Losonc, A. (2006). Nacelne naznake o indentitetu vojvodine. In Domonji, P. (Ed.), Vojvodjanski identitet (pp. 34-43). Belgrade, SRB: Helsinski odbor za ljudska prava u Srbiji.

Ludanyi, A. (1979). Titoist Integration of Yugoslavia: The Partisan Myth \& the Hungarians of the Vojvodina, 1945-1975. Polity, 12(2), 225-252. 
Malesevic, S. (2006). Identity as Ideology: Understanding Ethnicity and Nationalism. New York, NY: Palgrave Macmillan.

Malesevic, S. (2011). Nationalism, War and Social Cohesion. Ethnic and Racial Studies, $1-32$.

Malesevic, S. (2011). The chimera of national identity. Nations and Nationalism, 17(2), 272-290.

Manic, Z. (2011). Polozaj madjarske nacionalne manjine u Vojvodini: sociolosko-pravni aspect. Univerzitet u Beogradu, 345-366.

Meseznikov, G. (2012). The Danube Regional Cooperation as a Platform for Boosting Serbia's Chances in Euro-Integration: Some Political Considerations. In Sarcevic, N. J. \& Karanovic, E. S. (Ed.), Danube Strategy - Strategic Significance for Serbia (pp. 13-22). Belgrade, SRB: The Institute of International Politics and Economics.

Miller, D. (1997). On Nationality. Oxford, UK: Oxford University Press.

Ministarstvo za Ljudska i Manjinska Prava Srbije i Crne Gore. (2004). Etnicki Mozaik Srbije: prema podacima popisa stanovnistva 2002. Retrieved from http://publikacija.stat.gov.rs/G2002/Pdf/G20024061.pdf Minorities at Risk Project. (2009). Minorities at Risk Dataset. College Park, MD: Center for International Development and Conflict Management. Retrieved from http://www.cidcm.umd.edu/mar/data.aspx on: [data here].

Miscevic, N. (2000). Is National Identity Essential for Personal Identity? In Miscevic, N. (Ed.), Nationalism and Ethnic Conflict: Philosophical Perspectives (pp. 239-257). Chicago, IL: Open Court. 
Mitchell, C., \& Hancock, L. E. (2007). Zones of Peace. Bloomfield, CT: Kumarian Press. Nairn, T. (1977). The Break-Up of Britain: Crisis and neo-nationalism. London, UK: New Left Books.

National Council of the Hungarian National Minority. (2014). Retrieved from http://archiv.mnt.org.rs/en/6-Sajtokozlemenyek/913-Statement-of-Dr-TamasKorhecz-president-of-HNMC-concerning-the-decision-of-the-ConstitutionalCourt-on-the-constitutionality-of-the-Law-on-National-Councils

Nemzeti Valasztasi Iroda. (2018). Izvestaj o rezultatima Majdarskih parlamentarnih izbora za diasporu - Srbija. Retrieved by Emil Lulic - National Council of the Hungarian Ethnic Minority.

Nikolic, K. (2011). Srbija u Titovoj Jugoslaviji (1941-1980). Belgrade, SRB: Zavod za Udzbenike.

Orlovic, S. P. (2014). Najvisi pravni akti u autonomiji Vojvodine. Zbornik radova Pravnog fakulteta, Novi Sad, 48(2), 257-287.

Pannon RTV. (2017). O nama. Retrieved from https://pannonrtv.com/vesti-na-srpskom/onama

Patricolo, C. (2018). Hungary Seeks Support for Minority SafePack. Emerging Europe: The Gateway to the Region. Retrieved from https://emergingeurope.com/news/hungary-seeks-support-minority-safepack/

Pavlovic, D. (2003). Zastupljenost etnickih manjina u predstavnickim telima. Habitus, 9$10,139-146$.

Petrovic, N. (2017). KPJ i Madjari u Vojvodini nakon Drugog Svetskog Rata. Studentski Centar Novi Sad, 333-345. 
Petsinis, V. (2004). The Serbs and Vojvodina: Ethnic Identity within a Multiethnic Region. University of Birmingham, 1-288.

Phillips, M. (2007). Liberalism v Islamism. American Diplomacy. Retrieved from http://americandiplomacy.web.unc.edu/2007/06/liberalism-v-islamism/

Popov, C., \& Popov, J. (2000). Autonomija Vojvodine: Srpsko Pitanje. Sremski Karlovci, SRB: Kulturni centar - Karlovacka Umetnicka Radionica.

Pusic, L. (2008). Jedna slika multikulturalnosti u Vojvodini: jezik kao pretpostavka za komunikaciju. Univerzitet u Novom Sadu, 50(2), 175-190.

Renner, K. (2005). State and Nation. In Nimni, E. (Ed.), National Cultural Autonomy and its Contemporary Critics. New York, NY: Routledge.

Republicka Izborna Komisija. (2018, November 8). Izvestaj o ukupnim rezultatima izbora za clanove nacionalnog saveta madjarske nacionalne manjine. Belgrade, SRB: Sluzbeni Glasnik Republike Srbije.

Safran, W. (1999). Spatial and Functional Dimensions of Autonomy: Cross-national and Theoretical Perspectives. Nationalism and Ethnic Politics, 5(3), 11-34.

Sajti, E. A. (2003). Hungarians in the Voivodina, 1918-1947. Boulder, CO: Social Science Monographs.

Samardzic, M. (1999). Polozaj Manjina u Vojvodini. Belgrade, SRB: Centar za antiratnu akciju.

Sarcevic, N. J., \& Karanovic, E. S. (2012). Danube Strategy-Strategic Significance for Serbia. Belgrade, SRB: The Institute of International Politics and Economics. 
Schopflin, G. (2002). Liberal Pluralism and Post-Communism. In Kymlicka, W. \& Opalski, M. (Ed.), Can Liberal Pluralism be Exported?: Western Political Theory and Ethnic Relations in Eastern Europe (pp. 109-124). Oxford, UK: Oxford University Press.

Sekelj, L. (1990). Jugoslavija: Struktura Raspadanja. Belgrade, SRB: Izdavacko Preduzece RAD.

Shoup, P. (1963). Yugoslavia's National Minorities under Communism. Slavic Review, 22(1), 64-81.

Siber, I. (1998). War and the Changes in Social Distance Toward the Ethnic Minorities in Croatia. Politicka Misao: casopis za politologiju, 34(5), 3-26.

Smith, A. D. (2009). Ethno-symbolism and Nationalism: A cultural approach. New York, NY: Routledge.

Smith, A. D. (1991). National Identity. Reno, NV: University of Nevada Press.

Smith, A. D. (2010). Nationalism: Theory, Ideology, History (2nd ed.). Cambridge, UK: Polity Press.

Smith, T. W., \& Dempsey, G. R. (1983). The Polls: Ethnic Social Distance and Prejudice. The Public Opinion Quarterly, 47(4), 584-600.

Sokolovska, V. (2008) Istrazivanje akulturacionih procesa u Vojvodini na osnovu mesovitih brakova. Univerzitet u Novom Sadu, 42(3), 325-341.

Sokolovska, V. (2010). Ocuvanje identiteta i tradicije nacionalnih zajednica u Vojvodini. In Marinkovic, D., Lazar, Z., Sokolovska, V., \& Ristic, D. (Eds.), Kolektivna Dinamika Ethnickih Zajednica u Vojvodina (pp. 81-102). Novi Sad, SRB: Mediterran Publishing. 
Statistical Office of the Republic of Serbia. (2012). 2011 Census of Population, Households and Dwellings in the Republic of Serbia. Retrieved from http://pod2.stat.gov.rs/ObjavljenePublikacije/Popis2011/Nacionalna\%20pripadno st-Ethnicity.pdf

Statut Autonomne Pokrajine Vojvodine u Narodnoj Republici Srbiji, 1948. Sluzbeni List Autonomne Pokrajine Vojvodine Narodne Republike Srbije. Novi Sad: Izdavackostamparsko preduzece AP Vojvodine ZMAJ.

Statut Autonomne Pokrajine Vojvodina i Odluka o sprovodjenju Statuta Autonomne Pokrajine Vojvodine, 1953. Sluzbeni List Autonomne Pokrajine Vojvodine Narodne Republike Srbije. Novi Sad: Izdavacko-stamparsko preduzece AP Vojvodine ZMAJ.

Statute AP Vojvodina, 1991. Retrieved from http://www.puma.vojvodina.gov.rs/dokumenti/zakoni/Statut_APV.pdf Statute AP Vojvodina, 2009. Retrieved from https://vojvodjanskiklub.rs/statut-apvojvodine-2009/

Statute AP Vojvodina, 2014. Retrieved from https://www.skupstinavojvodine.gov.rs/Strana.aspx?s=statut\&j=SRL Stjepanovic, D. (2013). 'Perceived Co-Ethnics' and Kin-State Citizenship in Southeastern Europe (The Europeanisation of Citizenship in the Successor States of the Former Yugoslavia (CITSEE) Working Paper Series No. 2013/26). Edinburgh, UK: University of Edinburgh, School of Law.

Stjepanovic, D. (2018). Multiethnic Regionalisms in Southeastern Europe: Statehood Alternatives. London, UK: Palgrave Macmillan. 
Stojanovic, S. (1997). The Fall of Yugoslavia: Why Communism Failed. New York, NY: Prometheus Books.

Szijjarto, P. (2017). The whole nation is winning thanks to Hungary's increasing strength. Ministry of Foreign Affairs and Trade. Retrieved from http://www.kormany.hu/en/ministry-of-foreign-affairs-and-trade/news/the-wholenation-is-winning-thanks-to-hungary-s-increasing-strength

Szijjarto, P. (2018). Hungary continues to support Serbia's EU integration. Ministry of Foreign Affairs and Trade. Retrieved from http://www.kormany.hu/en/ministryof-foreign-affairs-and-trade/news/hungary-continues-to-support-serbia-s-euintegration

Tolvaisis, L. (2012). Hungarian cultural autonomy in Vojvodina from the 1974 Socialist Constitution to the 2009 Statute of Autonomy: path dependence dynamics against the reversal of minority policies. The Journal of Nationalism and Ethnicity, 40(1), 63-83.

Trivic, B. (2018, April 11). Vojvodjanski Madjari za Orbana. Radio Slobodna Evropa. Retrieved from https://www.slobodnaevropa.org/a/mađarska-vojvodina-izboriglasanje-orban/29158659.html

Ustavni sud Republike Srbije. (2013). Odluka u predmetu IYo-360/2009. Belgrade., SRB: Sluzbeni List APV, broj 17/09. Retrieved from http://www.ustavni.sud.rs/Storage/Global/Documents/Misc/IУo-360-2009.pdf 
Ustav Socijalisticke Autonomne Pokrajine Vojvodine i Ustavni Zakon za sprovodjenje Ustava Socijalisticke Autonomne Pokrajine Vojvodine, 1974. Sluzbeni List Socijalisticke Autonomne Pokrajine Vojvodine. Novi Sad: Stamparija NIP Dnevnik.

Varga, B. (2015). “Talas nasilja” u Vojvodini - eskalacija etnickog nacionalizma u ekstremizam. Politikon, 10, 89-108.

Van Evera, S. (1997). Guide to Methods for Students of Political Science. Ithaca, NY: Cornell University Press.

Verhegyi, A. (2001). Gyorkeres valtozas a magyarsag eleteben. Magyar Nemzet. Retrieved from https://mno.hu/velemeny/gyokeres-valtozas-a-magyarsageleteben-831728

Waever, O. (1995). Securitization and Desecuritization. In Lipschutz, R. (Ed.), On Security. New York, NY: Columbia University Press.

Walzer, M. (1992). Comment. In Gutmann, A. (Ed.), Multiculturalism and the Politics of Recognition (pp.99-103). Princeton, NJ: Princeton University Press.

Waterbury, M. A. (2005). Internal Exclusion, External Inclusion: Diaspora Politics and Party-Building Strategies in Post-Communist Hungary. East European Politics and Societies, 19(4), 1-33.

Waterbury, M. A. (2008). Bridging the Divide: Towards a comparative framework for understanding kin-state and migrant sending-state diaspora politics. IMISCOE European University Institute, 1-25. 
Wellman, C. H. (2000). On Liberalism's Ambivalence Regarding Nationalism. In Miscevic, N. (Ed.), Nationalism and Ethnic Conflict: Philosophical Perspectives (pp. 115-131). Chicago, IL: Open Court.

Weller, M. (2005). Enforced autonomy and self-governance: the post-Yugoslav experience. In Weller, M., \& Wolff, S. (Eds.), Autonomy, Self-governance and Conflict Resolution: Innovative approaches to institutional design in divided societies (pp. 49-75). London, UK: Routledge.

Yin, R. K. (2003). Case Study Research: Design and Methods (3rd ed.). Thousand Oaks, CA: Sage Publications.

Zacher, M. W. (2001). The Territorial Integrity Norm: International Boundaries and the Use of Force. International Organization, 55(2), 215-250.

Zigmanov, T. (2006). Medjuethnicki odnosi i Vojvodjanski identitet. In Domonji, P. (Ed.), Vojvodjanski identitet (pp. 68-79). Belgrade, SRB: Helsinski odbor za ljudska prava u Srbiji.

Znaniecki, F. (1952). Modern Nationalities: A Sociological Study. Chicago, IL: University of Illinois.

Zoric, O. (2019, November 4). Odrzani izbori za Nacionalne savete, stizu prvi rezultati. Radio Slobodna Evropa. Retrieved from https://www.slobodnaevropa.org/a/počeli-izbori-za-nacionalne-savetenacionalnih-manjina/29581588.html

Zundhausen, H. (2008). Istorija Srbije of 19. do 21. veka. Belgrade, SRB: Clio. 


\section{Appendix A - Interview Questions}

\begin{tabular}{|c|c|}
\hline Main Questions & Probes \\
\hline $\begin{array}{l}\text { - First, I would like to ask you how do you } \\
\text { identify yourself to other people? }\end{array}$ & $\begin{array}{l}\text { - What do you understand by your [primary] identity? } \\
\text { - } \quad \text { Do you think there is such a thing as a Vojvodinian identity? } \\
\text { Hungarian identity? Namely, is a provincial identity a threat } \\
\text { or complimentary to your ethnic identity? } \\
\text { Are Serbian cultural events and Serbian political affairs } \\
\text { really important for ethnic Hungarians in Vojvodina? } \\
\text { Namely, does what is going on with Serbia and its dominant } \\
\text { society have a bearing on you and the life the ethnic } \\
\text { Hungarian community? }\end{array}$ \\
\hline $\begin{array}{l}\text { As you may be aware, political identification } \\
\text { along Hungarian ethnic lines seems to be a } \\
\text { reoccurring topic of discussion on the } \\
\text { national political stage. What are some } \\
\text { political parties that you identify with? }\end{array}$ & $\begin{array}{l}\text { - What are some factors influencing the political identification } \\
\text { of ethnic Hungarians in Vojvodina? } \\
\text { Do you feel that ethnicity weighs on your political } \\
\text { preferences? }\end{array}$ \\
\hline $\begin{array}{l}\text { - How important is your religious affiliation to } \\
\text { your ethnic Hungarian identity? }\end{array}$ & $\begin{array}{l}\text { - How different or alien is Eastern Orthodoxy both culturally } \\
\text { and religiously to you as a [Protestant/Catholic] ethnic } \\
\text { Hungarian? } \\
\text { Do you consider the current position of the } \\
\text { [Catholic/Protestant] Church in the Republic of Serbia a } \\
\text { reflection of your own ethnic status in Vojvodina? }\end{array}$ \\
\hline $\begin{array}{l}\text { - How instrumental are cultural centers in your } \\
\text { community? }\end{array}$ & $\begin{array}{l}\text { Do you participate in cultural events and what meaning to } \\
\text { you derive from this participation? } \\
\text { Do these centers serve to nurture your ethnic Hungarian } \\
\text { identity? }\end{array}$ \\
\hline $\begin{array}{l}\text { - In regards to schooling, may I ask where did } \\
\text { you [and your children] go to school? }\end{array}$ & $\begin{array}{l}\text { - How valuable is the preservation of public educational } \\
\text { programs in Vojvodina for your community? } \\
\text { - What factors influence your decision whether to send your } \\
\text { child to public school where the language of instruction is } \\
\text { Hungarian? } \\
\text { - How would you feel if the only language of instruction in } \\
\text { public schools was Serbian? }\end{array}$ \\
\hline $\begin{array}{l}\text { - Now I would like to ask you how and in what } \\
\text { ways is agriculture important to the ethnic } \\
\text { Hungarian community in Vojvodina? }\end{array}$ & $\begin{array}{l}\text { If this area transitioned from agriculture to heavy industry } \\
\text { and technology sectors, would it make you feel as though } \\
\text { your existence here is more vulnerable and uncertain as a } \\
\text { member of a minority group? }\end{array}$ \\
\hline $\begin{array}{l}\text { - In your view, how would you characterize } \\
\text { inter-ethnic relations between Serbs and } \\
\text { Hungarians in Vojvodina? }\end{array}$ & $\begin{array}{l}\text { - In what areas of life to ethnic Hungarians in Vojvodina feel } \\
\text { they need to cooperate with the dominant society and in what } \\
\text { area do they feel self-sufficient? } \\
\text { Are there shared political goals between Vojvodinian Serbs } \\
\text { and Vojvodinian Hungarian? } \\
\text { - How valuable do you consider cooperation with Serbs in the } \\
\text { area of agriculture? } \\
\text { Do you think that in some areas you have more in common } \\
\text { with Serbs in Vojvodina then you do with Hungarians in } \\
\text { Vojvodina? }\end{array}$ \\
\hline $\begin{array}{l}\text { A recent development in Vojvodina has been } \\
\text { the apparent renewed activism of the kin } \\
\text { state (Republic of Hungary) in Vojvodina } \\
\text { among its own Hungarian diaspora. Can you } \\
\text { please elaborate how you see the role of } \\
\text { Hungary in your own life and that of your } \\
\text { community? }\end{array}$ & $\begin{array}{l}\text { Do you consider the official role of the Hungarian state a } \\
\text { guarantor or destabilization of your continued life in } \\
\text { Vojvodina? } \\
\text { What holds more weight for the ethnic Hungarian } \\
\text { community in Vojvodina: political events unfolding in } \\
\text { Budapest or those in Belgrade? } \\
\text { If the political and economic situation in Vojvodina became } \\
\text { volatile, would you consider moving to Hungary? If yes, } \\
\text { under what conditions? }\end{array}$ \\
\hline $\begin{array}{l}\text { - Finally, does autonomy for Vojvodina } \\
\text { support greater integration or distance } \\
\text { between ethnic groups residing here? }\end{array}$ & $\begin{array}{l}\text { - Does it matter what political form Vojvodina takes? What is } \\
\text { most important for your community in relation to provincial } \\
\text { politics? }\end{array}$ \\
\hline
\end{tabular}

